\author{
Universidade de São Paulo \\ Faculdade de Filosofia, Letras e Ciências Humanas \\ DEPARTAMENTO DE Linguística \\ Programa de Pós-GraduaÇÃo em Semiótica E \\ Linguística Geral
}

Lucia Helena Rozario da Silva

Aperfeiçoamento de um tradutor automático Português-Inglês: Tempos Verbais 
Universidade de São Paulo

Faculdade de Filosofia, Letras e Ciências Humanas

Departamento DE Linguística

Programa de Pós-GraduaÇão em Semiótica e Linguística Geral

\title{
Aperfeiçoamento de um tradutor automático Português-Inglês: Tempos Verbais
}

\author{
Lucia Helena Rozario da Silva
}

DissertaÇÃo apresentada ao Programa DE Pós-GraduaÇÃo EM SEmiótica E Linguística Geral do Departamento DE Linguística DA FACUldade DE FiloSOFia, Letras E Ciências Humanas da Universidade de SÃo Paulo.

Orientador: Prof. Dr. Marcello Modesto

São Paulo

2010 


\section{Agradecimentos. . .}

Ao meu orientador, Prof. Dr. Marcello Modesto, por me acompanhar nesta caminhada de amadurecimento profissional. Desde a orientação na área de tradução automática até as discussões sobre sintaxe na época em que fui sua monitora. Pela paciência e por confiar no meu trabalho.

Ao professor Marcos Lopes por toda a sua contribuição e dedicação.

Ao John Clark pelos inúmeros esclarecimentos sobre o sistema.

Ao professor Alon Lavie pela hospitalidade e pela ajuda técnica.

Ao grupo Avenue ${ }^{1}$ pelo desenvolvimento inicial do sistema juntamente com os professores Marcello Modesto e Alon Lavie.

Ao $\mathrm{CNPq}$ pelo auxílio financeiro que me concedeu para a realização deste trabalho.

À minha mãe e à minha família por apoiarem minhas escolhas.

Agradeço às minhas amigas Rhossane, Rhuzia e Rhaiane, por terem me feito acreditar que eu posso e por me receberem como a quarta irmã.

Ao Guilherme Pinto pelas longas caminhadas pela praia.

Ao Guilherme Ribeiro por todo o suporte.

À Ana Cristina, amiga e segunda mãe, por tudo o que tem feito por mim.

À Rosicléia, por apoiar e incentivar a expansão do meu conhecimento geográfico.

À Bianca e Fernanda por serem minhas companheiras desde a graduação.

Aos colegas do programa de linguística da USP: Alexandre Bueno, Fabiana Baldim, Julio Barbosa, Leonor Simioni, Mariana Pesirani, Rafael Minussi, Rerisson Cavalcante, entre outros, pela companhia entre os cursos da pós, pelas conversas nos intervalos e pelas risadas.

Sou grata à Àgata Soares, ao Antonio Neto, ao Caio Badner por serem membros do GLIC, pelas discussões e contribuições nos temas apresentados.

Agradeço aos amigos Aline Rodero, Indaiá Bassani e Marcus Lunguinho, por toda a contribuição acadêmica e por serem a minha família em São Paulo. Guardo vocês em meu coração.

À Prof. Claudia Roncarati, por ter sido a primeira a me mostrar que a linguística é, de fato, uma ciência e por despertar em mim o interesse pela área. Pelo grande exemplo de luta e de perseverança.

Agradeço especialmente ao meu companheiro por compreender e aceitar as minhas escolhas pessoais e profissionais. Por permanecer sempre ao meu lado, por me fazer esquecer do tempo e acreditar que, em breve, estaríamos juntos. Eu dedico esta dissertação ao Bruno por mostrar que meu coração fez a escolha certa.

\footnotetext{
${ }^{1}$ www.cs.cmu.edu/ avenue
} 


\section{Resumo}

Esta dissertação apresenta o aperfeiçoamento de um sistema de tradução automática português-inglês. Nosso objetivo principal é criar regras de transferência estrutural entre o par de línguas português e inglês e avaliar, através do uso da métrica de avaliação METEOR, o desempenho do sistema. Para isto, utilizamos um corpus teste criado especialmente para esta pesquisa.

Tendo como ponto de partida a relevância de uma correta tradução para os tempos verbais de uma sentença, este trabalho priorizou a criação de regras que tratassem a transferência entre os tempos verbais do português brasileiro para o inglês americano.

Devido ao fato de os verbos em português estarem distribuídos por três conjugações, criamos um corpus para cada uma dessas conjugações. O objetivo da criação desses corpora é verificar a aplicação das regras de transferência estrutural entre os tempos verbais em todas as três classes de conjugação.

Após a criação dos corpora, mapeamos os tempos verbais em português no modo indicativo, subjuntivo e imperativo para os tempos verbais do inglês. Em seguida, iniciamos a construção das regras de transferência estrutural entre os tempos verbais mapeados.

Ao final da construção das regras, submetemos os corpora obdecendo as três classes de conjugação à métrica de avaliação automática METEOR. Os resultados da avaliação do sistema após a inserção das regras apresentaram uma regressão quando comparado a avaliação do sistema no estágio incial da pesquisa.

Detectamos, através de análises dos resultados, que a métrica de avaliação automática METEOR não foi sensível às modificações feitas no sistema, embora as regras criadas sigam a gramática tradicional da língua portuguesa e estejam sendo aplicadas a todas as três classes de conjugação.

Apresentamos em detalhes o conjunto de regras sintáticas e os corpora utilizados neste estudo, e que acreditamos serem de utilidade geral para quaisquer sistemas de tradução automática entre o português brasileiro e o inglês americano. Outra contribuição deste trabalho está em discutir os valores apresentados pela métrica METEOR e sugerir que novos ajustes sejam feitos a esses parâmetros utilizados pela métrica.

Palavras-chave: Tradução Automática, Linguística Computacional, Processamento de Linguagem Natural, Linguística, Inteligência Artificial 


\section{Abstract}

This dissertation presents the development of a Portuguese-to-English Machine Translation system. Our main objective is creating structural transfer rules between this pair of languages, and evaluate the performance of the system using the METEOR evaluation metric. Therefore, we developed a corpus to enable this study.

Taking translation relevance as a starting point, we focused on verbal tenses and developed rules that dealt with transfer between verbal tenses from the Brazilian Portuguese to US English. Due to the fact that verbs in Portuguese are distributed in three conjugations, we created one corpus for each of these conjugations. The objective was to verify the application of structural transfer rules between verbal tenses in each conjugation class in isolation.

After creating these corpora, we mapped the Portuguese verbal tenses in the indicative, subjunctive and imperative modes to English. Next, we constructed structural transfer rules to these mapped verbal tenses. After constructing these rules, we evaluated our corpora using the METEOR evaluation metric. The results of this evaluation showed lack of improvement after the insertion of these transfer rules, when compared to the initial stage of the system.

We detected that the METEOR evaluation metric was not sensible to these modifications made to the system, even though they were linguistically sound and were being applied correctly to the sentences. We introduce in details the set of transfer rules and corpora used in this study, and we believe they are general enough to be useful in any rule-based Portuguese-to-English Machine Translation system. Another contribution of this work lies in the discussion of the results presented by the METEOR metric. We suggest adjustments to be made to its parameters, in order to make it more sensible to sentences variation such as those introduced by our rules.

Keywords: Machine Translation, Computational Linguistics, Natural Language Processing, Linguistics, Artificial Intelligence 


\section{Sumário}

1 Introdução: A Tradução Automática 8

1.1 Introdução . . . . . . . . . . . . . . . . . . . . 8

1.2 Breve histórico da Tradução Automática . . . . . . . . . . . 8

1.3 Níveis de automatização . . . . . . . . . . . . . . . . . . . 11

1.4 Métodos de Tradução Automática . . . . . . . . . . . . . . . 13

1.4.1 Conclusão do capítulo, objetivos e organização do trabalho . . . . . . . . . . . . . . . 20

2 Projeto Avenue 22

2.1 Introdução . . . . . . . . . . . . . . . . . . . . . 22

2.2 O sistema Avenue . . . . . . . . . . . . . . . . . . . . 23

2.2 .1 Morfologia . . . . . . . . . . . . . . . . . 23

2.2 .2 Gramática . . . . . . . . . . . . . . . . . . . . . . 23

2.2 .3 Léxico . . . . . . . . . . . . . . . . . . . . . . . . . 25

2.2 .4 Transferência . . . . . . . . . . . . . . . . . 26

2.2 .5 Decodificador . . . . . . . . . . . . . . . . 28

2.3 O sistema de tradução Português-Inglês . . . . . . . . . . . . . 29

2.3.1 Pré-processamento e Morfologia . . . . . . . . . . . . 30

2.3.2 Transferência . . . . . . . . . . . . . . . . . . 31

2.3 .3 Decodificação . . . . . . . . . . . . . . . . . . 31

3 Metodologia 32

3.1 Seleção dos dados para o estudo . . . . . . . . . . . . . . . . . 32

3.1 .1 Análise preliminar . . . . . . . . . . . . . . . 32

3.2 As etapas de seleção dos corpora . . . . . . . . . . . . . . 34

3.2 .1 Primeira etapa de seleção: o dicionário . . . . . . . . . 34

3.2 .2 Segunda etapa de seleção: critério de uso . . . . . . . . 35

3.3 Corpora dos tempos verbais . . . . . . . . . . . . . 35

3.4 Métodos de avaliação dos corpora . . . . . . . . . . . . . 36

3.4.1 METEOR . . . . . . . . . . . . . . . . 36

3.5 Resultados . . . . . . . . . . . . . . . . . 38 
4 Tempos verbais $\quad 41$

4.1 Modo Indicativo . . . . . . . . . . . . . . . . . . . . . . . 42

4.1 .1 Tempos simples . . . . . . . . . . . . . . . 42

4.1.2 Tempos compostos . . . . . . . . . . . . 55

4.2 Modo Subjuntivo . . . . . . . . . . . . . . . . . 65

4.2.1 Tempos simples . . . . . . . . . . . . . . . 65

4.2 .2 Tempos compostos . . . . . . . . . . . . 72

4.3 Modo Imperativo . . . . . . . . . . . . . . . . . . . . . . 79

5 Resultados $\quad 81$

5.1 Corpora dos tempos verbais . . . . . . . . . . . 81

5.2 Corpus Fapesp . . . . . . . . . . . . . . . . . . 84

6 Discussão $\quad 86$

$\begin{array}{lll}7 & \text { Conclusão } & 94\end{array}$

$\begin{array}{ll}\text { A Corpus preliminar } & 99\end{array}$

B Mapeamento dos tempos verbais português - inglês 106

B.1 Modo Indicativo . . . . . . . . . . . . . . . . . . . . 106

B.1.1 Tempos simples . . . . . . . . . . . . . 106

B.1.2 Tempos compostos . . . . . . . . . . . . 108

B.2 Subjuntivo . . . . . . . . . . . . . . . . 111

B.2.1 Tempos simples . . . . . . . . . . . . . . 111

B.2.2 Tempos Compostos . . . . . . . . . . . . . . 113

B.3 Modo Imperativo . . . . . . . . . . . . . . . . . . . . 115

B.4 Formas nominais . . . . . . . . . . . . . . . 115

B.4.1 Tempos simples . . . . . . . . . . . . . 115

B.4.2 Tempos compostos . . . . . . . . . . 116

$\begin{array}{ll}\text { C Corpora dos tempos verbais } & 118\end{array}$

C.1 Primeira Conjugação . . . . . . . . . . . . . . . . . . . . . 118

C.1.1 Modo Indicativo . . . . . . . . . . . . . . . 118

C.1.2 Modo Subjuntivo . . . . . . . . . . . . . . . 126

C.1.3 Modo Imperativo . . . . . . . . . . . . . . . . 130

C.1.4 Formas nominais . . . . . . . . . . . . . . 131

C.2 Segunda Conjugação . . . . . . . . . . . . . . . . . . . . 133

C.2.1 Modo Indicativo . . . . . . . . . . . . . . . . . . . . . . . . . . . . . . . . . . . .

C.2.2 Modo Subjuntivo . . . . . . . . . . . . . . . . 140

C.2.3 Modo Imperativo . . . . . . . . . . . . . . . . . 145

C.2.4 Formas nominais . . . . . . . . . . . . . . 146 
C.3 Terceira Conjugação . . . . . . . . . . . . . . . . . . . . . 147

C.3.1 Modo Indicativo . . . . . . . . . . . . . . . . . 147

C.3.2 Modo Subjuntivo . . . . . . . . . . . . . . . . 155

C.3.3 Modo Imperativo . . . . . . . . . . . . . . . . . 160

C.3.4 Formas Nominais . . . . . . . . . . . . . . . 160

D Frequência dos verbos 163 


\section{Capítulo 1}

\section{Introdução: A Tradução Automática}

\subsection{Introdução}

A Tradução Automática (TA) é o uso de sistemas computacionais para a tradução de textos escritos ou falados de uma língua para outra. O uso de máquinas que permitem a comunicação e transmissão de conhecimentos de uma cultura para a outra é uma das mais importantes aplicações da Linguística Computacional. Entretanto, a Tradução Automática tem sido caracterizada como um problema particularmente difícil por muitas décadas.

Muitas abordagens para a TA alcançaram diversos níveis de sucesso, decorrentes de seus diferentes objetivos. Entretanto, fatores como divergências estruturais e representacionais entre as línguas, sejam elas tipológicas ou idiossincráticas, se apresentam como uma das principais barreiras para o sucesso da TA.

\subsection{Breve histórico da Tradução Automática}

Apresentaremos nesta seção uma breve história da área de tradução automática, para isto nos baseamos em Hutchins [1] e em Specia e Rino [2].

O início da TA é tradicionalmente localizado no século XVII, a partir das propostas de Descartes e Leibniz, que apresentaram a idéia do uso de dicionários mecânicos para relacionar palavras entre diferentes línguas. Embora sugeridas como um marco na história da TA, ambas as propostas, obviamente, não resultaram no desenvolvimento de uma máquina que a concretizasse efetivamente.

Com a Segunda Guerra Mundial, surgiram os computadores eletrônicos 
digitais e suas primeiras aplicações foram no campo da Matemática e Física, mas rapidamente o número de suas aplicações se expandiu devido ao seu enorme potencial.

A primeira sugestão do uso de computadores eletrônicos na tradução de uma língua para outra remonta a Warren Weaver, vice-presidente da Fundação Rockfeller em Nova Iorque. Em 1947, Weaver menciona em uma carta a Norbert Wiener a possibilidade do uso de um computador para a tradução entre línguas, mas somente em 1949 Weaver distribuiu um memorando lançando a Tradução Automática como um projeto científico nos Estados Unidos.

Nesse memorando, Weaver apontava quatro importantes pontos e problemas na TA: o problema da polissemia, a base lógica da linguagem, a aplicação da teoria da informação e de técnicas de criptografia, e as possibilidades de uma linguagem universal.

Apesar de ter obtido impacto inquestionável, o memorando de Weaver foi recebido com grande ceticismo por muitos linguistas, que o rejeitaram baseando-se em suposições infundadas sobre a lógica da linguagem, além de se mostrarem incrédulos quanto à possibilidade de formalização de línguas naturais e do processo de tradução automática [1].

Durante os dois anos seguintes, começaram a se desenvolver grupos de estudos na área de TA em várias universidades, entre elas em Massachusetts Institute of Technology (MIT), Universidade de Washington em Seattle, entre outras.

Em 1952 ocorreu, no MIT, a primeira conferência de Tradução Automática, na qual foram discutidas as necessidades e possibilidades da TA, além de apresentarem problemas linguísticos em diferentes níveis de análise, como o sintático e morfológico.

Nos anos seguintes, começaram a aparecer publicações de trabalhos demonstrando a aplicabilidade da TA e em 1954, ocorreu a primeira demonstração pública de um sistema de TA, chamado de experimento GeorgetownIBM, o qual traduzia sentenças do russo para o inglês. Nesse experimento, o sistema contava com 6 regras sintáticas e com um vocabulário de 250 palavras, com as quais foram traduzidas apenas 49 sentenças. Embora apresentasse inúmeras limitações, esse experimento mostrou a funcionalidade de um sistema de TA e ajudou a estimular o financiamento e desenvolvimento de pesquisas na área pelas agências governamentais dos Estados Unidos.

Essas agências governamentais que financiavam os projetos em TA acreditavam que sistemas que produzissem traduções com boa qualidade poderiam ser desenvolvidos rapidamente. Porém, a TA dependia ainda de linguagens de programação de alto nível, evolução de hardware e de desenvolvimento nas pesquisas linguísticas em sintaxe, sobretudo as referentes às gramáticas 
formais. Com isso, o objetivo da TA tornou-se o desenvolvimento de sistemas que produzissem traduções com alta qualidade e de forma totalmente automatizada. As pesquisas buscavam teorias e métodos que possibilitassem alcançar esses objetivos.

Ao final da década de 1950, alguns países na Europa começaram a investir na área de TA e alguns sistemas de tradução foram instalados nos Estados Unidos, embora apresentassem uma baixa qualidade nos seus resultados.

No começo dos anos 60, a TA conseguiu ampliar seu domínio e aprofundar os estudos em sua área. Em 1960 a Association pour l'étude et le développement de la traduction automatique et de la linguistique apliquée (ATALA) foi fundada e publicaram-se vários outros trabalhos sobre o tema. Em 1961, ocorreu um novo congresso internacional sobre TA em Teddington, na Inglaterra, no qual quinze países participaram.

No entanto, os projetos em TA não alçaram suas grandes metas e o progresso se deu de forma mais lenta, decorrente de vários fatores, entre eles a dificuldade do tratamento computacional sob a perspectiva linguística. Estudos de linguística formal não explicavam os diversos problemas da TA. O resultado foi o descrédito na área, resultando na publicação do relatório ALPAC (Automatic Language Processing Advisory Committee) em 1966. Esse relatório provocou um grande impacto na área, pois declarava que TA falhou em atingir suas metas, dada a ausência de um tradutor completamente automático capaz de produzir boas traduções.

De acordo com Hutchins [3], a ALPAC resultou na diminuição do investimento público na área. Entretanto, alguns projetos, como o SYSTRAN ${ }^{1}$, ainda foram mantidos e agrupados em três classes: ferramentas computacionais de auxílio à tradução humana, tradutores automáticos auxiliados por humanos e pesquisas para melhoria dos métodos de TA.

No início dos anos 1980, alguns fatos re-estimularam o interesse pela TA: a criação da Comunidade Européia; desenvolvimento de teorias na área da Linguística formal; crescimento tecnológico, com avanços na área de Inteligência Artificial e de técnicas computacionais.

Nesse novo cenário, a TA passou a ter novos objetivos e interesses, fazendo com que a área voltasse a receber apoio governamental, principalmente na Europa e Japão. Acreditava-se que um sistema de TA, mesmo com resultados não muito bons, poderia ser útil, desde que permitisse a compreensão das idéias principais do texto. Um sistema ideal deveria gerar textos com qualidade, que necessitassem de pouca revisão para o aprimoramento dos resultados. Em decorrência, passaram-se a desenvolver sistemas de auxílio à tradução e programas que previam a intervenção humana.

\footnotetext{
${ }^{1}$ http://www.systransoft.com/
} 
Ao final da década de 80, novos fatores contribuíram para a consolidação de uma nova fase na TA: disponibilidade de sistemas de tradução para uso profissional ou para usuários comuns; amplo uso de computadores pessoais; desenvolvimento de sistemas em domínios específicos; o crescimento das redes de comunicação abrangendo diferentes línguas e em consequência a necessidade de sistemas de tradução que oferecessem resultados com diversos tipos de dados e em tempo real.

Durante os anos 1990, os desenvolvimentos em reconhecimento e síntese de voz também estimularam a aplicação da tradução no nível do discurso, culminando no projeto Verbmobil ${ }^{2}$, financiado pelo governo da Alemanha, que reconhece textos falados em língua alemã e os traduz para textos falados em língua inglesa.

Atualmente, com os avanços da tecnologia na área de computação e engenharia, podemos encontrar uma melhoria na velocidade e eficiência dos programas. Entretanto, um dos maiores obstáculos para a TA ainda são os problemas de ordem linguística tais como ambiguidade lexical, complexidade sintática e referências anafóricas, entre outros. Em consequência, o desenvolvimento de sistemas totalmente automatizados, que tratem dessas questões ainda se constitui um desafio para área, principalmente em domínios abertos.

\subsection{Níveis de automatização}

A motivação para o uso de tradutores automáticos varia de acordo com a sua utilidade, partindo do entendimento parcial de um texto até a sua total compreensão. De acordo com esses objetivos, um tradutor humano pode interferir no processo de tradução para melhorar a qualidade do resultado, por exemplo.

A distinção entre os níveis de automatização de TA decorre dos diferentes graus de intervenção humana no processo de tradução. Assim, de acordo com Schwarzl [4] existem três níveis de diferenciação: tradução humana auxiliada por computador, tradução automática auxiliada por humano e tradução totalmente automática. Autores como Hutchins [5], classificam somente o processo totalmente automático como pertencente a TA.

A tradução humana auxiliada por computador (MAHT - Machine-Aided Human Translation) consiste na tradução realizada por um tradutor humano, que usa um computador como um assistente. Esse método é também chamado tradução assistida por computador (CAT - Computer-Aided Translation) ou por memória de tradução.

\footnotetext{
${ }^{2}$ http://verbmobil.dfki.de/overview-us.html
} 
A memória de tradução pode ser descrita como um método de armazenamento e re-utilização de traduções. Os softwares comerciais Trados Translator's Workbench (TWB) ${ }^{3}$ e WordFast ${ }^{4}$ são exemplos desse tipo de assistente.

Ao trabalhar com os softwares de memória de tradução, um banco de dados contendo traduções já realizadas é criado para que o tradutor possa pesquisar e consultar as traduções armazenadas. Em casos de dúvidas sobre uma possível tradução, o sistema disponibiliza as opções armazenadas, às quais o tradutor opta por utilizar ou descartar. A utilização desse tipo de software é considerada muito útil por apresentar as palavras consultadas em uma sentença completa, preservando assim o contexto semântico em que elas apareceram.

Além de fornecer opções para traduções de itens lexicais, os programas de memória de tradução fornecem outros serviços, como consulta automática a glossários, verificação ortográfica e gramatical.

Na tradução automática auxiliada por humano (HAMT - Human-Aided Machine Translation), um tradutor automático realiza a tradução com a intervenção de um humano. Essa intervenção pode variar de acordo com as seguintes etapas:

- Pré-edição

A intervenção ocorre na edição do texto na língua de origem, preparandoo para agilizar o processo de tradução. Esta pré-edição pode compreender o preenchimento de elipses, explicitação de relações anafóricas, regularização sintática etc.

- Interação

Na interação, a intervenção é realizada na tradução do texto da língua de origem para a língua de destino, por exemplo, quando o sistema se depara com uma palavra polissêmica ou homônima e conta com o tradutor humano para selecionar a tradução mais adequada ao significado que a palavra apresenta na língua-fonte. Vejamos a sentença abaixo em um processo de tradução do português para o inglês:

(1) Ele me deu uma nova planta.

Diante da homonímia o sistema pode solicitar ao tradutor humano para selecionar a melhor opção:

\footnotetext{
${ }^{3}$ http://www.trados.com/en/

${ }^{4}$ http://www.wordfast.net/
} 
i Plant: designação comum aos organismos do reino Plantae, a maioria autotrófica, fixa a um substrato e caracterizada pela presença da clorofila e de celulose em suas células; vegetal [Em numerosas classificações antigas, os fungos e as bactérias são considerados plantas.] [6]

ii Ground plan: representação gráfica do corte horizontal de uma construção. [6]

iii Sole: parte do pé que assenta no chão; sola do pé. [6]

\section{- Pós-edição}

Na pós-edição, a intervenção humana ocorre na edição do texto em língua de destino, ou seja, ocorre uma revisão humana do texto já traduzido automaticamente.

Na tradução totalmente automática (FAMT - Fully Automatic Machine Translation), o sistema de tradução realiza o processo de forma autônoma, sem a intervenção humana. Neste tipo de processo, são utilizados diferentes tipos de textos, mas os melhores resultados são aqueles pertencentes a áreas restritas do conhecimento, em que o contexto de interpretação é restrito.

A tradução totalmente automática com alta qualidade (FAHQMT - Fully Automatic High Quality Machine Translation) representa o processo totalmente produzido por uma máquina, sem intervenções humanas, referindo-se à tradução de quaisquer textos. O sucesso de um tradutor FAHQMT representaria a substituição de um tradutor humano devido ao seu alto desempenho em traduções de diferentes tipos de texto.

\subsection{Métodos de Tradução Automática}

Como vimos, a Tradução Automática trabalha com o uso de softwares ou ferramentas computacionais para traduzir um texto de uma língua natural para outra. Nesta seção, apresentaremos os tipos de arquitetura e os paradigmas em TA baseando-se em Dorr et al. [7] e em Specia e Rino [2].

O processo de tradução pode ser caracterizado como: a) Decodificação do significado de um texto de origem e b) Codificação desse significado em uma língua de destino. Para realização do processo de decodificação do significado de um texto de partida, o tradutor deve reconhecer, interpretar e analisar todo o texto, o que requer conhecimentos linguísticos para a realização de tal tarefa.

Esse problema pode ser tratado de acordo com diferentes tipos de abordagens em TA. De acordo com Dorr et al. [7] podemos classificar um sistema 
de TA segundo dois tipos de informação: o tipo de arquitetura e o paradigma. Os tipos de arquitetura referem-se à organização do processamento e de seus diversos módulos. Os paradigmas dizem respeito aos componentes que compõem o design do processamento.

Existem três tipos de arquitetura em Tradução Automática: direta, interlíngua e transferência. Esses métodos podem ser agrupados nas categorias direta e indireta. As arquiteturas interlíngua e transferência são chamadas também de indiretas.

Na tradução direta, as sentenças em língua-fonte são traduzidas diretamente em sentenças em língua-alvo. Esse método de tradução apresenta variações, podendo constituir uma tradução palavra-por-palavra, ou seja, substituição das palavras da sentença em língua de origem por suas traduções correspondentes em língua de destino, reordenação das palavras da sentença na língua de destino entre outros.

Em geral, este método utiliza pouco processamento linguístico, realizando substituições de palavras da sentença em língua de origem por traduções correspondentes em língua de destino com a utilização de um dicionário bilíngue. Também é comum reordernar as palavras da sentença de saída a partir do uso de regras existentes entre as línguas tratadas. A Figura $1.1^{5}$ ilustra o método de tradução direta.

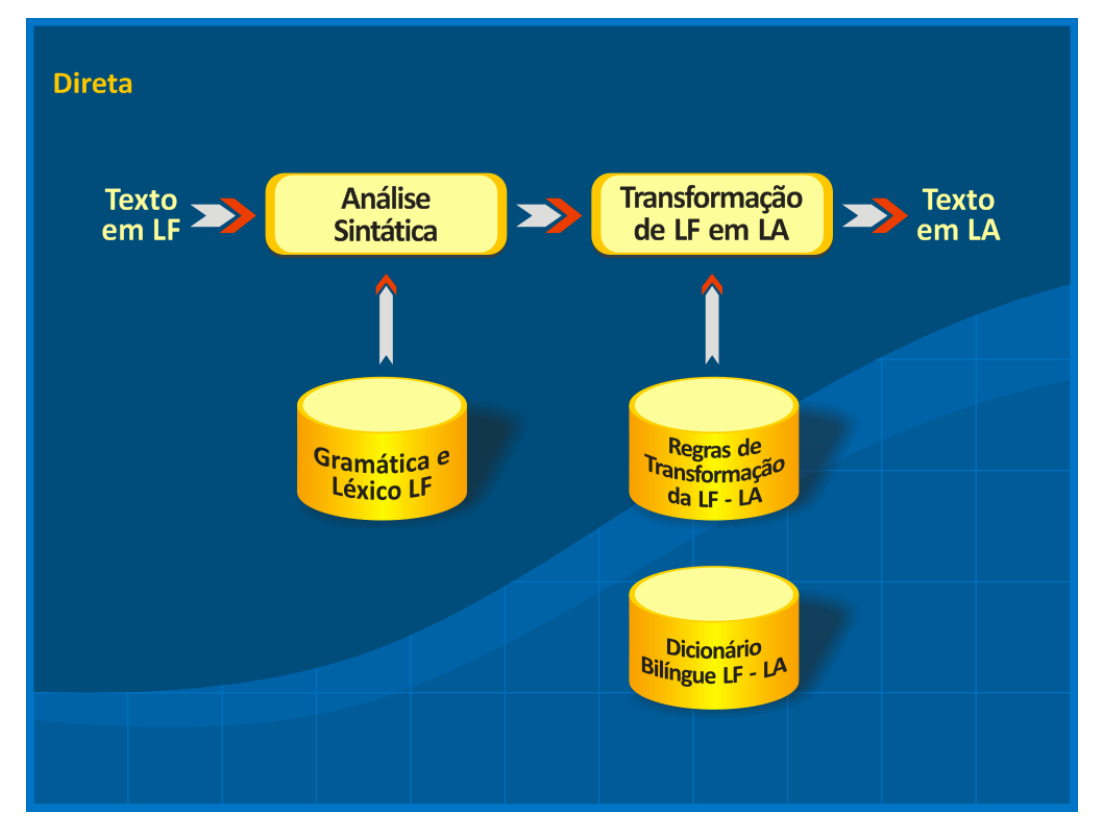

Figura 1.1: Exemplo de arquitetura do modelo de tradução direta

\footnotetext{
${ }^{5}$ Figura baseada em Specia e Rino [2]
} 
Geralmente os sistemas de TA que utilizam o método direto são construídos envolvendo um único par de línguas para evitar que a tradução sofra muitas perdas semênticas. O número de componentes e etapas de processamento depende do nível de qualidade que se pretende alcançar e das línguas envolvidas. Vejamos um exemplo de um sistema de tradução do português para o inglês constituído de quatro estágios.

(2) Maria não comprou um vestido vermelho

Entrada:

i Análise Morfológica: Maria não comprar PASSADO um vestido vermelho

ii Transferência Lexical: Mary not buy PAST a dress red

iii Reordenação: Mary DO-PAST not buy a red dress

iv Geração Morfológica: Mary did not buy a red dress

Dada a sentença de entrada $A$ Maria não comprou um vestido vermelho, ocorreu primeiramente uma análise morfológica superficial desta sentença, seguida de uma transferência lexical, que consiste em um mapeamento de cada palavra em língua-fonte em uma palavra em língua-alvo. Após a tradução de todas as palavras da sentença de entrada, ocorreu a reordenação, no qual regras simples são aplicadas e por último a geração morfológica da sentença de saída Mary did not buy a red dress.

O modelo de tradução direta apresenta alguns resultados satisfatórios, embora não seja considerado um método muito adequado para a TA, em virtude de resultados com baixa qualidade, tipicamente traduções literais. Expressões em línguas com sistemas estruturais mais complexos, como por exemplo, a negação em francês com o ne pas perdem o sentido quando são traduzidas a partir de suas unidades. Devido a essa baixa qualidade nos resultados do modelo direto fez-se necessária a busca por sistemas de tradução mais abrangentes.

De acordo com Dorr et al. [7], as traduções seguindo o método direto são consideradas pobres, mas se forem utilizadas em domínios restritos e com textos simples, podem ser bastante úteis. A utilização desse método foi bem desenvolvida em sistemas comerciais mais antigos, como o SYSTRAN, que se baseia basicamente em buscas em um dicionário, palavra por palavra.

Diferentemente do método direto, os sistemas de método indireto se baseiam na premissa de que um sistema de tradução de alta qualidade necessita de conhecimento linguístico das línguas envolvidas, bem como das diferenças 
existentes entre elas. Geralmente, esse conhecimento baseia-se em representações semânticas ou sintáticas entre as línguas. Portanto, as sentenças em língua-fonte são primeiramente transformadas em uma representação do conhecimento, a partir desta, são geradas sentenças em língua-alvo.

Existem dois métodos de TA indireta: o método por interlíngua e o método por transferência. A representação do conhecimento apresentada por esses métodos pode ser única: 1) independente de língua, que corresponde ao método interlíngua ou 2) dependente de língua, expressa no método por transferência). No caso do método dependente de língua, é necessário o uso de duas linguagens de representação, uma destinada à língua-fonte e outra à língua-alvo.

Na tradução por interlíngua a representação do significado da sentença em língua-fonte gera diretamente a sentença em língua-alvo, o que pode se aplicar a qualquer língua, contanto que haja regras de geração que transformem a representação em interlíngua em uma sentença. A ideia do modelo interlíngua é interpretar e analisar semanticamente uma sentença de uma língua de origem, transformá-la em uma representação abstrata e, a partir dessa representação, gerar uma saída em uma língua de destino. Nesse contexto, o processo de tradução segue as seguintes etapas: 1) análise do texto em língua-fonte, com a extração de seu significado e sua representação em interlíngua; e 2) geração do texto em língua-alvo a partir da representação em interlíngua. A sentença em língua de destino deverá conter o mesmo significado do texto em língua de origem. Abaixo a Figura $1.2^{6}$ ilustra a arquitetura do modelo interlíngua [2].

\footnotetext{
${ }^{6}$ Figura baseada em Specia e Rino [2]
} 


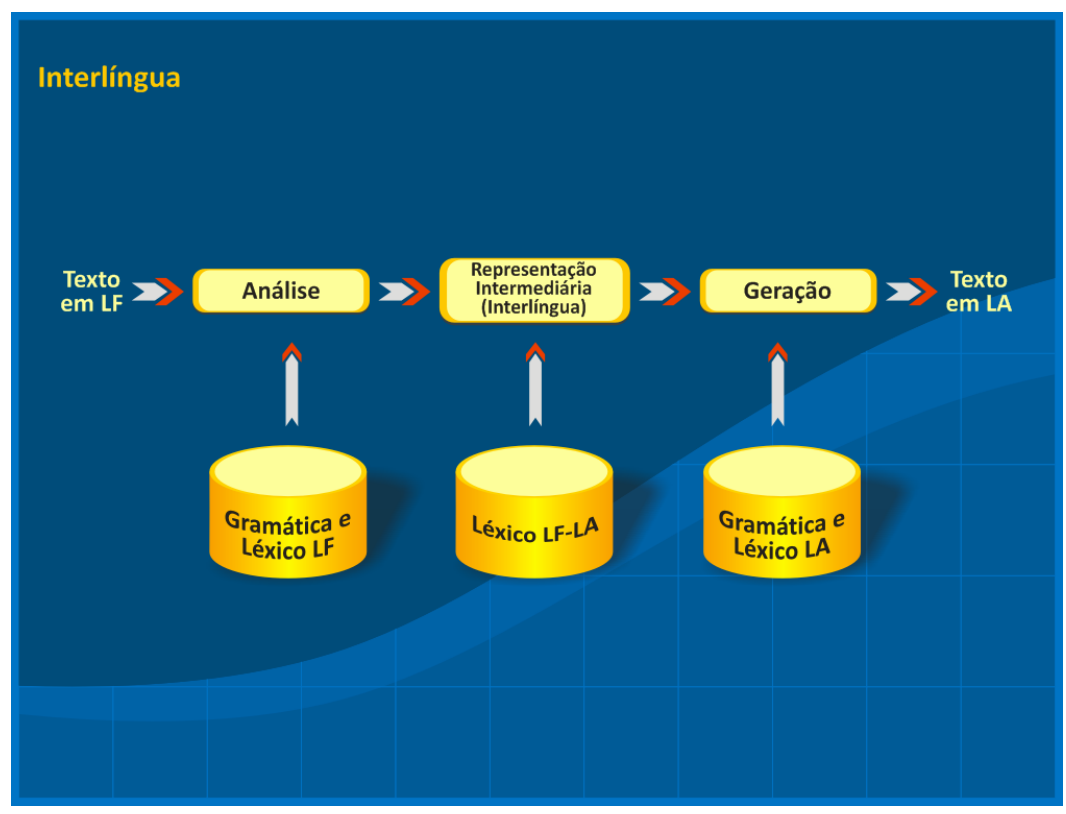

Figura 1.2: Exemplo de arquitetura do modelo de tradução interlíngua

O método interlíngua apresenta algumas vantagens, como a possibilidade de incluir níveis de representação mais profundos como o pragmático, gerando melhorias na qualidade dos resultados; e a facilidade de ampliar os usos desses sistemas a outras línguas com um baixo custo. As dificuldades apresentadas por esse método decorrem da especificação da própria representação em interlíngua, que deve ser independente de língua natural a fim de representar de forma uniforme e robusta o significado das sentenças. Alguns sistemas desenvolvidos sob esse método são o UNL - Universal Networking Language ${ }^{7}$ [8] e o UNITRAN [9].

A tradução por transferência também é uma instância do método indireto. Esse terceiro modelo baseia-se na conversão da estrutura da sentença de entrada, por meio de regras de mapeamento, transformando-a na estrutura da língua de destino. Essa transferência é realizada com a aplicação de conhecimento contrastivo, ou seja, o conhecimento sobre as diferenças entre duas línguas. As regras de mapeamento podem abranger as diferenças estruturais e lexicais.

Por requerer uma representação estrutural da sentença de entrada e de sua transposição para sentença de saída, o modelo de transferência envolve três etapas: 1) análise, na qual ocorre a geração da estrutura da sentença de entrada; 2) transferência, em que a estrutura da sentença de entrada é convertida para a estrutura da sentença em língua de destino; e 3) geração,

${ }^{7}$ http://www.undl.org/ 
na qual ocorre a geração da sentença na língua-alvo. Figura $1.3^{8}$ mostra a arquitetura do modelo de transferência.

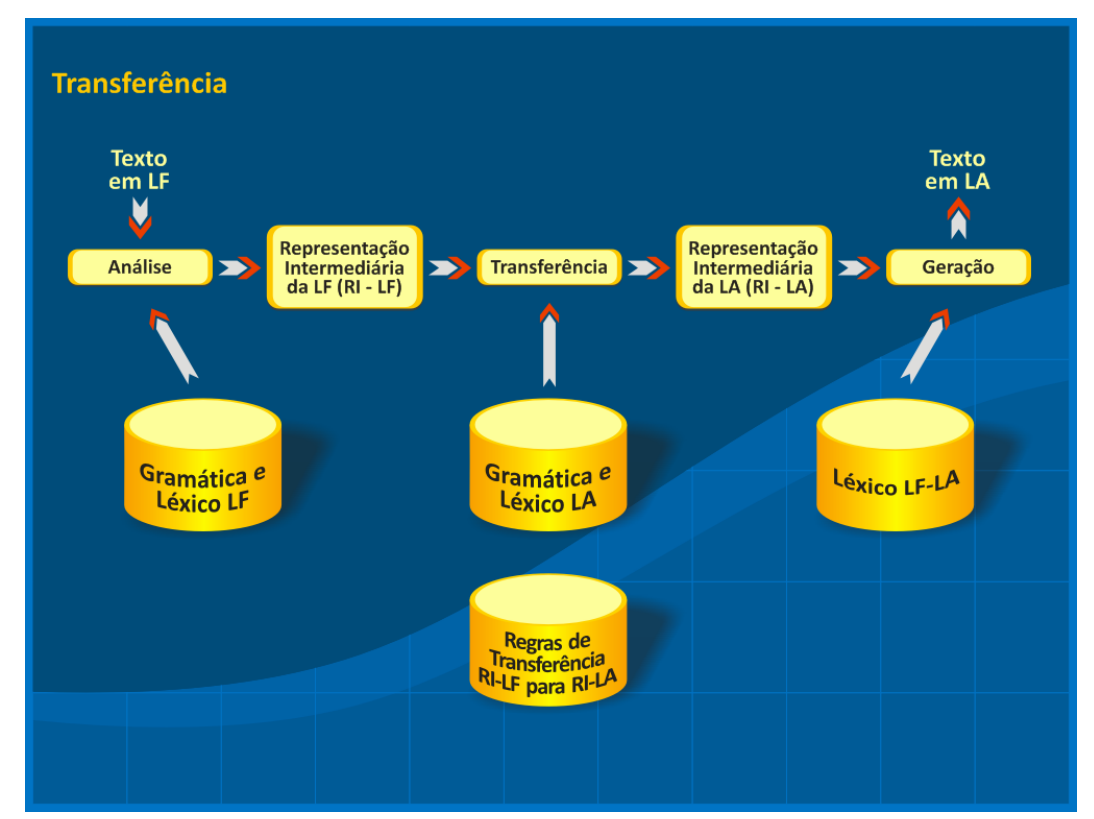

Figura 1.3: Exemplo de arquitetura do modelo de tradução transferência

A etapa de análise pode envolver diferentes níveis de análise linguística, mas, em geral, os sistemas se limitam à análise sintática, gerando como representação uma estrutura arbórea. Os sistemas baseados em transferência sintática oferecem resultados com uma qualidade melhor do que os sistemas de tradução direta, mas esses resultados tendem a ser piores do que aqueles dos sistemas baseados em tradução por interlíngua [7].

Os projetos EUROTRA ${ }^{9}$ e Vermobil são exemplos de abordagens de Tradução Automática por transferência.

Além dos métodos descritos, Dorr et al. [7], distingue os sistemas em três tipos de paradigmas: 1) linguístico; 2) não-linguístico; e 3) híbrido, baseado na combinação de dois ou mais paradigmas.

Os paradigmas linguísticos baseiam-se em teorias linguísticas bem definidas, utilizando recursos de restrição sintática, lexical ou semântica entre as línguas naturais envolvidas no processo de tradução. São exemplos desse paradigma, a Tradução Automática baseada em:

- Regras (Rule-Based Machine Translation - RBMT), que representam o

\footnotetext{
${ }^{8}$ Figura baseada em Specia e Rino [2]

${ }^{9} \mathrm{http}: / /$ www.ccl.kuleuven.ac.be/about/EUROTRA.html
} 
conhecimento linguístico entre as línguas de origem e destino por meio de regras nos diferentes níveis linguístico;

- Conhecimento (Knowledge-Based Machine Translation - KBMT), que se utilizam de conhecimentos linguísticos permitindo que o sistema gere inferências sobre a informação manipulada;

- Léxico (Lexicon-Based Machine Translation - LBMT), que fornece regras para relacionar as entradas da língua de origem à língua de destino;

- Restrições (Constraint-Based Machine Translation - CBMT), que utilizam construções específicas para representações nos diversos níveis de descrição linguística;

- Princípios (Principle-Based Machine Translation - PBMT), que se utiliza de um conjunto princípios que definem fenômenos morfológicos, gramaticais e lexicais para o mapeamento entre as línguas;

- Shake and Bake Machine Translation, que utiliza novos métodos de transferência na realização da tradução e no mapeamento dos itens lexicais

Os paradigmas não-linguísticos são aqueles não se utilizam de teorias linguísticas no processo de tradução. São exemplos desse paradigma, sistemas de tradução baseados em:

- Estatística (Statistical-Based Machine Translation - SBMT), em que as traduções são realizadas por meio de dados estatísticos extraídos automaticamente de pelo menos um corpus paralelo bilíngue, como por exemplo, o corpus EUROPARL, utilizado pelo sistema em desenvolvimento nesta pesquisa.

- Exemplos (Example-Based Machine Translation - EBMT). Nesse paradigma, a tradução é feita basicamente por analogia: o sistema se utiliza de métodos de aprendizado de máquina e baseando-se na solução de alguns problemas presentes no corpus, gera um resultado para uma sentença similar desconhecida. Essa abordagem também pode ser descrita como um processo de aprendizado supervisionado, no qual temos um conjunto de entradas contendo respostas corretas, o corpus, e desejamos encontrar padrões para calcular a resposta para uma entrada dada, a sentença em língua-fonte; 
- Diálogos (Dialogue-Based Machine Translation - DBMT), que voltamse para uma interação com o usuário durante o processo de tradução, permitindo que o usuário resolva eventuais problemas, como por exemplo, a resolução de ambiguidades. Nessa interação, o usuário é considerado o autor do texto traduzido;

- Redes neurais (Neural-Based Machine Translation - NBMT), que são basicamente utilizados em funções de parsing, desambiguização lexical e aprendizado de regras gramaticais.

As abordagens apresentadas não são mutuamente excludentes, elas podem ser combinadas a fim de gerar paradigmas híbridos satisfatórios, além de permitir uma livre estruturação, ou seja, qualquer desenvolvedor de um tradutor automático pode escolher que componentes utilizar e como organizá-los de maneira que possam compor um sistema.

\subsubsection{Conclusão do capítulo, objetivos e organização do trabalho}

Nesta introdução, apresentamos o que é a Tradução Automática, fizemos um breve apresentação do seu contexto histórico e discutimos as suas abordagens.

Partindo da análise de traduções de um corpus de teste, nosso objetivo principal é apresentar o aperfeiçoamento de um tradutor automático sob a perspectiva do tratamento dos tempos verbais entre ao português brasileiro e o inglês americano. Observamos que as características pertencentes à classe Verbo apresentam divergências entre o par de línguas mencionado. Verificaremos, baseados em métricas de avaliação automática de TA, se o aprimoramento de gramáticas de transferência contribui para a melhoria da qualidade das traduções.

Ainda caminhamos no sentido do esclarecimento das semelhanças e diferenças presentes na passagem dos tempos verbais do português para o inglês.

O restante da dissertação organiza-se da seguinte maneira:

- No capítulo 2, apresentamos o Projeto Avenue, no qual a pesquisa se insere e descrevemos o sistema em aperfeiçoamento;

- No capítulo 3, está descrita a metodologia de seleção dos dados estudados e a metodologia de avaliação dos resultados das traduções;

- No capítulo 4, mostramos a relação existente entre os tempos verbais envolvendo o português e o inglês, e apresentaremos as regras utilizadas para a melhoria da qualidade das traduções; 
- No capítulo 5, apresentamos os resultados obtidos a partir das avaliações.

- O capítulo 6 consiste na discussão dos resultados.

- Capítulo 7 conclui o trabalho. 


\section{Capítulo 2}

\section{Projeto Avenue}

\subsection{Introdução}

Atualmente, muitos sistemas de tradução automática estão disponíveis na Web para uso gratuito ou para comercialização. Essa ampla disponibilidade promete auxiliar a divulgação de informações em diversos países e assim, permitir que diferentes línguas continuem a ser faladas sem a necessidade de uma língua de contato. Entretanto, muitos desses sistemas disponíveis requerem esforços humanos para o desenvolvimento do software ou, alternativamente, uma grande quantidade de textos eletrônicos bilíngues com alta qualidade para a construção de sistemas. Esses requerimentos nem sempre são atendidos em todas as línguas, embora estejam facilmente disponíveis para línguas com maior quantidade de documentos publicados na Web, como inglês, francês e espanhol.

Um dos objetivos do projeto Avenue é estender o recurso de tradução automática para pequenos grupos linguísticos, que possuem uma menor participação no desenvolvimento de recursos digitais. Dentre outros objetivos, destacamos também o científico, o qual consiste em explorar métodos para redução de tempo e o custo no desenvolvimento de sistemas de tradução, tornando-os disponíveis para um maior número de usuários. Inicialmente o projeto dedicava-se a traduções de textos em línguas minoritárias, como a língua Quéchua falada no Peru e o Mapudungun falado no Chile. Atualmente o projeto abrange outras línguas tais como alemão, francês, português brasileiro, apresentado nesta pesquisa, entre outras. 


\subsection{O sistema Avenue}

O sistema de tradução Avenue Português-Inglês foi inicialmente desenvolvido pelos professores Marcello Modesto, da Universidade de São Paulo com auxílio da FAPESP, e Alon Lavie, da Universidade Carnegie Mellon, com participação de grupo Avenue da Universidade Carnegie Mellon.

A arquitetura do sistema Avenue apresenta os seguintes componentes: Morfologia, Gramática, Léxico, Transferência e Decodificador. Todos esses componentes serão descritos nas subseções a seguir.

\subsubsection{Morfologia}

Para a realização da análise morfológica dos itens da sentença de entrada, o sistema utiliza o analisador morfológico $\mathrm{Jspell}^{1}$, desenvolvido pela Universidade do Minho em Portugal que está disponível livremente na internet. O Jspell gera as etiquetas morfológicas possíveis para cada item lexical da sentença de entrada e fornece a raiz da palavra para cada etiqueta criada. Este analisador morfológico também é responsável pela identificação de prefixos utilizados pelas palavras.

O Jspell está disponível para nós como um componente fechado; por isso revisões, aperfeiçoamento ou introdução de novas variantes lexicais são tarefas mais complexas e não foram tratadas nesta pesquisa. Experimentos com corpora baseados em jornais, revistas científicas e livros obtiveram uma análise satisfatória.

\subsubsection{Gramática}

A Gramática é o componente responsável por analisar a sequência de palavras etiquetadas resultante do componente Morfologia. A Gramática é composta pelas regras gramaticais de transferências estruturais envolvendo as duas línguas. Essas regras podem conter somente partes dos constituintes, que podem ser encaixados a outros até a formação da estrutura completa da sentença de entrada. Esse componente também deverá fornecer o máximo de análises dos constituintes a fim de ampliar a possibilidade de uma tradução mais adequada figurar entre as selecionadas pelo decodificador [10].

As regras gramaticais foram manualmente desenvolvidas em linguagem declarativa e compõem um conjunto de regras livres de contexto. Elas seguem o formalismo descrito abaixo, baseado em Lavie et al. [11]. Em geral, o lado $x$ de uma regra de transferência se refere à língua de origem e o lado $y$, à língua de destino.

\footnotetext{
${ }^{1}$ http://natura.di.uminho.pt/wiki/doku.php?id=ferramentas:jspell
} 
- Tipo de informação: Identifica o tipo de informação da regra de transferência.

- Informação do constituinte: Para língua de origem e língua de destino, lista-se uma sequência linear dos constituintes que constituem o tipo da regra. Os elementos listados podem ser categorias lexicais, itens lexicais ou categorias frasais.

- Alinhamento: Descreve como o conjunto de componentes da língua de origem será alinhado e transferido para os componentes das língua de destino. Alinhamento zero ou múltiplos são permitidos.

- Restrições do lado $x$ : As restrições do lado $x$ provêm informações sobre os traços e seus valores para sentenças em língua de origem. Esses traços são utilizados para determinar se regra de transferência se aplica a uma dada sentença de entrada.

- Restrições do lado $y$ : As restrições do lado y são similares ao conceito das restrições do lado $x$, porém pertencem à língua de destino. Essas restrições servem para guiar e restringir a geração da sentença em língua de destino.

- Restrições $x y$ : As restrições $x y$ fornecem informações sobre os valores dos traços para a transferência da língua de origem para a língua de destino. Palavras específicas da língua de destino podem obter os valores dos seus traços a partir das palavras da língua de origem.

Abaixo, o exemplo de regra de transferência para a tradução do verbo no tempo presente do modo indicativo em português para o present simple no inglês.

$1\{\mathrm{VP}, 2\}$

2 ;; SL: ANDO

3 ; ; TL: WALK

4 VP: :VP [V] --> [V]

5(

$6(\mathrm{X} 1:: \mathrm{Y} 1)$

$7((\mathrm{X} 1$ tense $)=c$ pres $)$

$8((\mathrm{X} 1 \mathrm{mood})=\mathrm{c}(* \mathrm{NOT} *$ subj $))$

$9((Y 1$ tense $)=$ pres $)$

$10((X 0$ number $)=(X 1$ number $))$

$11((\mathrm{X} 0$ person $)=(\mathrm{X} 1$ person $))$

$12)$ 
A primeira linha indica o nome da regra, neste caso $V P, 2$. A segunda e terceira linhas apresentam exemplos da transferência entre ambas as línguas. $S L$ do inglês source language exemplifica a língua de origem, enquanto $T L$, do inglês target language, exemplifica a língua de destino. A quarta linha ilustra que o verbo simples na língua de origem será traduzido por outro verbo simples na língua de destino.

A condição para aplicação dessa regra encontra-se entre parênteses, presentes nas linhas cinco e doze. A linha seis, entre os parênteses da condição, indica que o primeiro elemento do sintagma verbal em língua de origem, $X 1$, será convertido para o primeiro elemento do sintagma verbal da língua de destino, Y1. A linha sete designa que $X 1$ deverá estar no tempo presente e linha oito, mostra que não poderá ser no modo subjuntivo. A linha nove indica que $Y 1$ receberá o traço de tempo presente. As linhas dez e onze mostram que $X 0$ receberá traços de número e pessoa do verbo em língua de origem, nesse caso $X 1$. X0 corresponde ao sintagma que está sendo formado pela regra.

Essa regra poderia ser aplicada a uma sentença, como, por exemplo, Eu caminho todos os dias cuja tradução seria I walk every day.

Por ser escrito manualmente, o componente Gramática vem sendo continuamente testado e refinado a fim de alcançar bons resultados para a maioria dos inputs.

\subsubsection{Léxico}

O componente Léxico é constituído de itens lexicais em português seguido de suas respectivas traduções para o inglês. Este léxico bilíngue no nível da palavra foi automaticamente extraído dos anais do Parlamento Europeu ${ }^{2}$, que compõe o corpus EUROPARL ${ }^{3}$, publicamente disponível na Web. Para o uso do sistema, foi necessário alterar a lista de palavras extraídas para um formato de leitura para o sistema. Abaixo, apresentamos o formalismo necessário para compor o componente Léxico.

- Informação do constituinte: Para língua de origem e língua de destino, lista-se uma sequência linear dos constituintes que constituem o tipo da regra. Os elementos listados podem ser categorias lexicais, itens lexicais ou categorias frasais.

- Alinhamento: Descreve como o conjunto de componentes da língua de origem será alinhado e transferido para os componentes da língua de

\footnotetext{
${ }^{2}$ http://www.europarl.europa.eu/

${ }^{3}$ http://www.statmt.org/europarl/
} 
destino. Alinhamento zero, singular ou múltiplo são permitidos.

O exemplo abaixo ilustra a representação formal requerida pelo sistema, em que o item lexical em português casa deverá ser traduzido pelo item house em inglês. Na linha 1 apresenta-se a classe de constituintes a que o item em língua de origem e língua de destino pertence, substantivo (N), seguido dos itens lexicais. A linha 2 indica a condição de alinhamento em que a regra de transferência lexical deverá ser aplicada, na qual o elemento presente na linha $3, x 1$ da língua de origem deverá ser transposto para o item y1, da língua de destino. A linha 4 indica o término da condição.

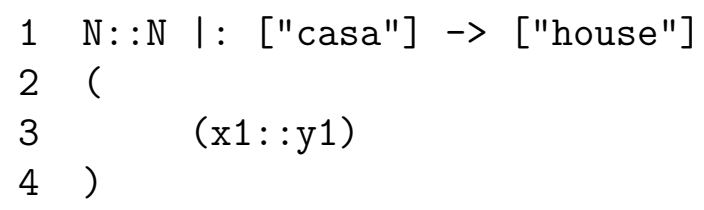

Apesar das palavras que compõem este componente terem sido extraídas do corpus EUROPARL, que é considerado um corpus representativo, diversas entradas lexicais apresentavam mais uma ocorrência, traduções inadequadas, bem como a ausência de diferentes itens e de suas respectivas traduções. Em consequência, foi necessário um esforço manual significativo para sua edição e revisão. As principais tarefas incluíram o acréscimo de entradas ausentes assim como correção de traduções incorretas e remoção de itens repetidos.

Este componente desempenha um importante papel na geração da sentença de saída, podendo contribuir significativamente na melhoria dos resultados. Para alcançar uma alta pontuação durante a avaliação da tradução, a seleção lexical da sentença de saída deverá corresponder aos mesmos itens lexicais apresentados na sentença de referência. Sinônimos são considerados, porém recebem uma penalidade e uma pontuação mais baixa em relação à tradução de referência.

\subsubsection{Transferência}

O componente Transferência foi desenvolvido pelo grupo AVENUE da Universidade Carnegie Mellon [12,13] e é responsável pela aplicação das regras de transferência lexicais, isto é, as entradas lexicais em português são substituídas por suas traduções em Inglês. Este componente também aplica as regras de transferência estruturais do português para o inglês produzindo constituintes traduzidos na estrutura sintática do Inglês.

A Transferência compõe-se de quatro principais sub-etapas: 1) transferência lexical dos tokens em português para o inglês; 2) análise dos cons- 
tituintes da sentença de entrada; 3) transferência estrutural dos constituintes da sentença de entrada para os constituintes da sentença de saída; e 4) produção dos constituintes da sentença de saída.

A transferência lexical constitui a primeira sub-etapa da Transferência. Neste estágio, todos os itens lexicais da sentença de entrada são submetidos às traduções individuais ou expressões a partir das traduções existentes no componente Léxico. As regras de transferência lexical são utilizadas para determinar as escolhas lexicais das palavras da sentença de entrada na sentença de saída. O resultado final da transferência lexical é automaticamente convertido para entrada da próxima sub-etapa.

Para a análise dos constituintes da sentença de entrada, o sistema utiliza o Chart parser sob a estratégia de análise bottom-up. A análise bottom-up é utilizada na análise de sentenças, iniciando pela identificação das classes de palavras, passando para o uso das propriedades dos itens lexicais a fim de inferir as relações gramaticais e a estrutura dos constituintes para, ao final, realizar a análise completa da sentença. O Chart parser, por sua vez utiliza uma tabela como ferramenta de auxílio para o armazenamento dos constituintes sintáticos segundo o processamento da sentença. As regras de transferência em conjunto com as saídas do Chart parser da sentença de entrada determinam a estrutura dos constituintes da sentença de saída.

A produção dos constituintes decorrente da aplicação das regras de transferência corresponde à saída do componente Transferência, que se constitui de um conjunto de todas as possíveis alternativas para a tradução da sentença de entrada.

Ao completar o estágio de transferência, tem-se um gráfico (hypergraph, em que cada vértice contém uma lista com os $n$ melhores para cada símbolo não terminal de cada arco. Cada entrada da lista possui o traço de unificação da estrutura e o log-linear da pontuação dos traços associados a ele.

Antes de prosseguir para a etapa de Decodificação, o gráfico é transformado em um arquivo lattice, no qual é removida a estrutura hierarquica e se respeita somente a ordenação dos constituintes da língua de destino produzida pela gramática. A unificação dos traços e das restrições apresentadas em cada regra removem as hipóteses agramaticais. [14]

O número de traduções para cada constituinte pode variar de acordo com ambiguidades lexicais e sintáticas, com a grande variedade de sinônimos para cada entrada lexical e com o número de regras envolvendo o fragmento trabalhado. O exemplo abaixo apresenta uma amostra da saída do componente Transferência, o lattice.

$1 \quad($

$2 \quad$ (0 0 "HE" -8.29445 "ELE" "(PRON,O 'HE')") 


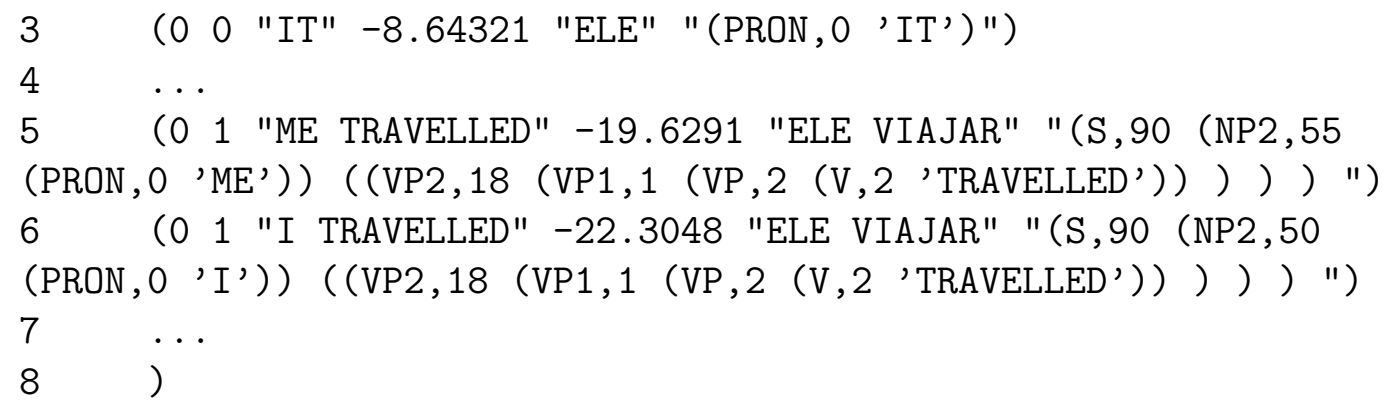

O exemplo do arquivo lattice acima apresenta seguinte estrutura para a sentença de entrada Eu viajei.

- Combinação do número de elementos trabalhados dentro do número total de elementos presentes no constituinte. Assim de acordo com o exemplo acima, a linha dois apresenta a análise do primeiro elemento, que é composto por um total de um elemento. A numeração se inicia com zero.

- A tradução para a palavra ou constituinte da sentença de entrada;

- A probabilidade de tradução que a palavra ou o conjunto de probabilidades do constituinte apresenta;

- A palavra ou constituinte em língua de origem;

- A regra gramatical aplicada para a tradução do determinado constituinte.

\subsubsection{Decodificador}

Decodificador é o componente responsável por agrupar partes dos constituintes até a formação da estrutura completa da sentença de entrada. Este componente também realiza a seleção das possíveis traduções da sentença de entrada, produzindo um ranking com todas as alternativas possíveis para a sentença de saída, ordenadas a partir do mais ao menos provável candidato a tradução. O Decodificador utiliza o modelo de linguagem e os traços adicionais para o cálculo de probabilidades das traduções de uma sentença. Os traços adicionais são compostos pelo modelo de linguagem e modelo de tradução.

O modelo de tradução, atualmente também conhecido por Léxico frasal ou Gramática, é composto por dois léxicos bilíngues probabilísticos, um no nível da palavra e o outro no nível da sentença. Esses léxicos, assim como 
o presente no componente Léxico, foram extraídos do corpus EUROPARL. Para a construção do modelo de traducão, o corpus EUROPARL foi automaticamente alinhado no nível da sentença com a utilizacão da ferramenta MGIZA $++{ }^{4}$, que implementa o modelo de alinhamento de palavras IBM. As heurísticas das sentenças alinhadas foram extraídas com a utilização do modelo Koehn e, em seguida, a essas sentenças foi atribuída uma pontuação baseada no método estatístico da estimativa Máxima verossimilhança.

O modelo de tradução também poderia utilizar probabilidades associadas a cada regra de transferência estrutural, mas no estado atual do sistema, tal recurso não é utilizado.

O modelo de linguagem é um modelo estatístico de sequências de palavras, que, baseado no modelo dos N-gramas, computa a próxima palavra de um Ngrama, com base na ocorrência da palavra anterior, ou seja, seria um modelo probabilístico de predição de palavra baseado no número de ocorrências de uma ou mais palavras anteriores.

O algoritmo de decodificação considera todas as possíveis sequências presentes no lattice e calcula a probabilidade a partir do modelo de linguagem e do modelo de tradução para os constituintes resultantes da transferência [11]. A partir de então, o componente Decodificador realiza uma decodificação monotônica no sentido da esquerda para a direita do arquivo lattice, sem nenhuma reordenação além da produzida pela gramática. Para cada arco de origem, o Decodificador mantém as $n$ hipóteses mais prováveis.

A saída do Decodificador é também a saída do sistema. O número de sentenças selecionadas para serem as melhores hipóteses da tradução de uma sentença é previamente determinado no arquivo de inicialização do sistema.

\subsection{O sistema de tradução Português-Inglês}

O sistema Português-Inglês apresenta a arquitetura descrita na seção anterior, porém, para apresentar o processo de tradução entre a língua de origem e a língua de destino, dividimos o sistema em três principais etapas: Préprocessamento e Morfologia, Transferência e Decodificação. A Figura 2.1 mostra as três sub-etapas utilizadas na tradução da língua portuguesa para a inglesa.

\footnotetext{
${ }^{4}$ http://www.cs.cmu.edu/ qing/
} 


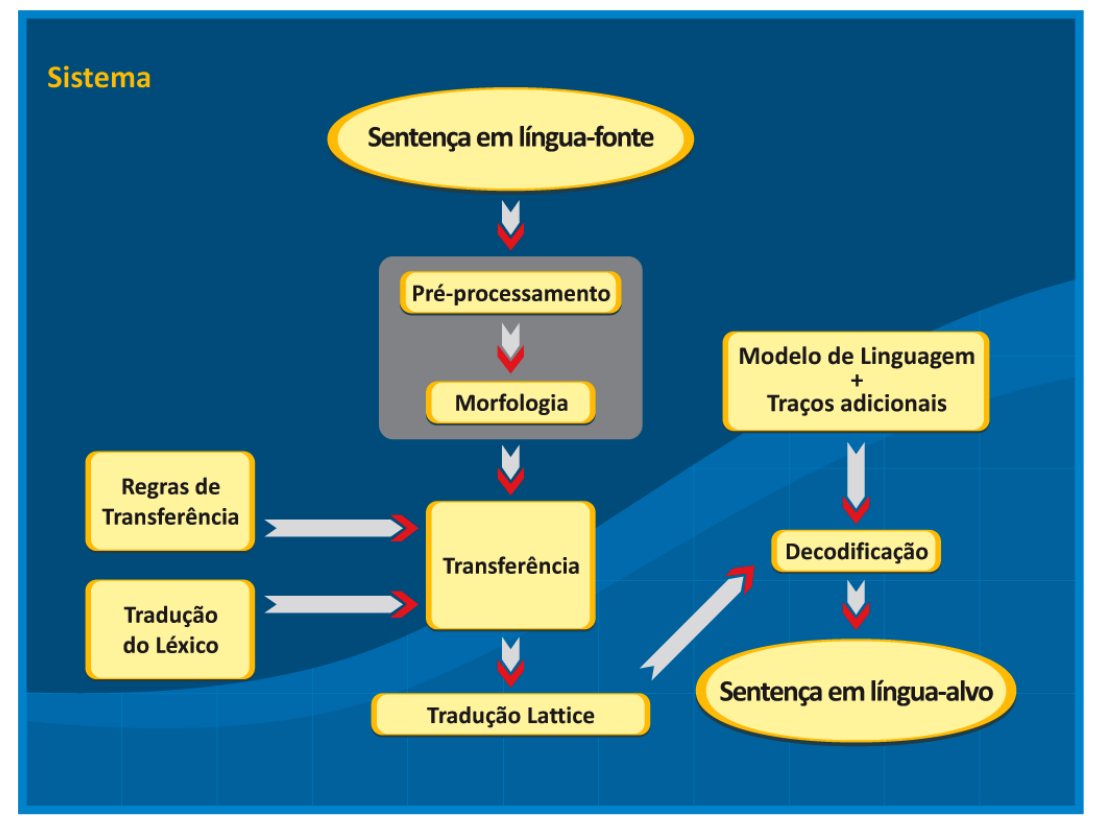

Figura 2.1: Arquitetura do sistema

Para realizarmos a tradução usando o sistema Avenue, faz-se necessária a edição do arquivo de inicialização do sistema. Nesse arquivo deverão ser inseridos o nome do arquivo de entrada contendo as sentenças em língua de origem e o nome do arquivo de saída, que terá as sentenças traduzidas pelo sistema. O arquivo de entrada deverá ser um arquivo do tipo texto puro ou plain text. Por se encontrar em fase de desenvolvimento, também podemos definir o número de sentenças hipóteses a serem fornecidas pelo sistema para cada sentença de entrada. Nessa pesquisa, adotamos como parâmetro o número cinquenta. Essa medida nos permite verificar o desempenho do sistema e analisar as traduções fornecidas.

Descreveremos agora todas as etapas do processo de tradução envolvendo o sistema Português-Inglês, tendo como ponto inicial uma sentença de entrada em português, input, até chegarmos ao objetivo final que é a sentença traduzida para o inglês, isto é, o output.

\subsubsection{Pré-processamento e Morfologia}

Dada uma sentença de entrada em português, o primeiro passo que se segue é a segmentação dos itens lexicais desta sentença. Neste estágio, também conhecido como Tokenização, o processo de segmentação toma como parâmetro os espaços em branco presentes na sentença; assim, cada token ou item é reconhecido como tal pela ocorrência anterior e posterior de espaços em branco. 
Símbolos alfa-numéricos também são reconhecidos como tokens. Na versão atual do sistema, a pontuação também é vista como uma palavra.

Após a tokenização, as palavras sofrem uma modificação, tornando-se todas capitalizadas, passando a adquirir o formato em "caixa alta", ou seja, as palavras adquirem o formato de letras maiúsculas. Esse processo atua como prevenção para evitar que uma mesma palavra apareça com variações, como por exemplo, para evitar que ela ora apareça com todas as letras minúsculas ora com apenas a primeira letra maiúscula e as demais minúsculas.

Realizada a segmentação e a capitalização, as palavras da sentença de entrada passam pela etapa de análise morfológica a fim de que sejam produzidas todas as possíveis análises para cada palavra do input. Essas análises correspondem à identificação dos traços morfossintáticos, como número, pessoa, gênero entre outros; das classes de palavras; dos afixos etc. A saída dessa etapa servirá de entrada para a etapa de Transferência.

\subsubsection{Transferência}

De acordo com a etapa anterior, dado uma sentença de entrada em Português, esta passará pelos processos de tokenização, capitalização e análise morfológica. O resultado da etapa Pré-processamento e Morfologia é agora utilizado como entrada para a etapa de Transferência.

Na Transferência, a sentença em língua de origem é traduzida para a sentença em língua de destino com a aplicação das regras de transferência lexical e estrutural. O resultado da etapa de Transferência compreende o arquivo lattice, que servirá de entrada para a próxima etapa, a Decodificação.

\subsubsection{Decodificação}

Nesta última etapa, ocorre a seleção das sequências traduzidas que apresentam as maiores probabilidades de serem as traduções corretas para a sentença de entrada. Essas probabilidades são advindas do modelo de tradução e do modelo de linguagem. O componente Decoder considera todas as possíveis sequências presentes no lattice para a seleção da sentença em língua de origem com a maior probabilidade.

A saída final do sistema é também a saída do processo de decodificação, que consiste em um arquivo contendo as $n$ melhores sentenças traduzidas para a língua inglesa ordenadas das mais às menos prováveis. Contudo, a sentença de saída contendo a maior probabilidade fornecida pelo sistema nem sempre apresenta alta correlação com a tradução de referência. 


\section{Capítulo 3}

\section{Metodologia}

\subsection{Seleção dos dados para o estudo}

A seleção dos dados linguísticos seguiu alguns critérios metodológicos que serão aqui descritos.

\subsubsection{Análise preliminar}

De acordo com Ma [15], em traduções, o verbo principal de uma sentença é o elemento mais importante para a sua compreensão. Na TA, o principal objetivo é produzir traduções compreensíveis. Para verificarmos se as divergências entre os tempos verbais do português e inglês constituíam um real problema para os sistemas de tradução automática, utilizamos um corpus preliminar $^{1}$ composto por cento e vinte e sete sentenças [16] português-inglês para uma avaliação inicial. As sentenças que compõem esse corpus preliminar foram extraídas do site de recursos para o processamento computacional da língua portuguesa, Linguateca ${ }^{2}$ e retiradas de diversos corpora paralelos bidirecionais de português e inglês utilizando a ferramenta COMPARA ${ }^{3}$. Essa ferramenta permite a consulta a um banco de dados contendo textos originais em ambas as línguas e suas respectivas traduções.

Primeiramente, traduzimos o corpus preliminar em um tradutor já consolidado, o Google Translate ${ }^{4}$. Este tradutor apresenta o paradigma puramente estatístico, sendo assim diferente do sistema Avenue. Os exemplos abaixo ilustram diferentes resultados nas traduções entre os tempos verbais entre o português e o inglês. A pontuação aparece entre espaços em branco,

\footnotetext{
${ }^{1}$ Ver Anexo A.

${ }^{2}$ http://www.linguateca.pt/

${ }^{3} \mathrm{http}: / /$ www.linguateca.pt/COMPARA/Bem-vindos.html

${ }^{4} \mathrm{http}: / /$ translate.google.com.br
} 
pois, para o sistema Avenue, a pontuação é reconhecida como um token. A ordem de apresentação dos exemplos segue a seguinte estrutura: a. sentenças em português; b. sentenças de referência e c. traduções apresentadas pelo Google Translate.

(1) a. Ele teria se suicidado .

b. He would have committed suicide .

c. He reportedly committed suicide.

(2) a. O melhor é que não saia ... não saia ...

b. It's best that he doesn't go out ... doesn't go out ...

c. It is best not skirt ... do not leave ...

(3) a. Iremos ambos .

b. We will both go .

c. We'll both.

No exemplo (1), vimos que a tradução fornecida pelo Google Translate contém divergência quanto ao tempo verbal, em comparação à tradução de referência. O exemplo (2) ilustra o emprego de uma tradução inapropriada, em que saia, verbo sair no tempo presente do modo subjuntivo, aparece traduzido pelo seu homônimo, o substantivo simples. Em (3), o resultado oferecido pelo sistema não apresenta tradução para o verbo $i r$.

Após verificarmos que as traduções dos tempos verbais representavam um problema recorrente, traduzimos as mesmas cento e vinte e sete sentenças do corpus preliminar no sistema Avenue, para averiguarmos se os mesmos problemas se apresentariam nesse sistema. Abaixo, os exemplos contendo as saídas do sistema. A ordem de apresentação dos exemplos segue a seguinte estrutura: a. sentenças em português; b. sentenças de referência e c. traduções apresentadas pelo sistema Avenue.

(4) a. Eu iria ao dentista

b. I would go to the dentist

c. HE WILL GO TO THE DENTIST .

(5) a. Ela parara de miar.

b. She had stopped meowing .

c. THEM TO STOP TO MEOW .

(6) a. Iremos ambos .

b. We will both go .

c. TO GO BOTH .

Com exemplo (4), podemos notar que a tradução do verbo ir no futuro do pretérito do indicativo fornecida pelo sistema Avenue se apresentou com 
o auxiliar will ao invés do would, conforme a tradução de referência em (4) a. Em (5), o pretérito mais-que-perfeito de parar foi traduzido por um infinitivo seguido do infinitivo de miar. Em (7), o sistema apresentou o uso do infinitivo para o futuro do presente $i r$.

Com a verificação da sistematicidade das questões dos tempos verbais, nos deparamos com o problema de como verificar quais tempos verbais específicos, pessoa e número apresentam traduções inconsistentes? Em quais casos a sentença de saída não apresenta seu tempo verbal traduzido corretamente? Para podermos criar ou modificar as regras de transferência do sistema corretamente, achamos por bem criar um corpus específico para os tempos verbais ${ }^{5}$, contendo sentenças mais simples do que as apresentadas pela ferramenta COMPARA.

\subsection{As etapas de seleção dos corpora}

\subsubsection{Primeira etapa de seleção: o dicionário}

Para que obtivéssemos uma amostra de verbos que iriam compor o corpus dos tempos verbais com o menor viés pessoal possível, selecionamos todos os verbetes do Dicionário Eletrônico Houaiss da Língua Portuguesa [6] que possuíam terminações em -ar, $-e r$ e -ir. Ao todo, nessa primeira seleção foram obtidas 15.496 ocorrências de verbetes ${ }^{6}$. Contudo, essa primeira amostra não restringia os verbetes à categoria Verbo, por isso, fomos levados a fazer uma filtragem manual dos verbos, respeitando o critério das conjugações:

1. primeira: verbos terminados em -ar

2. segunda: verbos terminados em $-e r+$ verbo por e suas derivações

3. terceira: verbos terminado em $-i r$

Esse novo filtro de seleção nos permitiu refinar a amostra de verbos e chegarmos assim a 12.939 ocorrências de verbos. Em suma, selecionamos 12.939 verbos a partir dos seguintes critérios:

- Ser verbo

- Estar no infinitivo

\footnotetext{
${ }^{5}$ Ver Anexo C.

${ }^{6}$ Agradecemos ao Prof. Dr. Zwinglio Guimarães do Instituto de Física e ao grupo de Morfologia Histórica do Português (http://www.usp.br/gmhp/) da Faculdade de Filosofia, Letras e Ciências Humanas, ambos da Universidade de São Paulo pela ajuda com a extração dos verbos a partir do dicionário eletrônico.
} 


\subsubsection{Segunda etapa de seleção: critério de uso}

Embora o dicionário seja uma fonte confiável para seleção dos verbos, existem algumas desvantagens em sua utilização. A presença de verbetes arcaicos ou de frequência somente em variantes literárias são alguns exemplos que ilustram essas suas desvantagens.

Logo, verificou-se que da amostra de 12.939 verbos, grande parte deles seriam pouco utilizados em textos de entrada em um sistema de TA. No entanto, acreditamos que um número considerável de verbos podem ser considerados produtivos na utilização de textos digitais, que constituem candidatos potenciais à TA. Assim, decidimos ordenar os verbos pelo critério de frequência de uso para priorizar a análise.

Para obtermos uma amostra com verbos frequentes, utilizamos uma ferramenta computacional escrita na linguagem Python ${ }^{7}$ que permitisse consultas automatizadas ao site de busca Google ${ }^{8}$. Usamos como filtros para esta consulta os seguintes parâmetros: idioma português e páginas do Brasil.

Da consulta realizada no site de busca, foi extraído o total das ocorrências dos verbos em sites da internet. Ao fim, selecionamos os cem verbos mais frequentes em cada conjugação ${ }^{9}$ para a construção do corpus dos tempos verbais.

\subsection{Corpora dos tempos verbais}

Para superarmos as diferenças entre os tempos verbais em português e inglês e para que nenhum tempo verbal fosse omitido na passagem de uma língua para a outra, selecionamos sentenças contendo todos os tempos e modos verbais do português [17] e fizemos um mapeamento para os tempos verbais do inglês ${ }^{10}$.

Após o mapeamento dos tempos verbais entre as línguas em questão, optamos por selecionar sentenças que continham verbos em todas as três conjugações: a) em -ar; b) em -er; e c) em -ir; e de acordo com a transitividade verbal: i) intransitivos; ii) transitivos diretos; iii) transitivos indiretos; e iv) bitransitivos.

\footnotetext{
${ }^{7}$ Agradecemos a Fidel Beraldi do Instituto de Matemática e Estatística e a Indaiá Bassani da Faculdade de Filosofia, Letras e Ciências Humanas, ambos da Universidade de São Paulo, pelo desenvolvimento do programa de consulta às ocorrências dos verbos no site de busca Google.

${ }^{8}$ http://www.google.com.br

${ }^{9}$ Ver Anexo D.

${ }^{10}$ Ver Anexo B.
} 
Embasados nessa diferenciação, selecionamos os cem verbos mais frequentes em cada conjugação e dispomos de sentenças concordando em pessoa e em número dos modos e tempos verbais para constituirmos o corpus de análise. Assim, foram construídos três corpora classificados pelas três classes de conjugação. Cada corpus é composto por 165 sentenças contendo os cem verbos mais frequentes. Cada verbo não foi utilizado mais do que três vezes. Desse modo, temos um corpora dos tempos verbais com um total de 495 sentenças.

As sentenças de referência desses corpora foram manualmente traduzidas por um tradutor humano ${ }^{11}$.

\subsection{Métodos de avaliação dos corpora}

A avaliação envolvendo tradutores automáticos pode ser feita tanto por avaliadores humanos quanto por avaliadores automáticos. Porém, recentemente, a utilidade e praticidade de métricas automáticas de avaliação têm recebido grande atenção na área de TA. As métricas de avaliação automática oferecem grandes vantagens sobre os tradutores humanos, por serem fáceis, rápidas e baratas em contraste com os avaliadores humanos [18].

A avaliação do desenvolvimento de um software desempenha um papel muito importante na área de Engenharia de software, auxiliando encontrar as falhas do sistema e em consequência possibilitando a sua melhoria. Em geral, os avaliadores automáticos são submetidos à técnica de avaliação caixapreta, no qual somente a saída do tradutor é avaliada e não os componentes do sistema.

Para mensurarmos o estado inicial do sistema de tradução Avenue, submetemos nosso corpus preliminar à métrica de avaliação automática METEOR [19].

Apresentaremos, na subseção a seguir a descrição da métrica METEOR, baseada em Lavie e Agarwal [19].

\subsubsection{METEOR}

A métrica METEOR ${ }^{12}$ (Metric for Evaluation of Translation with Explicit ORdering) foi desenvolvida pela Universidade Carnegie Mellon e tem por objetivo corrigir algumas fraquezas presentes em outros avaliadores automáticos, como por exemplo a métrica BLEU.

\footnotetext{
${ }^{11}$ Agradecemos a Bianca Mendes de Oliveira da Primacy Translations pela tradução das sentenças que constituem o corpus de referência dos corpora utilizado para análise da pesquisa

${ }^{12} \mathrm{http}: / /$ www.cs.cmu.edu/ alavie/METEOR/
} 
De acordo com Lavie e Agarwal [19] o Meteor utiliza uma métrica automática de avaliação que se baseia na associação de palavra por palavra entre a sentença de saída do sistema, considerada a hipótese a ser avaliada, e entre uma ou mais sentenças de referência, que são compostas por traduções humanas da sentença em língua de origem. Dado um par de sentenças a ser avaliado, a hipótese e a referência, esta métrica cria um alinhamento entre essas duas sentenças. O alinhamento é um mapeamento entre as palavras da hipótese com a referência. Uma palavra pode ser mapeada com uma ou mais palavras correspondentes. O alinhamento é produzido pela seguinte sequência de módulos de mapeamento:

1. Módulo exact: mapeia duas palavras exatamente idênticas.

2. Módulo porter stem: mapeia duas palavras idênticas após o uso do algoritmo Porter stemmer.

3. Módulo WN synonym: mapeia duas palavras sinônimas, caso elas pertençam ao mesmo synset ${ }^{13}$ no WordNet $^{14}$

Os módulos de mapeamento identificam todos os possíveis acertos entre os pares de sentença. A ordem em que os módulos são executados reflete a ordem de preferência dos mapeamentos.

Após o alinhamento entre o par de sentenças, o METEOR computa a sua pontuação. Baseado no número de unigramas da sentença hipótese mapeado na sentença de referência $(m)$, no número total de unigramas da hipótese $(t) \mathrm{e}$ no número total de unigramas da referência $(r)$, a métrica calcula a Precisão de unigramas (Unigram Precision) $(P=m / t)$ e a taxa de recuperação de unigramas (Unigram Recall) $(R=m / r)$, para então computar a Média Harmônica (Harmonic Mean) parametrizada de $P$ e $R$ :

$$
F_{\text {mean }}=\frac{P \cdot N}{\alpha \cdot P+(1-\alpha) \cdot R}
$$

A Precisão, a Taxa de recuperação e a Média Harmônica são baseadas em acertos de uma palavra. Para considerar os acertos dos unigramas na mesma ordem nas duas sentenças, o METEOR computa a Penalidade para cada alinhamento. Primeiro, a sequência de acertos dos unigramas entre as duas sentenças é dividido em poucos números de fragmentos (chunks). O número

\footnotetext{
${ }^{13}$ De acordo com o WordNet, synset é um grupo de um ou mais sinônimos intercambiáveis em alguns contextos, sem alterar o valor verdade da proposição em que estão inseridas.

${ }^{14} \mathrm{http}: / /$ wordnet.princeton.edu/
} 
de fragmentos $(c h)$ e o número de acertos $(m)$ são usados para calcular a fração de Fragmentação: frag $=c h / m$. A Penalidade é calculada como:

$$
\text { Pen }=\gamma \cdot \operatorname{frag}^{\beta}
$$

O valor de $\gamma$ determina a Penalidade máxima e o valor de $\beta$ determina a função de relação entre a Fragmentação e a Penalidade. Finalmente, a pontuação do METEOR para o alinhamento entre as duas sentenças é calculada de acordo com:

$$
\text { score }=(1-\text { Pen }) \cdot F_{\text {mean }}
$$

A pontuação fornecida pelo METEOR está em uma escala entre zero e um, sendo zero a tradução mais distante da tradução de referência e um a tradução que mais se correlaciona com aquela feita por humanos.

Nesta pesquisa, os valores utilizados dos parâmetros $\alpha, \beta$ e $\gamma$ são apresentados na tabela 3.1, e representam: controle do peso relativo da Precisão e a Taxa de recuperação para computar a Média Harmônica $(\alpha)$; a forma da Penalidade como função de fragmentação $(\beta)$ e o peso relativo para assinar a fragmentação da penalidade $(\gamma)$.

\begin{tabular}{cc}
\hline Variável & Valor \\
\hline$\alpha$ & 0.65 \\
$\beta$ & 1.8 \\
$\gamma$ & 0.45 \\
\hline
\end{tabular}

Tabela 3.1: Valores dos parâmetros da métrica METEOR

Em todas as versões do METEOR, esses valores foram instanciados com base em dados experimentais e objetiva a máxima correlação com os julgamentos humanos. Experimentos permitiram aperfeiçoar esses parâmetros com os julgamentos humanos de adequação e fluência de uma tradução.

\subsection{Resultados}

Utlizamos a métrica de avaliação automática METEOR para podermos medir o desempenho do sistema no estado inicial da pesquisa. Nessa primeira avaliação, o corpus preliminar foi traduzido no sistema Avenue e no sistema Google Translate. Os resultados estão apresentados graficamente através da Figura 4.1 e através da tabela 4.2 contendo a pontuação geral fornecida pelo METEOR. 
Para a avaliação do sistema Avenue, levamos em consideração apenas a sentença $n$-melhor ( $n$-best oferecida pelo sistema, ou seja, aquela que o sistema apresentou com a maior probabilidade de ser a tradução da sentença em língua-fonte, considerando o modelo de linguagem e o modelo de tradução.

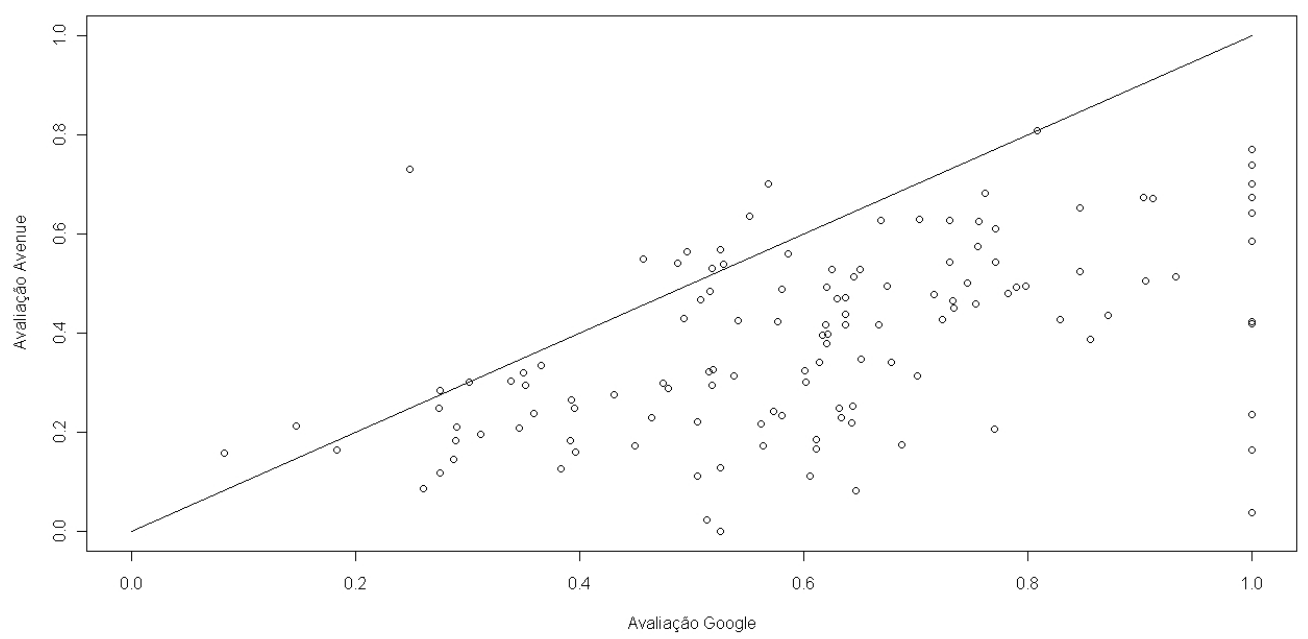

Figura 3.1: Avaliação do corpus preliminar

\begin{tabular}{lc}
\hline Sistema & Pontuação \\
\hline Google Translate & 0.6166 \\
Avenue & 0.4040 \\
\hline
\end{tabular}

Tabela 3.2: Resultados das avaliações dos sistema Google Translate e Avenue

A Figura 3.1 mostra os resultados das avaliações das cento e vinte e sete sentenças durante o estado incial do sistema do projeto Avenue em comparação com o sistema Google Translate. Cada ponto significa a tradução de uma das cento e vinte e sete sentenças traduzidas e avaliadas, distribuídas no eixo $x$ e $y$. A reta de $45^{\circ}$ graus faz a divisão entre os resultados vantajosos para as traduções nos sistemas Avenue e Google Translate. Assim, os pontos acima da reta de $45^{\circ}$ graus, indicam as traduções que o sistema Avenue obteve resultados vantajosos acima do sistema Google Translate. Os resultados das traduções do sistema Google Translate estão dispostos abaixo da reta.

Conforme a pontuação fornecida pelo METEOR, verificamos que o resultado das avaliações do Google translator é superior ao Avenue, embora 
ambos estejam distantes da alta correlação com a tradução humana. Fatores como a inconsistência dos tempos verbais entre as hipóteses e a tradução de referência contribuíram para a baixa pontuação. Contudo, outros fatores podem ser adicionados, como a existência de palavras sinônimas e a não traduções de alguns itens. 


\section{Capítulo 4}

\section{Tempos verbais}

Na perspectiva da gramática tradicional, em especial em Cunha [20] a categoria verbo é definida como uma palavra de forma variável que exprime o que se passa, isto é, um acontecimento representado no tempo. Os verbos, em geral, estão associados a uma localização temporal, embora a classe de advérbios também possa desempenhar a mesma função.

Situar temporalmente os verbos em relação à comunicação ainda é uma tarefa controversa, porém Reichenbach [21], em Elements of Symbolic Logic, propõe três momentos para a determinação da temporalidade dos verbos: momento da enunciação ou momento da fala; momento de referência, a partir do qual podemos situar o evento (presente, passado e futuro); e momento do acontecimento ou evento, que se refere ao tempo do evento descrito pela frase, isto é, se é concomitante, anterior ou posterior ao momento de referência. A partir desses momentos defindos por Reichenbach, muitos autores têm classificado o tempo verbal em diversas línguas.

Segundo Comrie [22], as línguas naturais não compartilham das mesmas propriedades relacionadas ao verbo. O par de línguas português e inglês, por exemplo, apresenta divergências quanto aos tempos verbais.

Tendo em conta a classificação proposta por Cunha [23], apresentaremos os modos Indicativo, Subjuntivo e Imperativo do português, seus tempos verbais simples e compostos, e seus mapeamentos para o inglês. Não apresentaremos aqui uma análise semântica acerca dos tempos verbais e as suas relações, pois isso não se insere no foco do presente trabalho.

A ordem de apresentação dos exemplos nas seções a seguir segue a seguinte estrutura: a. sentenças em português seguidas de b. sentenças de referência.

É importante destacar que determinados traços presentes no corpo das regras não correspondem aos tempos das línguas tratadas. Esses traços são distintivos apenas para uso do sistema. Um exemplo da não correspondência entre esses traços é a forma nominal gerúndio, que na descrição das regras 
apresenta o traço progressivo. A numeração presente no lado esquerdo do corpo das regras também não pertecem a elas, são apenas para facilitar a sua explicação.

\subsection{Modo Indicativo}

Nesta seção trataremos os tempos verbais do modo indicativo simples e composto.

\subsubsection{Tempos simples}

\section{Presente}

Tradicionalmente o tempo presente refere-se a situações que ocupam o período do momento da enunciação e é usado quando falamos de estados, processos e situações habituais, baseado na ocorrência de eventos de um mesmo tipo, como em (1) e (2).

(1) a. Eu falo inglês

b. I speak english

(2) a. Eu falo com você todos os dias

b. I talk to you everyday

Abaixo, a regra para transferência do presente do indicativo para o present simple.

1. $\{\mathrm{VP}, 100\}$

2. ; ; CHEGAM

3. ; ; ARRIVE

4. VP::VP [V] $\rightarrow[\mathrm{V}]$

5. (

6. $\quad(\mathrm{X} 1:: \mathrm{Y} 1)$

7. $\quad((\mathrm{X} 1$ tense $)=\mathrm{C}$ pres $)$

8. $((\mathrm{X} 1 \mathrm{mood})=(* \mathrm{NOT} * \mathrm{subj}))$

9. $((Y 1$ tense $)=(X 1$ tense $))$

10. $((Y 1$ number $)=(X 1$ number $))$

11. $((Y 1$ person $)=(X 1$ person $))$

12. $((X 0$ tense $)=(X 1$ tense $))$

13. $((X 0$ number $)=(X 1$ number $))$

14. $((\mathrm{X} 0$ person $)=(\mathrm{X} 1$ person $))$

15. ) 
A regra $V P, 100$ apresenta a transferência do verbo no tempo presente do modo indicativo para o present simple em inglês, conforme o exemplo nas linhas dois e três. As linhas cinco e quinze apresentam o início e término da condição para aplicação da regra. A linha seis apresenta a correspondência entre o verbo em português, $X 1$ e o verbo em inglês $Y 1$. As linhas sete e oito indicam que $X 1$ deverá apresentar os traços de tempo presente e não pode estar no modo subjuntivo. As linhas nove, dez e onze indicam que o verbo em inglês, $Y 1$ receberá os traços de tempo, número e pessoa de $X 1$. As linhas doze, treze e catorze mostram que $X 0$ receberá traços de tempo, número e pessoa de $X 1$. O $X 0$ corresponde ao sintagma que está sendo formado pela regra. Esta regra poderá ser aplicada a todas as pessoas do singular e plural.

(3) a. Eu viajo para a França amanhã

b. I am travelling to France tomorrow

(4) a. Eu falo com você amanhã

b. I am going to talk to you tomorrow

a. Eu falo com você amanhã

b. I will talk to you tomorrow

Em construções como em (3), (4) e (5), o tempo presente é utilizado para se referir a um evento futuro em relação ao momento da enunciação, auxiliado pelo emprego do advérbio temporal amanhã.

Embora o presente em português apresente valores aspectuais diferentes sob a mesma forma, em inglês essas diferenças são bem marcadas e representadas pelos tempos present simple, present continuous, e pelo tempo futuro realizado com o auxiliar will, assim como o uso do verbo to be e going, seguido do verbo prinicpal no infinitivo. Abaixo, as regras de transferência para esses tempos.

1. $\{\mathrm{VP}, 120\}$

2. ; ;FALO

3. ; ;AM SPEAKING

4. VP::VP [V] $\rightarrow[" \mathrm{AM} " \mathrm{~V}]$

5.

6. (X1::Y2)

7. $\quad((X 1$ tense $)=c$ pres $)$

8. $((X 1$ mood $)=(*$ NOT $*$ subj $))$

9. $((X 1$ person $)=C 1)$

10. ((X1 number $)=c$ sg)

11. $(($ Y2 tense $)=$ prog $)$

12. $((\mathrm{X} 0$ tense $)=(\mathrm{X} 1$ tense $))$ 
13. $((X 0$ number $)=(X 1$ number $))$

14. $((\mathrm{X} 0$ person $)=(\mathrm{X} 1$ person $))$

15. )

A regra $V P, 120$ apresenta a transferência do verbo no tempo presente do modo indicativo para o present continuous em inglês, conforme ilustração nas linhas dois e três. A linha quatro apresenta a inserção do verbo auxiliar $a m$. As linhas cinco e quinze apresentam o início e término da condição para aplicação da regra. A linha seis apresenta a correspondência entre o verbo em português, X1 e o verbo em inglês $Y$ 2. As linhas oito e nove indicam que o verbo deverá apresentar os traços de primeira pessoa e número singular. O verbo principal em inglês, Y2 receberá o traço de tempo progressivo, conforme linha onze. As linhas doze, treze e catorze indicam que $X 0$ receberá traços de tempo, número e pessoa de $X 1$. X0 corresponde ao sintagma que está sendo formado pela regra. Outras regras similares a essa foram criadas, em que os traços de número e pessoa foram alterados, assim como a inserção do item lexical, conforme linha quatro.

1. $\{\mathrm{VP}, 130\}$

2. ; ;FALO

3. ; ; AM GOING TO SPEAK

4. VP: :VP [V] $\rightarrow[$ "AM" "GOING" V]

5. (

6. $\quad(\mathrm{X} 1:: \mathrm{Y3})$

7. $\quad((\mathrm{X} 1$ tense $)=\mathrm{c}$ pres $)$

8. $\quad((X 1$ mood $)=(*$ NOT $*$ subj $))$

9. $\quad((X 1$ person $)=c 1)$

10. ( $(\mathrm{X} 1$ number $)=c \mathrm{sg})$

11. $(($ Y3 tense $)=$ inf $)$

12. $((\mathrm{X} 0$ tense $)=(\mathrm{X} 1$ tense $))$

13. $((X 0$ number $)=(X 1$ number $))$

14. $((\mathrm{X} 0$ person $)=(\mathrm{X} 1$ person $))$

15. )

A regra $V P, 130$ deverá ser aplicada a verbos no tempo presente do modo indicativo do português, que apresentarão traduções com auxiliares to be e going seguido do verbo principal no infinitivo, em inglês. As linhas dois e três apresentam um exemplo da aplicação da regra. A inserção dos auxiliares 
está expressa pela linha quatro. As linhas cinco e quinze indicam o início e término das restrições para aplicação da regra. A linha seis apresenta a correspondência entre o verbo em português, $X 1$ e o verbo em inglês $Y$ 3. As linhas sete e oito indicam que o verbo em português deverá estar no tempo presente e não pertencer ao modo subjuntivo. As linhas nove e dez apresentam as restrições para primeira pessoa do singular para $X 1$. O verbo principal em inglês receberá o traço de tempo infinitivo, presente na linha onze. As linhas doze, treze e catorze mostram que $X 0$ receberá traços de tempo, número e pessoa de $X 1$. $\mathrm{O}$ elemento $X 0$ corresponde ao sintagma que está sendo formado pela regra. Esta regra deverá ser aplicada somente à primeira pessoa do singular. Outras regras similares a essa foram criadas para as demais pessoas do singular e plural, em que foram alterados os traços de pessoa e número, assim como o respectivo verbo auxiliar.

1. $\{\mathrm{VP}, 140\}$

2. ; ; CHEGAM

3. ; ;WILL ARRIVE

4. VP: :VP $[\mathrm{V}] \rightarrow[\mathrm{V}]$

5. (

6. $(\mathrm{X} 1:: \mathrm{Y} 1)$

7. $\quad((\mathrm{X} 1$ tense $)=c$ pres $)$

8. $\quad((Y 1$ tense $)=$ fut $)$

9. $\quad((\mathrm{Y} 1$ number $)=(\mathrm{X} 1$ number $))$

10. $((\mathrm{Y} 1$ person $)=(\mathrm{X} 1$ person $))$

11. $((\mathrm{X} 0$ tense $)=(\mathrm{X} 1$ tense $))$

12. $((X 0$ number $)=(X 1$ number $))$

13. $((\mathrm{X} 0$ person $)=(\mathrm{X} 1$ person $))$

14. )

A regra $V P, 140$ apresenta a transferência do verbo no tempo presente em português para o tempo futuro com o auxiliar will em inglês. As linhas dois e três apresentam um exemplo da aplicação dessa regra. As linhas cinco e catorze indicam o início e término da aplicação das restrições. A linha seis apresenta a correspondência entre os verbos em português e inglês. A linha sete indica que o verbo em português, $X 1$ deverá apresentar o traço de tempo presente, enquanto o $Y 1$ deverá receber o traço de tempo futuro em inglês. As linhas nove e dez indicam que $Y 1$ receberá os traços de número, pessoa de $X 1$. As linhas onze, doze e treze mostram que $X 0$ receberá traços de tempo, número e pessoa de X1. X0 corresponde ao sintagma que está 
sendo formado pela regra. Esta regra poderá ser aplicada a todas as pessoas do singular e plural.

\section{Pretérito perfeito}

O pretérito perfeito indica que o evento de que se fala aconteceu e se concluiu no tempo anterior ao momento da enunciação.

(6) a. Eu já falei com você ontem

b. I already spoke with you yesterday

a. Eu falei com João sobre essa questão

b. I have spoken to John about this issue

Os exemplos (6) e (7) apresentam a informação de um evento terminado. Entretanto, existe uma diferenciação em inglês com relação ao pretérito perfeito em português. De acordo com Fiorin [24] em português, o passado enuncivo, que toma o pretérito como momento de referência, e o enunciativo, que toma o presente (ou seja, a enunciação) como momento de referência, são representados pelo mesmo tempo verbal pretérito perfeito em (6) e (7), ao passo que no inglês essas diferenças são expressas em tempos verbais diferentes. Em (6), o advérbio de tempo ontem indica o tempo de referência em que a ação foi concluída, marcando o passado enuncivo, que implica no uso do simple past na tradução para o inglês. A sentença (7) não apresenta o indicador temporal de quando o evento foi realizado, o que marca o passado enunciativo e justifica o uso do present perfect.

Abaixo, as regras para transferência do tempo pretérito perfeito no modo indicativo do português para os tempos simple past e present perfect em inglês.

1. $\{\mathrm{VP}, 30\}$

2. ; ; CHEGOU

3. ; ;ARRIVED

4. VP: :VP [V] $\rightarrow[\mathrm{V}]$

5. (

6. $\quad(\mathrm{X} 1:: \mathrm{Y} 1)$

7. $\quad((\mathrm{X} 1$ tense $)=\mathrm{c}$ past $)$

8. $\quad((X 1$ mood $)=(*$ NOT $*$ subj $))$

9. $\quad((Y 1$ tense $)=(X 1$ tense $))$

10. $((Y 1$ number $)=(X 1$ number $))$

11. $((\mathrm{Y} 1$ person $)=(\mathrm{X} 1$ person $))$

12. $((\mathrm{X} 0$ tense $)=(\mathrm{X} 1$ tense $))$ 
13. $((X 0$ number $)=(X 1$ number $))$

14. $((\mathrm{X} 0$ person $)=(\mathrm{X} 1$ person $))$

15. )

A regra $V P, 30$ apresenta a transferência do tempo pretérito perfeito do modo indicativo para o simple past em inglês. As linhas dois e três apresentam um exemplo da transferência dos tempos verbais. As linhas cinco e quinze indicam o início e término das restrições para aplicação da regra. A linha seis apresenta a correspondência entre o verbo em português, $X 1$ e o verbo em inglês $Y 1$. De acordo com as linhas sete e oito, $X 1$ deverá apresentar o traço de tempo passado e não poderá estar no modo subjuntivo. As linhas nove, dez e onze indicam que $Y 1$ receberá os traços de tempo passado, número e pessoa de $X 1$. As linhas doze, treze e catorze mostram que X0 receberá traços de tempo, número e pessoa de X1. X0 corresponde ao sintagma que está sendo formado pela regra. Esta regra poderá ser aplicada a todas as pessoas do singular e plural.

1. $\{\mathrm{VP}, 31\}$

2. ; ; CHEGOU

3. ; ; HAS ARRIVED

4. VP: :VP [V] $\rightarrow[$ "HAS" V]

5. (

6. $(\mathrm{X} 1:: \mathrm{Y} 2)$

7. $\quad((X 1$ mood $)=(*$ NOT $*$ subj $))$

8. $((\mathrm{X} 1$ tense $)=c$ past $)$

9. $((X 1$ number $)=c$ sg $)$

10. $((X 1$ person $)=c 3)$

11. $(($ Y2 tense $)=$ past $)$

12. $((\mathrm{X} 0$ tense $)=(\mathrm{X} 1$ tense $))$

13. $((X 0$ number $)=(X 1$ number $))$

14. $((X 0$ person $)=(X 1$ person $))$

15. )

Na regra $V P, 31$, o verbo no tempo pretérito perfeito do modo indicativo do português deverá ser traduzido para o tempo present perfect em inglês. As linhas dois e três apresentam um exemplo da transferência dos tempos verbais. A linha quatro indica a inclusão do verbo auxiliar has. As linhas 
cinco e quinze indicam o início e término das restrições para aplicação da regra. A linha seis apresenta a correspondência entre o verbo em português, $X 1$, e o verbo em inglês, $Y 1$. De acordo com as linhas sete e oito, $X 1$ deverá apresentar o traço de tempo passado e não poderá estar no modo subjuntivo. As linhas nove e dez indicam que $X 1$ deverá apresentar os traços de terceira pessoa e estar no singular. A linha onze indica que $Y 2$ receberá o traço de tempo passado. As linhas doze, treze e catorze mostram que X0 receberá traços de tempo, número e pessoa do verbo em português, nesse caso $X 1$. XO corresponde ao sintagma que está sendo formado pela regra. Esta regra deverá ser aplicada somente a terceira pessoa do singular. Outras regras similares a essa foram criadas para as demais pessoas do singular e plural, em que foram alterados os traços de pessoa e número, assim como o respectivo verbo auxiliar.

\section{Pretérito imperfeito}

O pretérito imperfeito indica acontecimentos habituais em um tempo passado, mas sem apresentar características temporais de término. Por se tratar de um tempo que se apresenta em relação a outro, ambos com informação de passado, é necessário o estabelecimento de marcas temporais para delimitar a leitura.

(8) a. Eu falava sobre tudo quando era jovem

b. I used to talk about everything when I was young

(9) a. Eu falava quando Maria chegou

b. I was speaking when Mary arrived

No exemplo (8) verifica-se a ocorrência do evento falar no passado e embora o advérbio forneça uma localização temporal, não podemos estabelecer a conclusão desse evento. A sentença indica um hábito passado que, em inglês, pode ser representado pelo used seguido do verbo no infinitivo. Em (9), a chegada de Maria está incluída no tempo de falar, que pode ter continuado após a sua chegada, havendo uma concomitância temporal entre o evento falar e chegar, caracterizado em inglês pelo tempo past continuous. Abaixo, as regras para transferência desses tempos verbais.

1. $\{\mathrm{VP}, 34\}$

2. ; ; CHEGAVA

3. ; ; USED TO ARRIVE

4. VP: :VP [V] $\rightarrow$ ["USED" V]

5. (

6. $(\mathrm{X} 1:: \mathrm{Y} 2)$ 


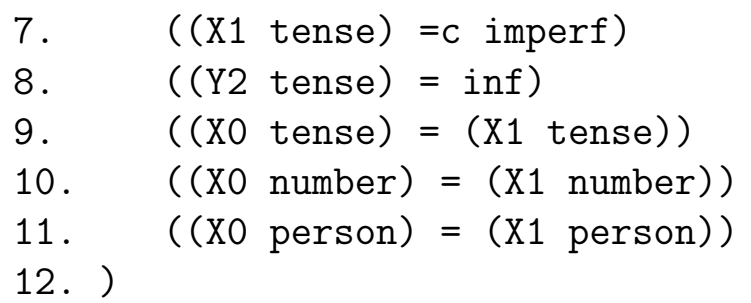

Na regra $V P, 34$, o verbo no tempo pretérito imperfeito do modo indicativo em português deverá ser traduzido para o tempo passado com o uso do auxiliar used seguido do verbo no infinitivo em inglês. As linhas dois e três apresentam um exemplo da transferência dos tempos verbais. A linha quatro indica a inclusão do verbo auxiliar used. As linhas cinco e doze indicam o início e término das restrições para aplicação da regra. A linha seis apresenta a correspondência entre o verbo em português, $X 1$, e o verbo em inglês, $Y$ Q . Para a aplicação dessa regra, $X 1$ deverá apresentar o traço de tempo pretérito imperfeito, presente na linha sete. A linha oito indica que o verbo principal em inglês receberá o traço de tempo infinitivo. As linhas nove, dez e onze indicam que $X 0$ receberá os traços de tempo, número e pessoa de $X 1$. X0 corresponde ao sintagma que está sendo formado pela regra. Essa regra se aplica a todas as pessoas e números.

1. $\{\mathrm{VP}, 341\}$

2. ;; FALAVA

3. ; ; WAS SPEAKING

4. VP: :VP [V] $\rightarrow[$ [WAS" V]

5. (

6. (X1::Y2)

7. $\quad((X 1$ tense $)=c$ imperf $)$

8. $\quad((X 1$ mood $)=(*$ NOT $*$ subj $))$

9. $((\mathrm{X} 1$ person $)=(* \mathrm{OR} * 13))$

10. $((X 1$ number $)=c \mathrm{sg})$

11. $(($ Y2 tense $)=$ prog $)$

12. $((X 0$ tense $)=(X 1$ tense $))$

13. $((X 0$ number $)=(X 1$ number $))$

14. $((X 0$ person $)=(X 1$ person $))$

15. )

Na regra $V P, 341$, o verbo no tempo pretérito imperfeito do modo indicativo do português deverá ser traduzido para o tempo past continuous ou past 
progressive em inglês. As linhas dois e três apresentam um exemplo da transferência dos tempos verbais. A linha quatro indica a inserção do verbo auxiliar was. As linhas cinco e quinze indicam o início e término das restrições para aplicação da regra. A linha seis apresenta a correspondência entre o verbo em português, X1, e o verbo em inglês, Y2. Para a aplicação dessa regra, o verbo em português deverá apresentar o traço de tempo pretérito imperfeito, presente na linha sete. A linha oito indica que esse verbo não poderá apresentar traço do modo subjuntivo. As linhas nove e dez apresentam a restrição para a primeira e terceira pessoa do singular. O verbo principal em inglês, Y2, receberá o traço de tempo progressivo, isto é, gerúndio, conforme indica a linha onze. As linhas doze, treze e catorze indicam que $X 0$ receberá os traços de tempo, número e pessoa de $X 1$. X0 corresponde ao sintagma que está sendo formado pela regra. Esta regra deverá ser aplicada somente a primeira e terceira pessoa do singular. Outras regras similares a essa foram criadas para as demais pessoas do singular e plural, em que foram alterados os traços de pessoa e número, assim como o respectivo verbo auxiliar.

\section{Pretérito mais-que-perfeito}

No pretérito mais-que-perfeito temos a informação temporal de um evento anterior a outro também ocorrido no passado.
a. Ele dormira antes da minha partida
b. He had slept before my departure
c. He slept before my departure

Em (10) temos uma ação partir realizada após o evento dormir, indicando (talvez) uma sobreposição temporal entre os dois eventos, em que a ação de dormir se iniciou antes do evento partir. A tradução para este tempo verbal em inglês é feita com o past perfect e past simple. Abaixo, as regras para transferência para esses tempos verbais.

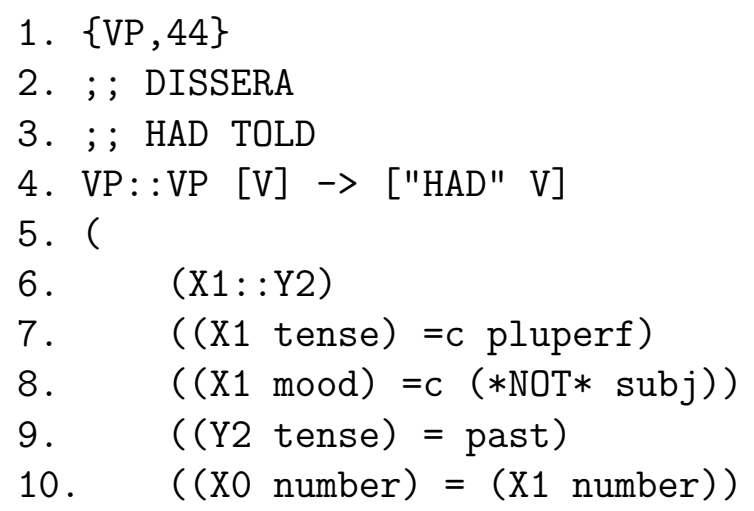


11.

$((\mathrm{X} 0$ person $)=(\mathrm{X} 1$ person $))$

12. )

Na regra $V P, 44$, o verbo no tempo pretérito mais-que-perfeito do modo indicativo em português será traduzido para o tempo past perfect do inglês. As linhas dois e três apresentam um exemplo da transferência desses tempos verbais. A linha quatro indica a inserção do verbo auxiliar had. As linhas cinco e doze indicam o início e término das restrições para aplicação da regra. As linha seis apresenta a correspondência entre o verbo em português, $X 1$, e o verbo em inglês, Y2. Para a aplicação dessa regra, X1 deverá apresentar o traço de tempo mais-que-perfeito, presente na linha sete, e não poderá apresentar o traço de modo subjuntivo. A linha nove indica que $Y$ 2 receberá o traço de passado. As linhas dez e onze indicam que $X 0$ receberá os traços de número e pessoa de $X 1$. X0 corresponde ao sintagma que está sendo formado pela regra. Não há restrições de número e pessoa para a aplicação dessa regra.

1. $\{\mathrm{VP}, 441\}$

2. ; ; DISSERA

3. ; ; TOLD

4. VP::VP $[\mathrm{V}] \rightarrow[\mathrm{V}]$

5 .

6. $\quad(\mathrm{X} 1:: \mathrm{Y} 1)$

7. $\quad((\mathrm{X} 1$ tense $)=\mathrm{c}$ pluperf $)$

8. $\quad((\mathrm{X} 1 \mathrm{mood})=\mathrm{c}(* \mathrm{NOT} * \mathrm{subj}))$

9. $\quad((Y 1$ tense $)=$ past $)$

10. $((\mathrm{X} 0$ number $)=(\mathrm{X} 1$ number $))$

11. $((\mathrm{X} 0$ person $)=(\mathrm{X} 1$ person $))$

12. )

A regra $V P, 441$ será aplicada a verbos no tempo pretérito mais-queperfeito do modo indicativo do português com traduções para o simple past em inglês. As linhas dois e três apresentam um exemplo da transferência desses tempos verbais. As linhas cinco e doze indicam o início e término das restrições para aplicação da regra. A linha seis apresenta a correspondência entre o verbo em português, $X 1$, e o verbo em inglês, $Y 1$. Para a aplicação dessa regra, X1 deverá apresentar o traço de tempo mais-que-perfeito, presente na linha sete, e não poderá apresentar o traço de modo subjuntivo. A linha nove indica que $X 0$ receberá o traço de passado. As linhas dez e onze 
indicam que $X 0$ receberá os traços de número e pessoa de $X 1$. X $X 0$ corresponde ao sintagma que está sendo formado pela regra. Não há restrições de número e pessoa para a aplicação dessa regra.

\section{Futuro do presente}

O futuro geralmente expressa um tempo posterior ao momento de enunciação, seguido ou não de advérbios de tempo com marcas de futuro.

(11) a. Eu estudarei com você semestre que vem

b. I will study with you next semester

a. Eu falarei com você nesse mês

b. I am going to talk to you this month

Em inglês, o tempo futuro pode ser marcado pelo uso do auxiliar will seguido do verbo principal ou pelo uso do verbo to be e going seguido do verbo principal no infinitivo, conforme os exemplos (11) e (12). Abaixo, as regras para transferência desses tempos verbais.

1. $\{\mathrm{VP}, 20\}$

2. ; ; CHEGAREI

3. ; ; WILL ARRIVE

4. VP: :VP $[\mathrm{V}] \rightarrow[\mathrm{V}]$

5. (

6. $\quad(\mathrm{X} 1:: \mathrm{Y} 1)$

7. $\quad((X 1$ mood $)=(*$ NOT $*$ subj $))$

8. $\quad((\mathrm{X} 1$ tense $)=\mathrm{c}$ fut $)$

9. $\quad((\mathrm{Y} 1$ tense $)=(\mathrm{X} 1$ tense $))$

10. $((\mathrm{X} 0$ tense $)=(\mathrm{X} 1$ tense $))$

11. $\quad((X 0$ number $)=(X 1$ number $))$

12. $((\mathrm{X} 0$ person $)=(\mathrm{X} 1$ person $))$

13. )

A regra $V P, 20$ apresenta a transferência do verbo no tempo futuro do presente do modo indicativo em português para o futuro com o verbo auxiliar will em inglês. As linhas dois e três apresentam um exemplo da transferência desses tempos verbais. As linhas cinco e treze indicam o início e término das restrições para aplicação da regra. A linha seis apresenta a correspondência entre o verbo em português, $X 1$, e o verbo em inglês, $Y 1$. Para a aplicação dessa regra, $X 1$ deverá apresentar o traço de tempo futuro, presente na linha sete, e não poderá apresentar o traço de modo subjuntivo. A linha nove indica que $Y 1$ receberá o traço de tempo futuro de $X 1$. A linha nove indica 
que $X 0$ receberá o traço de passado. As linhas dez, onze e doze indicam que X0 receberá os traços de tempo, número e pessoa de $X 1$. X0 corresponde ao sintagma que está sendo formado pela regra. Não há restrições de número e pessoa para a aplicação dessa regra.

1. $\{\mathrm{VP}, 210\}$

2. ; ; VENDEREI

3. ; ;AM GOING TO SELL

4. VP::VP [V] $\rightarrow[$ [AM" "GOING" V]

5. (

6. $\quad(\mathrm{X} 1:: \mathrm{Y} 3)$

7. $\quad((X 1$ tense $)=c$ fut $)$

8. $\quad((X 1$ mood $)=(*$ NOT $*$ subj $))$

9. $\quad((\mathrm{X} 1$ person $)=\mathrm{C} 1)$

10. $\quad((X 1$ number $)=c$ sg $)$

11. $(($ Y3 tense $)=$ inf $)$

12. $((\mathrm{X} 0$ tense $)=(\mathrm{X} 1$ tense $))$

13. $((X 0$ number $)=(X 1$ number $))$

14. $((\mathrm{X} 0$ person $)=(\mathrm{X} 1$ person $))$

15. )

Na regra $V P, 210$, o verbo no tempo futuro do modo indicativo do português será traduzido para o tempo futuro expresso pelo uso dos verbos auxiliares to be e going seguido do verbo no tempo infinitivo no inglês. As linhas dois e três apresentam um exemplo da transferência desses tempos verbais. A linha quatro indica a inserção dos verbos auxiliares am e going. As linhas cinco e quinze indicam o início e término das restrições para aplicação da regra. A linha seis apresenta a correspondência entre o verbo em português, $X 1$, e o verbo em inglês, Y3. Para a aplicação dessa regra, X1 deverá apresentar o traço de tempo futuro, presente na linha sete, e não poderá apresentar o traço de modo subjuntivo, conforme linha oito. As linhas nove e dez indicam que $X 1$ deverá apresentar os traços de primeira pessoa e número singular. A linha onze indica que $Y 3$ receberá o traço de tempo infinitivo em inglês. As linhas doze, treze e catorze indicam que $X 0$ receberá os traços de tempo, número e pessoa de $X 1$. X0 corresponde ao sintagma que está sendo formado pela regra. Esta regra deverá ser aplicada somente a primeira pessoa do singular. Outras regras similares a essa foram criadas para as demais pessoas do singular e plural, em que foram alterados os traços de pessoa e número, assim como os respectivos verbos auxiliares. 


\section{Futuro do pretérito}

O futuro do pretérito apresenta um evento posterior ao momento da enunciação condicionado a outros eventos ou fatos.

a. Eu falaria com ele se tivesse tempo

b. I would speak with him If I had time

O exemplo (13) apresenta a leitura de condicional com a utilização do tempo futuro do pretérito do modo indicativo seguido do modo subjuntivo. O condicional ou futuro do pretérito apresenta o seu equivalente em inglês com o tempo conditional. Abaixo, a regra para a transferência desses tempos verbais.

1. $\{\mathrm{VP}, 23\}$

2. ; ; CHEGARIA

3. ; ; WOULD ARRIVE

4. VP: :VP [V] $\rightarrow$ ["WOULD" V]

5. (

6. $(\mathrm{X} 1:: \mathrm{Y} 2)$

7. $\quad((X 1$ tense $)=c$ cond $)$

8. $\quad(($ Y2 tense $)=$ pres $)$

9. $((\mathrm{X} 0$ tense $)=(\mathrm{X} 1$ tense $))$

10. $((X 0$ number $)=(X 1$ number $))$

11. $((X 0$ person $)=(X 1$ person $))$

12. )

Na regra $V P, 23$, o verbo no tempo futuro do pretérito do modo indicativo do português deverá ser traduzido para o tempo condicional expresso pelo uso do verbo auxiliar would seguido do verbo principal em inglês. As linhas dois e três apresentam um exemplo da transferência desses tempos verbais. A linha quatro indica a inserção do verbo auxiliar would. As linhas cinco e doze indicam o início e término das restrições para aplicação da regra. A linha seis apresenta a correspondência entre o verbo em português, $X 1$, e o verbo em inglês, Y2. Para a aplicação dessa regra, $X 1$ deverá apresentar o traço de tempo condicional, presente na linha sete, e $Y 2$ receberá o traço de tempo presente, conforme linha oito. As linhas nove, dez e onze indicam que $X 0$ receberá os traços de tempo, número e pessoa de $X 1$. X0 corresponde ao sintagma que está sendo formado pela regra. Não há restrições de número e pessoa para a aplicação dessa regra. 


\subsubsection{Tempos compostos}

\section{Pretérito perfeito composto}

$\mathrm{Na}$ forma composta, o pretérito perfeito é usado para indicar uma ação que se iniciou no passado e se prolonga até o momento da enunciação.

(14) a. Eu tenho estudado todas as manhãs

b. I have been studying every morning

O exemplo (14) apresenta o evento estudar com a característica de iteratividade, seguido do advérbio todas as manhãs para estabelecer os limites temporais. O tempo present perfect progressive em inglês corresponde ao tempo pretérito perfeito composto em português. Abaixo, a regra de transferência para esses tempos verbais.

1. $\{\mathrm{VP}, 37\}$

2. ; ; TEM CHEGADO

3. ; ; HAVE BEEN ARRIVING

4. VP1::VP1 [V V] $\rightarrow[\mathrm{V}$ "BEEN" V]

5. (

6. $(\mathrm{X} 1:: \mathrm{Y} 1)$

7. $\quad(\mathrm{X} 2:: \mathrm{Y} 3)$

8. $((\mathrm{X} 1$ tense $)=$ pres $)$

9. $((X 1$ lex $)=$ ter $)$

10. $((\mathrm{X} 2$ tense $)=$ part $)$

11. $((\mathrm{Y} 1$ tense $)=(\mathrm{X} 1$ tense $))$

12. $((\mathrm{Y} 1$ person $)=(\mathrm{X} 1$ person $))$

13. $((Y 1$ number $)=(X 1$ number $))$

14. ((Y3 tense $)=$ prog $)$

15. $((X 0$ tense $)=(X 1$ tense $))$

16. $((X 0$ number $)=(X 1$ number $))$

17. $((\mathrm{X} 0$ person $)=(\mathrm{X} 1$ person $))$

18. )

Na regra $V P, 3 \%$, o verbo no tempo pretérito perfeito do modo indicativo do português deverá ser transferido para o tempo present perfect progressive em inglês. As linhas dois e três apresentam um exemplo da transferência desses tempos verbais. A linha quatro indica a inserção do verbo auxiliar flexionado been. As linhas cinco e doze indicam o início e término das restrições para aplicação da regra. As linhas seis e sete apresentam a correspondência entre os verbos em português, $X 1$ e $X 2$, e os verbos em inglês, $Y 1$ e $Y$ 3. Para a aplicação dessa regra, $X 1$ deverá ser o item lexical ter e apresentar o traço 
de tempo presente, conforme linhas oito e nove. A linha dez indica que X2 deverá estar no particípio. Y1 receberá os traços de tempo, pessoa e número de $X 1$ indicados pelas linhas onze, doze e treze, e $Y 3$ deverá receber o traço de tempo progressivo, conforme linha catorze. As linhas quinze, dezesseis e dezessete indicam que $X 0$ receberá os traços de tempo, número e pessoa de X1. X0 corresponde ao sintagma que está sendo formado pela regra. Não há restrições de número e pessoa para a aplicação dessa regra.

\section{Pretérito mais-que-perfeito composto}

O pretérito mais-que-perfeito composto descreve situações anteriores ao momento da enunciação. Para a sua localização temporal, o pretérito mais-queperfeito composto necessita de um momento de referência também anterior ao momento da enunciação, que em geral é o expresso pelo Pretérito perfeito.

a. Eu tinha falado com ele quando você chegou

b. I had spoken to him when you arrived

Em (15), o estado ter falado é um evento completo e terminado antes da realização do evento chegar. O tempo past perfect simple corresponde em inglês ao tempo pretérito mais-que-perfeito composto. Abaixo, a regra de transferência para esses tempos verbais.

1. $\{\mathrm{VP}, 381\}$

2. ; ; TINHA CHEGADO

3. ; ; HAD ARRIVED

4. VP: :VP $[\mathrm{V}$ V] $\rightarrow[\mathrm{V}$ V]

5. (

6. $\quad(\mathrm{X} 1:: \mathrm{Y} 1)$

7. $\quad(\mathrm{X} 2:: \mathrm{Y} 2)$

8. $\quad((X 1$ tense $)=$ imperf $)$

9. $((X 1$ lex $)=$ ter $)$

10. $((\mathrm{X} 2$ tense $)=$ part $)$

11. $((Y 1$ tense $)=$ past $)$

12. $((Y 1$ person $)=(X 1$ person $))$

13. $((Y 1$ number $)=(X 1$ number $))$

14. $(($ Y2 tense $)=$ past $)$

15. $((\mathrm{X} 0$ tense $)=(\mathrm{X} 1$ tense $))$

16. $((X 0$ number $)=(X 1$ number $))$

17. $((X 0$ person $)=(X 1$ person $))$

18. ) 
Na regra $V P, 381$, o verbo no tempo pretérito mais-que-perfeito composto do modo indicativo do português deverá ser transferido para o tempo past perfect em inglês. As linhas dois e três apresentam um exemplo da transferência desses tempos verbais. As linhas cinco e dezoito indicam o início e término das restrições para aplicação da regra. As linhas seis e sete apresentam a correspondência entre os verbos em português, $X 1$ e $X$ 2, e os verbos em inglês, $Y 1$ e $Y$ 2. Para a aplicação dessa regra, $X 1$ deverá ser o item lexical ter e apresentar o traço de tempo pretérito imperfeito, conforme linhas oito e nove. A linha dez indica que X2 deverá estar no particípio. Y1 receberá o traço de particípio e os traços pessoa e número de $X 1$, indicados pelas linhas onze, doze e treze. Y3 receberá o traço de tempo passado, conforme linha catorze. As linhas quinze, dezesseis e dezessete indicam que $X 0$ receberá os traços de tempo, número e pessoa de $X 1$. X0 corresponde ao sintagma que está sendo formado pela regra. Não há restrições de número e pessoa para a aplicação dessa regra.

\section{Futuro do presente composto}

O futuro do presente composto apresenta uma leitura de um tempo futuro em relação ao momento da enunciação, no qual a forma composta constitui uma marcação de anterioridade a outro tempo posterior ao momento da enunciação, representado pelo tempo futuro do modo subjuntivo.

a. Eu já terei falado quando ele chegar

b. I will have already spoken when he arrives

Em (16), a oração principal se apresenta como um evento futuro e completo, com valor de passado, realizado anteriormente ao evento chegar. Em inglês, o tempo verbal que marca essa relação é o future perfect. Abaixo, a regra de transferência para esses tempos verbais.

1. $\{\mathrm{VP}, 250\}$

2. ; ; TEREI FALADO

3. ; ;WILL HAVE SPOKEN

4. VP: :VP [V V] $\rightarrow$ ["WILL" "HAVE" V]

5. (

6. (X2::Y3)

7. $((X 1$ lex $)=$ ter $)$

8. $((\mathrm{X} 1$ tense $)=c$ fut $)$

9. ( (X2 tense $)=c$ part $)$

10. $(($ Y3 tense $)=$ past $)$

11. $((\mathrm{X} 0$ tense $)=(\mathrm{X} 1$ tense $))$ 
12. $((X 0$ number $)=(X 1$ number $))$

13. $((\mathrm{X} 0$ person $)=(\mathrm{X} 1$ person $))$

14. )

Na regra $V P, 250$, o verbo no tempo futuro do presente composto do modo indicativo do português deverá ser transferido para o tempo future perfect em inglês. As linhas dois e três apresentam um exemplo da transferência desses tempos verbais. A linha quatro indica a inserção dos verbos auxiliares will e have. As linhas cinco e quartorze indicam o início e término das restrições para aplicação da regra. A linha seis apresenta a correspondência entre o verbo em português, X2, e o verbo em inglês, Y3. Para a aplicação dessa regra, $X 1$ deverá ser o item lexical ter e apresentar o traço de tempo futuro, conforme linhas sete e oito. Linha nove indica que X2 deverá estar no particípio. $Y 3$ receberá o traço de tempo passado, indicado na linha dez. As linhas onze, doze e treze indicam que $X 0$ receberá os traços de tempo, número e pessoa de $X 1$. X0 corresponde ao sintagma que está sendo formado pela regra. Não há restrições de número e pessoa para a aplicação dessa regra.

\section{Futuro do pretérito composto}

Este tempo apresenta características de modalização e trata de eventos condicionais não realizados, de eventos ou situações irreais. O futuro do pretérito composto se relaciona com o pretérito imperfeito composto do tempo pretérito imperfeito do modo subjuntivo.

a. Eu teria falado se ele tivesse chegado na hora

b. I would have spoken if he arrived on time

Em (17) podemos inferir que o evento ter falado não se realizou devido a não ocorrência do evento condicional anterior. O conditional perfect caracteriza o futuro do pretérito composto. Abaixo, a regra para transferência desses tempos verbais.

1. $\{\mathrm{VP}, 261\}$

2. ; ; TERIA FALADO

3. ; ;WOULD HAVE SPOKEN

4. VP::VP [V V] $\rightarrow$ ["WOULD" "HAVE" V]

5. (

6. $\quad(\mathrm{X} 2:: \mathrm{Y3})$

7. $\quad((\mathrm{X} 1$ lex $)=$ ter $)$

8. $\quad((\mathrm{X} 1$ tense $)=\mathrm{c}$ cond $)$ 


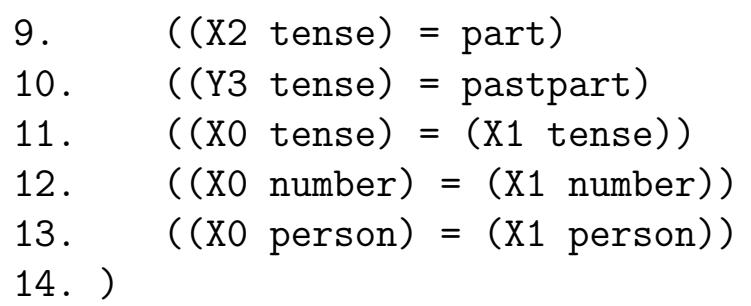

Na regra $V P, 261$, o verbo do tempo futuro do pretérito composto do modo indicativo do português deverá ser transferido para o tempo conditional perfect em inglês. As linhas dois e três apresentam um exemplo da transferência desses tempos verbais. A linha quatro indica a inserção do verbo auxiliar flexionado been. As linhas cinco e doze indicam o início e término das restrições para aplicação da regra. As linhas seis e sete apresentam a correspondência entre os verbos em português, $X 1$ e $X$ 2, e os verbos em inglês, $Y 1$ e $Y 3$. Para a aplicação dessa regra, $X 1$ deverá ser o item lexical ter e apresentar o traço de tempo presente, conforme linhas oito e nove. Linha dez indica que $X 2$ deverá estar no particípio. $Y 1$ receberá os traços de tempo, pessoa e número de $X 1$ indicados pelas linhas onze, doze e treze, e $Y 3$ deverá receber o traço de tempo progressivo, conforme linha catorze. As linhas onze, doze e treze indicam que $X 0$ receberá os traços de tempo, número e pessoa de X1. X0 corresponde ao sintagma que está sendo formado pela regra. Não há restrições de número e pessoa para a aplicação dessa regra.

\section{Presente progressivo}

O presente progressivo refere-se a situações que ocupam o período de tempo do momento presente e indica ações em progresso no momento da enunciação.

a. Ele está lendo um bom livro

b. He is reading a good book

Em (18), temos a ação contínua de ler expressa pelo tempo present continuous do inglês que corresponde ao mesmo valor do tempo presente progressivo em português. Abaixo, a regra de transferência para ambos os tempos verbais.

1. $\{\mathrm{VP}, 160\}$

2. ; ;ESTOU LENDO

3. ; ; AM READING

4. VP: :VP $[\mathrm{V}$ V] $\rightarrow[\mathrm{V} V]$

5. (

6. (X1::Y1) 


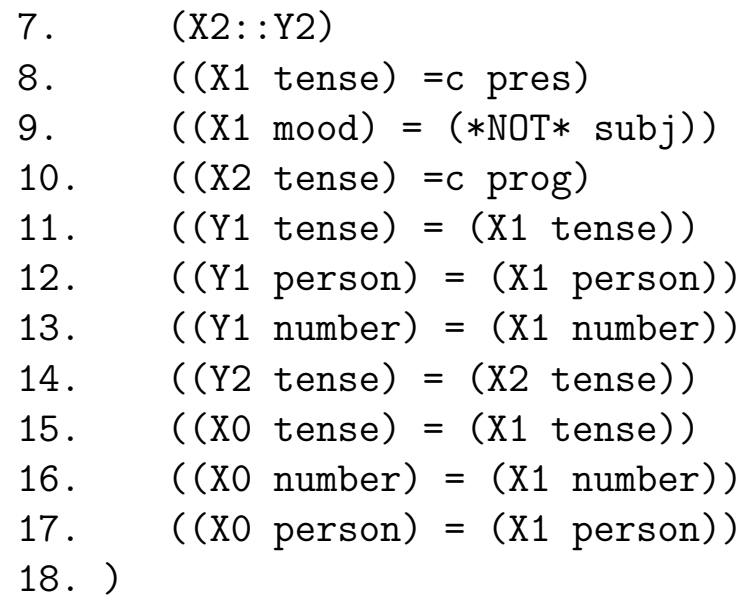

Na regra $V P, 160$, o verbo no tempo presente progressivo do modo indicativo do português deverá ser transferido para o tempo present continuous em inglês. As linhas dois e três apresentam um exemplo da transferência desses tempos verbais. As linhas cinco e dezoito indicam o início e término das restrições para aplicação da regra. As linhas seis e sete apresentam a correspondência entre os verbos em português, $X 1$ e $X$ 2, e os verbos em inglês, $Y 1$ e $Y$ 2. Para a aplicação dessa regra, $X 1$ deverá apresentar o traço de tempo presente e não pertencer ao modo subjuntivo, conforme linhas oito e nove; e X2 deverá estar no tempo progressivo. $Y 1$ receberá os traços de tempo, pessoa e número de $X 1$ indicados pelas linhas onze, doze e treze, e Y2 receberá o traço de tempo progressivo de X2, conforme linha catorze. As linhas quinze, dezesseis e dezessete indicam que $X 0$ receberá os traços de tempo, número e pessoa de $X 1$. X0 corresponde ao sintagma que está sendo formado pela regra. Não há restrições de número e pessoa para a aplicação dessa regra.

\section{Pretérito perfeito progressivo}

Este tempo marca um evento progressivo que teve duração em um momento anterior ao momento de enunciação, porém em concomitância ao momento de referência.

(19) a. Ele esteve falando de nós dois enquanto nós jantávamos

b. He had been talking about us while we were dining

Em (19), ocorre uma simultaneidade entre os dois eventos, no qual o evento falar ocorre juntamente com o evento jantar. O emprego do pretérito imperfeito funciona como uma localização temporal na delimitação da sobreposição do tempo nos dois eventos. Em inglês, o tempo verbal que marca essa relação 
é o past perfect progressive. Abaixo, a regra de transferência para ambos os tempos verbais.

1. $\{\mathrm{VP}, 45\}$

2. ; ;ESTEVE FALANDO

3. ; ;HAD BEEN SPEAKING

4. VP::VP [V V] $\rightarrow[$ "HAD" "BEEN" V]

5.

6. $\quad(\mathrm{X} 2:: \mathrm{Y} 3)$

7. $\quad((\mathrm{X} 1$ tense $)=c$ past $)$

8. $\quad((\mathrm{X} 2$ tense $)=\mathrm{c}$ prog $)$

9. $(($ Y3 tense $)=(\mathrm{X} 2$ tense $))$

10. $((\mathrm{X} 0$ tense $)=(\mathrm{X} 1$ tense $))$

11. $((X 0$ number $)=(X 1$ number $))$

12. $((\mathrm{X} 0$ person $)=(\mathrm{X} 1$ person $))$

13. )

A regra $V P, 45$ apresenta a transferência do verbo no tempo pretérito perfeito progressivo do modo indicativo em português para o tempo past perfect em inglês. As linhas dois e três apresentam um exemplo da transferência desses tempos verbais. A linha quatro indica a inserção dos verbos auxiliares had e been. As linhas cinco e treze indicam o início e término das restrições para aplicação da regra. A linha seis apresenta a correspondência entre os verbos em português, X2, e o verbo em inglês, $Y$ 3. Para a aplicação dessa regra, $X 1$ deverá apresentar o traço de tempo passado, conforme linha sete. A linha oito indica que $X 2$ deverá estar no tempo progressivo. Y3 receberá os traços de tempo progressivo de $X 2$ indicados pela linha nove. As linhas dez, onze e doze indicam que $X 0$ receberá os traços de tempo, número e pessoa de $X 1$. X0 corresponde ao sintagma que está sendo formado pela regra. Essa regra não apresenta restrição quanto a pessoa e número.

\section{Pretérito imperfeito progressivo}

O pretérito imperfeito progressivo marca um evento anterior ao momento da enunciação e ao momento de referência.

a. Eu estava falando quando ela entrou

b. I was speaking when she came in

Em (20) o evento falar se iniciou em um momento anterior ao acontecimento chegar. O pretérito perfeito e o pretérito imperfeito são, em geral, utilizados para fornecer a marcação temporal ao momento de referência. O tempo past 
progressive em inglês caracteriza o pretérito imperfeito progressivo. Abaixo, a regra de transferência para ambos os tempos verbais.

1. $\{\mathrm{VP}, 46\}$

2. ; ;ESTAVA FALANDO

3. ; ;WAS SPEAKING

4. VP: :VP $[\mathrm{V}$ V] $\rightarrow[\mathrm{V}$ V]

5.

6. $(\mathrm{X} 1:: \mathrm{Y} 1)$

7. $\quad(\mathrm{X} 2:: \mathrm{Y} 2)$

8. $\quad((\mathrm{X} 1$ tense $)=c$ imperf $)$

9. ( (X2 tense $)=c$ prog $)$

10. $((Y 1$ person $)=$ past $)$

11. $((Y 1$ person $)=(X 1$ person $))$

12. $((Y 1$ number $)=(X 1$ number $))$

13. $((Y 2$ tense $)=(X 2$ tense $))$

14. $((\mathrm{X} 0$ tense $)=(\mathrm{X} 1$ tense $))$

15. $((X 0$ number $)=(X 1$ number $))$

16. $((X 0$ person $)=(X 1$ person $))$

17. )

A regra $V P, 46$ apresenta a transferência do tempo verbal pretérito imperfeito progressivo do modo indicativo do português para o tempo past continuous em inglês. As linhas dois e três apresentam um exemplo da transferência desses tempos verbais. As linhas cinco e dezesseis indicam o início e término das restrições para aplicação da regra. As linhas seis e sete apresentam a correspondência entre os verbos em português, $X 1$ e $X$ 2, e os verbos em inglês, $Y 1$ e Y2. Para a aplicação dessa regra, $X 1$ deverá apresentar o traço de tempo passado imperfeito, conforme linha oito. A linha nove indica que $X 2$ deverá estar no tempo progressivo. $Y 1$ receberá os traços de tempo passado e traços de pessoa e número de $X 1$, presentes nas linhas dez, onze e doze. Enquanto $Y 2$ receberá o traço de tempo progressivo de $X \mathscr{2}$ indicado pela linha treze. As linhas catorze, quinze e dezesseis indicam que $X 0$ receberá os traços de tempo, número e pessoa de $X 1$. X0 corresponde ao sintagma que está sendo formado pela regra. Essa regra não apresenta restrição quanto a pessoa e número.

\section{Futuro do presente progressivo}

Neste tempo, temos expressos os eventos futuros em progresso em relação a um tempo posterior ao momento da enunciação. 
(21) a. Amanhã a essa hora eu estarei falando de você

b. By this time tomorrow I will be speaking of you

Em (21), temos uma leitura de um evento progressivo, que ocorrerá em um tempo posterior o momento da enunciação. Além de advérbios temporais, também é frequente o uso do futuro do modo subjuntivo em conjunto com o futuro do presente progressivo para indicar uma marcação de temporal posterior ao momento da enunciação. Em inglês, o future continuous representa esse tempo verbal. Abaixo, a regra de transferência para esses tempos verbais.

1. $\{\mathrm{VP}, 27\}$

2. ; ;ESTAREI FALANDO

3. ;;WILL BE SPEAKING

4. VP: :VP [V V] $\rightarrow$ ["WILL" "BE" V]

5. (

6. $\quad(\mathrm{X} 2:: \mathrm{Y} 3)$

7. $\quad((X 1$ tense $)=c$ fut $)$

8. $\quad((\mathrm{X} 2$ tense $)=c$ prog $)$

9. $(($ Y3 tense $)=(\mathrm{X} 2$ tense $))$

10. $((\mathrm{X} 0$ tense $)=(\mathrm{X} 1$ tense $))$

11. $((X 0$ number $)=(X 1$ number $))$

12. $((\mathrm{X} 0$ person $)=(\mathrm{X} 1$ person $))$

13. )

A regra $V P, 27$, apresenta a transferência do tempo verbal o futuro do presente progressivo do modo indicativo do português para o tempo future continuous em inglês. As linhas dois e três apresentam um exemplo da transferência desses tempos verbais. A linha quatro indica a inserção do verbo auxiliar will e be. As linhas cinco e treze indicam o início e término das restrições para aplicação da regra. A linha seis apresenta a correspondência entre o verbo em português, X2, e o verbo em inglês, Y3. Para a aplicação dessa regra, $X 1$ deverá apresentar o traço de tempo futuro, conforme linha sete, e X2 deverá estar no tempo progressivo, conforme linha oito. Y3 receberá o traço de tempo progressivo de $X 2$, presente na linha nove. As linhas dez, onze e doze indicam que $X 0$ receberá os traços de tempo, número e pessoa de $X 1$. X0 corresponde ao sintagma que está sendo formado pela regra. Essa regra não apresenta restrição quanto a pessoa e número.

\section{Futuro do pretérito progressivo}

O futuro do pretérito progressivo apresenta uma leitura condicional composta por eventos e situações hipotéticas. O futuro do pretérito progressivo se re- 
laciona com o pretérito imperfeito composto do modo subjuntivo, para apresentar uma localização temporal posterior ao momento do acontecimento, em relação ao momento de referência pretérito, como em (22).

a. Eu estaria falando de você se eu tivesse tempo

b. I would be speaking about you if I had the time

O futuro do pretérito composto tem seu correspondente em inglês formado pelo future perfect continuous, também conhecido como future progressive. Abaixo, a regra de transferência para esses tempos verbais.

1. $\{\mathrm{VP}, 28\}$

2. ; ;ESTARIA FALANDO

3. ; ;WOULD BE SPEAKING

4. VP: :VP [V V] $\rightarrow[$ "WOULD" "BE" V]

5. (

6. $\quad(\mathrm{X} 2:: \mathrm{Y} 3)$

7. $\quad((X 1$ tense $)=c$ cond $)$

8. $\quad((\mathrm{X} 2$ tense $)=\mathrm{c}$ prog $)$

9. $\quad(($ Y3 tense $)=(X 2$ tense $))$

10. $((\mathrm{X} 0$ tense $)=(\mathrm{X} 1$ tense $))$

11. $((X 0$ number $)=(X 1$ number $))$

12. $((\mathrm{X} 0$ person $)=(\mathrm{X} 1$ person $))$

13. )

Na regra $V P, 28$, o verbo no tempo futuro do presente progressivo do modo indicativo do português deverá ser transferido para o tempo future perfect continuous em inglês. As linhas dois e três apresentam um exemplo da transferência desses tempos verbais. A quarta linha apresenta a inserção dos verbos auxiliares would e be. As linhas cinco e treze indicam o início e término das restrições para aplicação da regra. De acordo com a linha sete, o elemento $X 1$ deverá apresentar os traços de tempo condicional; enquanto o elemento $X 2$ deverá conter o traço de tempo progressivo, presente na oitava linha. $\mathrm{O}$ verbo principal em inglês, $Y$ 3, receberá o traço de tempo progressivo de $X$ 2, conforme linha nove. As linhas quinze, dezesseis e dezessete indicam que $X 0$ receberá os traços de tempo, número e pessoa de $X 1$. X0 corresponde ao sintagma que está sendo formado pela regra. Essa regra poderá ser aplicada a todas as pessoas e números. 


\subsection{Modo Subjuntivo}

Nesta seção, trataremos os tempos verbais do modo subjuntivo simples e composto.

\subsubsection{Tempos simples}

\section{Presente}

Este tempo, em geral, apresenta os tempos presente simples e o pretérito perfeito do modo indicativo na frase principal e o tempo presente do modo subjuntivo na oração subordinada, indicando uma leitura temporal futura ou simultânea em relação ao tempo da oração principal e ao tempo da enunciação.

(23) a. Espero que os embriões estejam congelados

b. I hope that the embryo are frozen

(24) a. Desejo que ele fale por horas

b. I want him to speak for hours

(25) a. Desejo que ele assista tv todos os dias

b. I wish he would watch tv every day

(26) a. Eu espero que ele fale de nós

b. I hope he will speak of us

Em inglês, o tempo presente do modo subjuntivo, apresenta as seguintes opções para tradução: present simple, como em (23); infinitivo, como em (24); conditional, exemplificado em (25); e future com o auxiliar will, presente em (26). Abaixo, a regra de transferência para esses tempos verbais.

1. $\{\mathrm{VP}, 151\}$

2. ; ; CHEGUE

3. ; ; ARRIVE

4. VP: :VP [V] $\rightarrow[\mathrm{V}]$

5. (

6. $(\mathrm{X} 1:: \mathrm{Y} 1)$

7. $\quad((X 1$ mood $)=c$ subj $)$

8. $\quad((\mathrm{X} 1$ tense $)=\mathrm{c}$ pres $)$

9. $\quad((Y 1$ tense $)=$ pres $)$

10. $((\mathrm{X} 0$ tense $)=(\mathrm{X} 1$ tense $))$

11. $((X 0$ mood $)=(X 1$ mood $))$

12. $((X 0$ number $)=(X 1$ number $))$ 
13. $((\mathrm{X} 0$ person $)=(\mathrm{X} 1$ person $))$

14. )

Na regra $V P, 151$, o verbo no tempo presente do modo subjuntivo do português deverá ser transferido para o tempo present simple em inglês. As linhas dois e três apresentam um exemplo da transferência desses tempos verbais. As linhas cinco e treze indicam o início e término das restrições para aplicação da regra. A linha seis apresenta a correspondência entre o verbo em português, $X 1$, e o verbo em inglês, $Y 1$. Para a aplicação dessa regra, $X 1$ deverá apresentar os traços de tempo presente do modo subjuntivo, conforme linhas sete e oito. $Y 1$ receberá o traço de tempo presente, indicado pela linha nove. As linhas dez, onze, doze e treze indicam que $X 0$ receberá os traços de modo, tempo, número e pessoa de $X 1$. X0 corresponde ao sintagma que está sendo formado pela regra. Essa regra não apresenta restrição quanto a pessoa e número.

1. $\{\mathrm{VP}, 152\}$

2. ; ; CHEGUE

3. ;; TO ARRIVE

4. VP: :VP $[\mathrm{V}] \rightarrow[\mathrm{V}]$

5. (

6. $(\mathrm{X} 1:: \mathrm{Y} 1)$

7. $\quad((\mathrm{X} 1 \mathrm{mood})=\mathrm{c}$ subj $)$

8. $\quad((\mathrm{X} 1$ tense $)=c$ pres $)$

9. $\quad(($ Y1 tense $)=$ inf $)$

10. $((\mathrm{X} 0$ tense $)=(\mathrm{X} 1$ tense $))$

11. $((X 0$ mood $)=(X 1$ mood $))$

12. $((X 0$ number $)=(X 1$ number $))$

13. $((\mathrm{X} 0$ person $)=(\mathrm{X} 1$ person $))$

14. )

Na regra $V P, 152$, o tempo verbal presente do modo subjuntivo em português deverá ser transferido para o tempo infinitive em inglês. As linhas dois e três apresentam um exemplo da transferência desses tempos verbais. As linhas cinco e catorze indicam o início e término das restrições para aplicação da regra. A linha seis apresenta a correspondência entre o verbo em português, $X 1$, e o verbo em inglês, $Y 1$. Para a aplicação dessa regra, $X 1$ deverá apresentar os traços de tempo presente do modo subjuntivo, conforme linhas sete e oito. $Y 1$ receberá o traço de tempo infinitivo, indicado pela linha nove. As linhas dez, onze, doze e treze indicam que $X 0$ receberá os traços de modo, tempo, número e pessoa de $X 1$. X0 corresponde ao sintagma que 
está sendo formado pela regra. Essa regra não apresenta restrição quanto a pessoa e número.

1. $\{\mathrm{VP}, 153\}$

2. ; ; CHEGUE

3. ; ; WOULD ARRIVE

4. VP: :VP [V] $\rightarrow$ ["WOULD" V]

5.

6. $\quad(\mathrm{X} 1:: \mathrm{Y} 2)$

7. $\quad((X 1$ mood $)=c$ subj $)$

8. $\quad((\mathrm{X} 1$ tense $)=c$ pres $)$

9. $\quad(($ Y2 tense $)=$ pres $)$

10. $((\mathrm{X} 0$ tense $)=(\mathrm{X} 1$ tense $))$

11. $((X 0$ mood $)=(X 1$ mood $))$

12. $((X 0$ number $)=(X 1$ number $))$

13. $((X 0$ person $)=(X 1$ person $))$

14. )

Na regra $V P, 153$, o tempo verbal presente do modo subjuntivo em português deverá ser transferido para o tempo conditional em inglês. As linhas dois e três apresentam um exemplo da transferência desses tempos verbais. A quarta linha apresenta a inserção do verbo auxiliar would. As linhas cinco e catorze indicam o início e término das restrições para aplicação da regra. A linha seis apresenta a correspondência entre o verbo em português, $X 1$, e o verbo em inglês, Y2. Para a aplicação dessa regra, $X 1$ deverá apresentar os traços de tempo presente do modo subjuntivo, conforme linhas sete e oito. Y2 receberá o traço de tempo presente, indicado pela linha nove. As linhas dez, onze, doze e treze indicam que $X 0$ receberá os traços de modo, tempo, número e pessoa de $X 1$. X0 corresponde ao sintagma que está sendo formado pela regra. Essa regra não apresenta restrição quanto a pessoa e número.

1. $\{\mathrm{VP}, 154\}$

2. ; ; CHEGUE

3. ; ; WILL ARRIVE

4. VP::VP [V] $\rightarrow$ ["WILL" V]

5. (

6. $\quad(\mathrm{X} 1:: \mathrm{Y} 2)$

7. $\quad((X 1$ mood $)=c$ subj $)$

8. $\quad((\mathrm{X} 1$ tense $)=\mathrm{c}$ pres $)$

9. $(($ Y2 tense $)=$ pres $)$

10. $((\mathrm{X} 0$ tense $)=(\mathrm{X} 1$ tense $))$ 
11. $((X 0$ mood $)=(X 1$ mood $))$

12. $((X 0$ number $)=(X 1$ number $))$

13. $((X 0$ person $)=(X 1$ person $))$

14. )

Na regra $V P, 154$, o tempo verbal presente do modo subjuntivo em português deverá ser transferido para o tempo future simple em inglês. As linhas dois e três apresentam um exemplo da transferência desses tempos verbais. A quarta linha apresenta a inserção do verbo auxiliar will. As linhas cinco e catorze indicam o início e término das restrições para aplicação da regra. A linha seis apresenta a correspondência entre o verbo em português, X1, e o verbo em inglês, Y2. Para a aplicação dessa regra, X1 deverá apresentar os traços de tempo presente do modo subjuntivo, conforme linhas sete e oito. Y2 receberá o traço de tempo presente, indicado pela linha nove. As linhas dez, onze, doze e treze indicam que $X 0$ receberá os traços de modo, tempo, número e pessoa de $X 1$. X0 corresponde ao sintagma que está sendo formado pela regra. Essa regra não apresenta restrição quanto a pessoa e número.

\section{Pretérito imperfeito}

Em geral, a subordinada com o pretérito imperfeito do modo subjuntivo se apresenta com o pretérito perfeito, pretérito imperfeito e futuro do pretérito do indicativo em sua oração principal, apresentando uma leitura temporal de pretérito em relação ao tempo da oração anterior e ao tempo da enunciação, conforme os exemplos (27), (28) e (29) abaixo.

(27) a. Desejava que ele falasse sobre o acontecido

b. I wanted him to speak about what happened

(28) a. Eu queria que ele assistisse tv todos os dias

b. I wish he would watch tv every day

(29) a. Lamentaria se eles chegassem atrasados

b. I would be sorry if they arrived late

Nos exemplos (27), (28) e (29), os verbos falar, assistir e chegar se apresentam morfologicamente como passado, porém com o tempo de futuro em relação a desejar, querer e lamentar, respectivamente.

Os tempos infinitive, conditional e past simple caracterizam o pretérito imperfeito do subjuntivo em inglês. Abaixo, a regra de transferência para ambos os tempos verbais.

1. $\{\mathrm{VP}, 43\}$ 


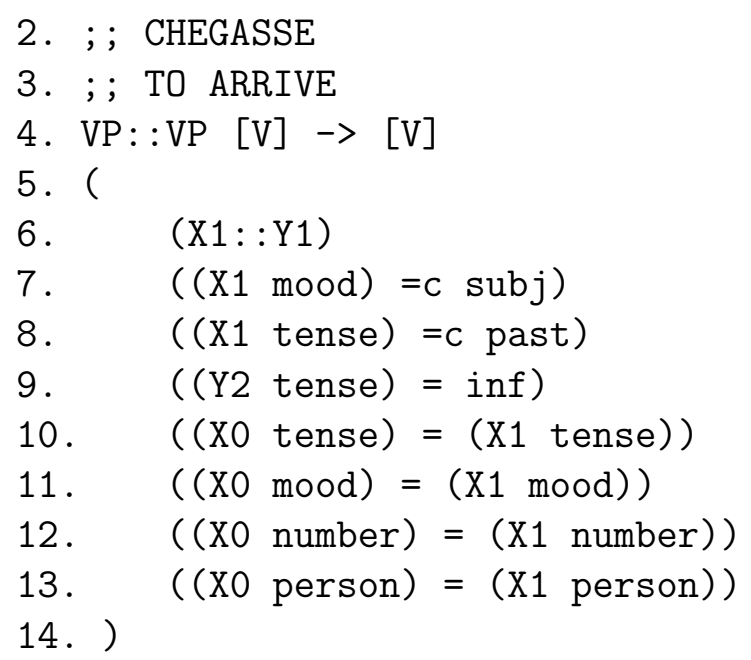

Na regra $V P, 43$, o tempo verbal pretérito imperfeito do modo subjuntivo em português será transferido para o tempo infinitive em inglês. As linhas dois e três apresentam um exemplo da transferência desses tempos verbais. As linhas cinco e catorze indicam o início e término das restrições para aplicação da regra. A linha seis apresenta a correspondência entre o verbo em português, $X 1$, e o verbo em inglês, $Y 1$. Para a aplicação dessa regra, $X 1$ deverá apresentar os traços de tempo passado do modo subjuntivo, conforme linhas sete e oito. $Y 1$ receberá o traço de tempo infinitivo, indicado pela linha nove. As linhas dez, onze, doze e treze indicam que $X 0$ receberá os traços de modo, tempo, número e pessoa de $X 1$. X0 corresponde ao sintagma que está sendo formado pela regra. Essa regra não apresenta restrição quanto a pessoa e número.

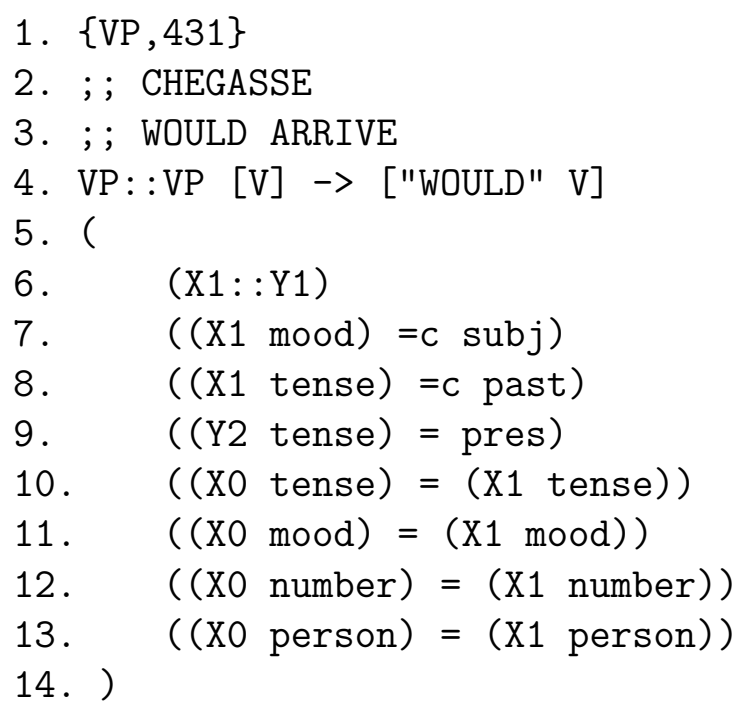


Na regra $V P, 431$, o tempo verbal pretérito imperfeito do modo subjuntivo em português será transferido para o tempo contidional em inglês. As linhas dois e três apresentam um exemplo da transferência desses tempos verbais. A quarta linha apresenta a inserção do verbo auxiliar would. As linhas cinco e catorze indicam o início e término das restrições para aplicação da regra. A linha seis apresenta a correspondência entre o verbo em português, $X 1$, e o verbo em inglês, Y2. Para a aplicação dessa regra, $X 1$ deverá apresentar os traços de tempo passado do modo subjuntivo, conforme linhas sete e oito. Y2 receberá o traço de tempo presente, indicado pela linha nove. As linhas dez, onze, doze e treze indicam que $X 0$ receberá os traços de modo, tempo, número e pessoa de $X 1$. X0 corresponde ao sintagma que está sendo formado pela regra. Essa regra não apresenta restrição quanto a pessoa e número.

1. $\{\mathrm{VP}, 40\}$

2. ; ; CHEGASSE

3. ; ; ARRIVED

4. VP::VP [V] $\rightarrow[\mathrm{V}]$

5. (

6. $\quad(\mathrm{X} 1:: \mathrm{Y} 1)$

7. $\quad((X 1$ mood $)=c$ subj $)$

8. $\quad((X 1$ tense $)=c$ past $)$

9. $(($ Y1 tense $)=(\mathrm{X} 1$ tense $))$

10. $((X 0$ tense $)=(X 1$ tense $))$

11. $((X 0$ mood $)=(X 1$ mood $))$

12. $((X 0$ number $)=(X 1$ number $))$

13. $((X 0$ person $)=(X 1$ person $))$

14. )

Na regra $V P, 40$, o tempo verbal pretérito imperfeito do modo subjuntivo em português será transferido para o tempo simple past em inglês. As linhas dois e três apresentam um exemplo da transferência desses tempos verbais. A quarta linha apresenta a inserção do verbo auxiliar would. As linhas cinco e catorze indicam o início e término das restrições para aplicação da regra. A linha seis apresenta a correspondência entre o verbo em português, $X 1$, e o verbo em inglês, $Y 1$. Para a aplicação dessa regra, $X 1$ deverá apresentar os traços de tempo passado do modo subjuntivo, conforme linhas sete e oito. $Y 1$ receberá o traço de tempo passado de $X 1$, indicado pela linha nove. As linhas dez, onze, doze e treze indicam que $X 0$ receberá os traços de modo, tempo, número e pessoa de $X 1$. X0 corresponde ao sintagma que está sendo formado pela regra. Essa regra não apresenta restrição quanto a pessoa e número. 


\section{Futuro}

O tempo futuro do modo subjuntivo é utilizado para marcar uma possibilidade a ser concluída em relação a um evento no futuro, porém condicional a outra ação também futura. Seu emprego é, em geral, acompanhado dos tempos futuro do presente e pretérito imperfeito do modo indicativo na oração principal.

(30) a. Quando ele voltar pra casa, eu estarei longe

b. When he comes back home I will be far away

a. Quando ele vier eu estarei aqui

b. When he comes I will be here

Nos exemplos (30) e (31), os verbos no tempo futuro do modo subjuntivo possuem valor condicionado a um segundo evento futuro, marcado pelo verbo estar. O tempo em inglês que estabelece essa correspondência é o present simple. Abaixo, a regra de transferência para ambos os tempos verbais.

1. $\{\mathrm{VP}, 390\}$

2. ; ; ELE VOLTAR

3. ; ; HE COMES

4. VP: :VP $[\mathrm{V}] \rightarrow[\mathrm{V}]$

5. (

6. $(\mathrm{X} 1:: \mathrm{Y} 1)$

7. $((X 1$ tense $)=$ inf $)$

8. $((Y 1$ tense $)=$ pres $)$

9. $\quad((\mathrm{Y} 1$ tense $)=(\mathrm{X} 1$ number $))$

10. $(($ Y1 tense $)=(X 1$ person $))$

11. $((\mathrm{X} 0$ tense $)=(\mathrm{X} 1$ tense $))$

12. $((X 0$ number $)=(X 1$ number $))$

13. $((X 0$ person $)=(X 1$ person $))$

14. )

Na regra $V P, 390$, o tempo verbal futuro do modo subjuntivo em português será transferido para o tempo present simple em inglês. As linhas dois e três apresentam um exemplo da transferência desses tempos verbais. As linhas cinco e catorze indicam o início e término das restrições para aplicação da regra. A linha seis apresenta a correspondência entre o verbo em português, $X 1$, e o verbo em inglês, $Y 1$. Para a aplicação dessa regra, $X 1$ deverá apresentar os traços de tempo infinitivo, conforme linha sete. Y1 receberá o traço de tempo presente, indicado na linha oito, e receberá os traços de número e pessoa de $X 1$, conforme linhas nove e dez. As linhas onze, doze e 
treze indicam que $X 0$ receberá os traços de tempo, número e pessoa de $X 1$. X0 corresponde ao sintagma que está sendo formado pela regra. Essa regra não apresenta restrição quanto a pessoa e número.

\subsubsection{Tempos compostos}

\section{Pretérito perfeito}

Este tempo apresenta a informação de um evento concluído em relação ao momento da oração principal, geralmente apresentada pelo tempo presente simples do modo indicativo, como em (32) e (33) ou progressivo e pretérito perfeito do modo indicativo.

a. Ela não acredita que eu tenha falado isso

b. She doesn't believe that I said that

a. Ela não acredita que eu tenha falado isso

b. She doesn't believe that I had said that

Os tempos past simple e past perfect em inglês correspondem ao tempo pretérito perfeito do modo subjuntivo. Abaixo, a regra de transferência para ambos os tempos verbais.

1. $\{\mathrm{VP}, 295\}$

2. ;; TENHA FALADO

3. ; ; SAID

4. VP: :VP $[\mathrm{V} V] \rightarrow[\mathrm{V}]$

5. (

6. $(\mathrm{X} 2:: \mathrm{Y} 1)$

7. $\quad((X 1 \mathrm{mood})=\mathrm{c}$ subj $)$

8. $\quad((\mathrm{X} 1$ tense $)=\mathrm{c}$ pres $)$

9. $(($ Y1 tense $)=$ past $)$

11. $((\mathrm{X} 0$ tense $)=(\mathrm{X} 1$ tense $))$

12. $((X 0 \operatorname{mood})=(X 1 \operatorname{mood}))$

13. $((\mathrm{X} 0$ person $)=(\mathrm{X} 1$ person $))$

14. $((\mathrm{X} 0$ person $)=(\mathrm{X} 1$ person $))$

15. )

Na regra $V P, 295$, o verbo do tempo pretérito perfeito composto do modo subjuntivo do português deverá ser transferido para o tempo past simple em inglês. As linhas dois e três apresentam um exemplo da transferência desses tempos verbais. As linhas cinco e quinze indicam o início e término das restrições para aplicação da regra. A linha seis apresenta a correspondência 
entre o verbo em português, $X 2$, e o verbo em inglês, $Y 1$. Para a aplicação dessa regra, $X 1$ deverá apresentar os traços de tempo presente do modo subjuntivo, conforme linhas sete e oito. $Y 1$ receberá o traço de tempo passado, indicado na linha nove. As linhas onze, doze, treze e catorze indicam que $X 0$ receberá os traços de modo, tempo, número e pessoa de $X 1$. X0 corresponde ao sintagma que está sendo formado pela regra. Essa regra não apresenta restrição quanto a pessoa e número.

1. $\{\mathrm{VP}, 296\}$

2. ; ; TENHA FALADO

3. ; ; HAD SAID

4. VP: :VP $[\mathrm{V}$ V] $\rightarrow[\mathrm{V}$ V]

5.

6. (X1::Y1)

7. $\quad(\mathrm{X} 2:: \mathrm{Y} 2)$

8. $((X 1$ lex $)=$ ter $)$

9. $\quad((\mathrm{X} 1$ tense $)=c$ pres $)$

10. $((\mathrm{X} 1 \mathrm{mood})=\operatorname{subj})$

11. $((\mathrm{X} 2$ tense $)=$ part $)$

11. $((Y 1$ tense $)=$ past $)$

12. $((\mathrm{Y} 1$ person $)=(\mathrm{X} 1$ person $))$

13. $((Y 1$ number $)=(X 1$ number $))$

14. $(($ Y2 tense $)=$ past $)$

15. $((X 0$ tense $)=(X 1$ tense $))$

16. $((X 0$ number $)=(X 1$ number $))$

17. $((\mathrm{X} 0$ person $)=(\mathrm{X} 1$ person $))$

18. )

Na regra VP,296, o tempo verbal pretérito perfeito do modo subjuntivo em português será transferido para o tempo past perfect em inglês. As linhas dois e três apresentam um exemplo da transferência desses tempos verbais. As linhas cinco e dezoito indicam o início e término das restrições para aplicação da regra. A linhas seis e sete apresentam a correspondência entre os verbo em português, $X 1$ e X2, e os verbos em inglês, $Y 1$ e $Y$ 2. Para a aplicação dessa regra, $X 1$ deverá ser o item lexical ter e apresentar os traços de tempo presente do modo subjuntivo, conforme as linhas oito, nove e dez. X2 deverá apresentar o traço de particípio. Y1 receberá o traço de tempo passado, indicado na linha onze, e receberá os traços de número e pessoa de $X 1$, conforme linhas doze e treze. A linha catorze indica que $Y^{2}$ receberá o traço de tempo passado. As linhas quinze, dezesseis e dezessete indicam que $X 0$ receberá os traços de tempo, número e pessoa de $X 1$. X0 
corresponde ao sintagma que está sendo formado pela regra. Essa regra não apresenta restrição quanto a pessoa e número.

\section{Pretérito mais-que-perfeito}

O tempo pretérito mais-que-perfeito representa uma situação passada e hipotética, podendo ocorrer seguido dos tempos pretérito perfeito, como em (34) ou futuro do pretérito do modo indicativo.

(34) a. Se eu tivesse esperado mais, tínhamos nos encontrado

b. If I had waited a little, we would have met

Em inglês, o tempo pretérito mais-que-perfeito é formado pelo tempo past perfect, conforme o exemplo (34). Abaixo, a regra de transferência para esse tempo verbal.

1. $\{\mathrm{VP}, 296\}$

2. ; ; TIVESSE ESPERADO

3. ; ; HAD WAITED

4. VP: :VP [V V] $\rightarrow[$ [HAD" V]

5. (

6. $(\mathrm{X} 2:: \mathrm{Y} 2)$

7. $((X 1$ lex $)=$ ter $)$

8. $((\mathrm{X} 1$ tense $)=c$ past $)$

9. $((X 1 \operatorname{mood})=\operatorname{subj})$

10. $((\mathrm{X} 2$ tense $)=$ part $)$

11. $(($ Y2 tense $)=$ past $)$

12. $((\mathrm{X} 0$ tense $)=(\mathrm{X} 1$ tense $))$

13. $((X 0$ number $)=(X 1$ number $))$

14. $((X 0$ person $)=(X 1$ person $))$

15. )

Na regra $V P, 250$, o verbo no tempo pretérito mais-que-perfeito do modo subjuntivo do português deverá ser transferido para o tempo past perfect em inglês. As linhas dois e três apresentam um exemplo da transferência desses tempos verbais. A quarta linha apresenta a inserção do verbo auxiliar had. As linhas cinco e quinze indicam o início e término das restrições para aplicação da regra. A linha seis apresenta a correspondência entre o verbo em português, X2, e o verbo em inglês, Y2. Para a aplicação dessa regra, $X 1$ deverá ser o item lexical ter e apresentar os traços de tempo passado do modo subjuntivo, conforme as linhas sete, oito e nove. X2 deverá apresentar o traço de tempo particípio. Linha onze indica que $Y 2$ receberá o traço de 
tempo passado. As linhas doze, treze e catorze indicam que $X 0$ receberá os traços de tempo, número e pessoa de $X 1$. X0 corresponde ao sintagma que está sendo formado pela regra. Essa regra não apresenta restrição quanto a pessoa e número.

\section{Futuro}

O futuro apresenta uma possibilidade incerta, em um tempo passado, ou em um tempo passado em relação a um tempo futuro marcado pelo futuro do presente do modo Indicativo, conforme exemplo em (35).

a. Você só acreditará depois que eu tiver falado com ele

b. You will only believe after I have spoken to him

No exemplo (35), tiver falado indica um evento condicional posterior ao momento da enunciação, mas já concluído antes de outro evento futuro, o acreditar. Em inglês este tempo verbal pode ser representado pelo present perfect simple. Abaixo, a regra de transferência para ambos os tempos verbais.

1. $\{\mathrm{VP}, 290\}$

2. ; ; TIVER FALADO

3. ; ; HAVE SPOKEN

4. VP: :VP $[\mathrm{V}$ V] $\rightarrow[\mathrm{V}$ V]

5. (

6. $(\mathrm{X} 1:: \mathrm{Y} 1)$

$7 . \quad(\mathrm{X} 2:: \mathrm{Y} 2)$

8. $((X 1$ lex $)=$ ter $)$

9. $((X 1$ tense $)=$ fut $)$

10. $((X 1$ mood $)=$ subj $)$

11. $((\mathrm{X} 2$ tense $)=$ part $)$

12. $((Y 1$ tense $)=$ pres $)$

13. $((\mathrm{Y} 1$ person $)=(\mathrm{X} 1$ person $))$

14. $((\mathrm{Y} 1$ number $)=(\mathrm{X} 1$ numer $))$

15. $(($ Y2 tense $)=$ past $)$

16. $((\mathrm{X} 0$ tense $)=(\mathrm{X} 1$ tense $))$

17. $\quad((X 0$ number $)=(X 1$ number $))$

18. $((\mathrm{X} 0$ person $)=(\mathrm{X} 1$ person $))$

19. )

Na regra $V P, 290$, o verbo no tempo futuro do modo subjuntivo do português deverá ser transferido para o present perfect em inglês. As linhas dois e três apresentam um exemplo da transferência desses tempos verbais. 
As linhas cinco e dezenove indicam o início e término das restrições para aplicação da regra. A linhas seis e sete apresentam a correspondência entre os verbos em português, $X 1$ e $X$ 2, e os verbos em inglês, Y1 e Y2. Para a aplicação dessa regra, $X 1$ deverá ser o item lexical ter e apresentar os traços de tempo futuro no modo subjuntivo, conforme as linhas oito, nove e dez. X2 deverá apresentar o traço de particípio. Linha doze indica que $Y 1$ receberá o traço de tempo presente, enquanto linhas treze e catorze, indicam que $Y 1$ receberá o número e pessoa de $X 1$. As linhas dezesseis, dezessete e dezoito indicam que $X 0$ receberá os traços de tempo, número e pessoa de $X 1$. X0 corresponde ao sintagma que está sendo formado pela regra. Essa regra não apresenta restrição quanto a pessoa e número.

\section{Presente progressivo}

O presente progressivo apresenta sentido similar ao tempo presente progressivo do modo indicativo, representando eventos concomitantes ao momento da enunciação. Em geral, a oração principal que acompanha esse tempo está em tempo presente simples do modo indicativo.

a. Eu espero que eles estejam falando da prova

b. I hope they are discussing the exam

Em inglês, este o tempo presente progressivo do modo subjuntivo é formado pelo presente continuous conforme exemplo (36). Abaixo, a regra de transferência para esse tempo verbal.

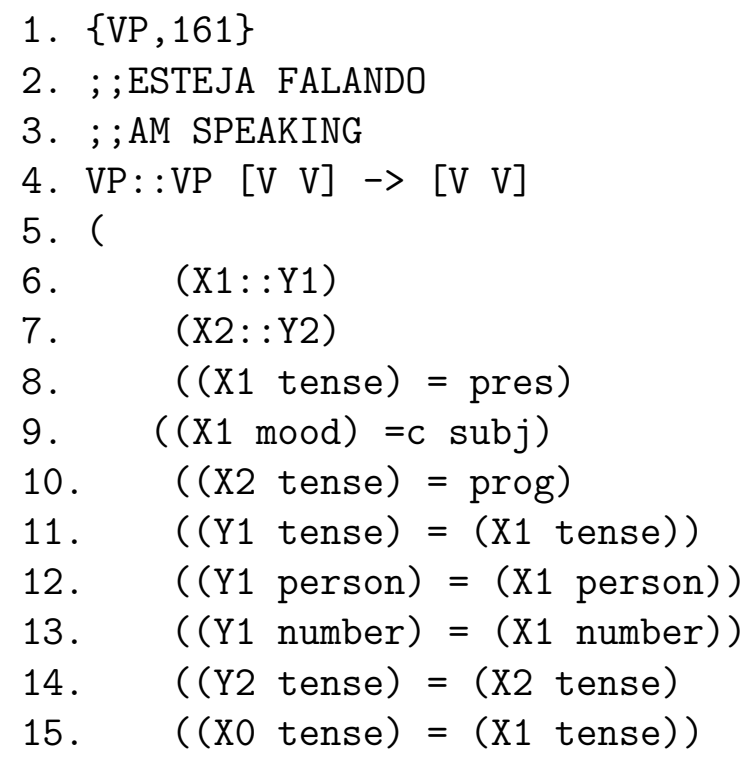




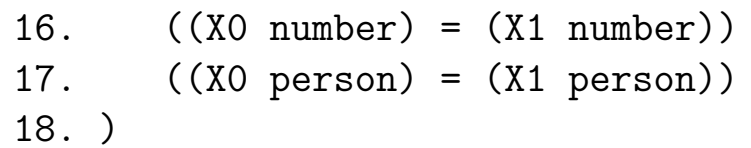

Na regra $V P, 161$, o verbo no tempo presente progressivo do modo subjuntivo do português deverá ser transferido para o present continuous em inglês. As linhas dois e três apresentam um exemplo da transferência desses tempos verbais. As linhas cinco e dezessete indicam o início e término das restrições para aplicação da regra. As linhas seis e sete apresentam a correspondência entre os verbos em português, $X 1$ e $X$ 2, e os verbos em inglês, $Y 1$ e $Y$ 2. Para a aplicação dessa regra, $X 1$ deverá apresentar os traços de tempo presente no modo subjuntivo, conforme as linhas oito e nove. X2 deverá apresentar o traço de tempo progressivo. Linhas onze, doze e treze indicam que $Y 1$ receberá os traços de tempo presente, número e pessoa de $X 1$. Linha catorze indica que $Y 2$ receberá o traço de tempo progressivo de $X$ 2. As linhas quinze, dezesseis e dezessete indicam que $X 0$ receberá os traços de tempo, número e pessoa de $X 1$. X0 corresponde ao sintagma que está sendo formado pela regra. Essa regra não apresenta restrição quanto a pessoa e número.

\section{Pretérito mais-que-perfeito progressivo}

O pretérito mais-que-perfeito progressivo representa um evento hipotético passado não realizado.

a. Eu esperava que ele estivesse cantando em Paris

b. I expected that they would be singing in Paris

O tempo conditional continuous em inglês corresponde ao tempo pretérito mais-que-perfeito continuous em português, conforme (37). Abaixo, a regra de transferência para esse tempo verbal.

1. $\{\mathrm{VP}, 431\}$

2. ; ; ESTIVESSE CANTANDO

3. ; ; WOULD BE SINGING

4. VP: :VP [V V] $\rightarrow$ ["WOULD" "BE" V]

5. (

6. (X2::Y3)

7. $\quad((\mathrm{X} 1 \mathrm{mood})=\mathrm{c}$ subj $)$

8. $\quad((\mathrm{X} 1$ tense $)=\mathrm{c}$ past $)$

9. $\quad((\mathrm{X} 2$ tense $)=$ prog $)$

10. $(($ Y3 tense $)=(\mathrm{X} 2$ tense $))$ 


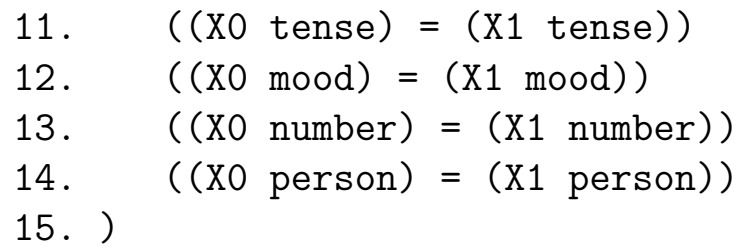

A regra $V P, 431$ deverá ser aplicada aos verbos no tempo pretérito maisque-perfeito progressivo do modo subjuntivo do português. As linhas dois e três apresentam um exemplo da transferência desses tempos verbais. As linhas cinco e quize indicam o início e término das restrições para aplicação da regra. A linha seis apresenta a correspondência entre o verbo em português, $X$ 2, e o verbo em inglês, e $Y$ 3. Para a aplicação dessa regra, $X 1$ deverá apresentar os traços de tempo passado no modo subjuntivo, conforme as linhas sete e oito. X2 deverá apresentar o traço de tempo progressivo. A linha dez indica que $Y 3$ receberá o traço de tempo progressivo de X2. As linhas onze, doze, treze e catorze indicam que $X 0$ receberá os traços de modo, tempo, número e pessoa de $X 1$. X0 corresponde ao sintagma que está sendo formado pela regra. Essa regra não apresenta restrição quanto a pessoa e número.

\section{Futuro progressivo}

O tempo futuro progressivo no modo subjuntivo apresenta um valor hipotético posterior ao momento da enunciação, em concomitância a outro evento também futuro, marcado pelo tempo futuro do presente no modo indicativo.

a. Ele chegará quando eu estiver cantando

b. He will arrive when I'm singing

Em inglês, o tempo present continuous correponde ao tempo futuro progressivo do modo subjuntivo, conforme (38). Abaixo, a regra para transferência para esse tempo verbal.

1. $\{\mathrm{VP}, 294\}$

2. ; ;ESTIVER CANTANDO

3. ; ;ARE SINGING

4. VP::VP [V V] $\rightarrow[$ [ARE" V]

5. (

6. (X2::Y2) 


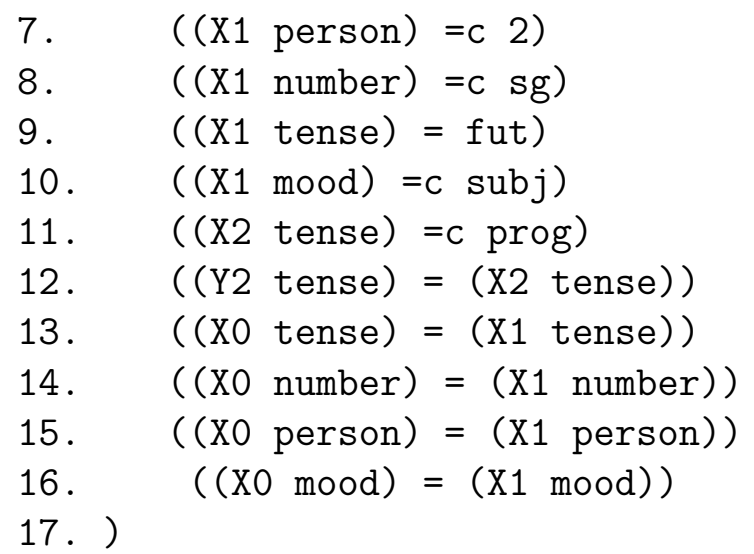

A regra $V P, 294$ indica que o verbo no tempo futuro progressivo do modo subjuntivo do português deverá ser traduzido para o present continuous em inglês. As linhas dois e três apresentam um exemplo da transferência desses tempos verbais. A linha quatro apresenta a inserção do verbo auxiliar are. As linhas cinco e dezessete apresentam o início e término da condição para aplicação da regra. A linha seis apresenta a correspondência entre o verbo em português, X2 e o verbo em inglês $Y$ 2. As linhas sete, oito, nove e dez indicam que $X 1$ deverá apresentar o traço de segunda pessoa, número singular e tempo futuro no modo subjuntivo . A linha onze indica que X2 deverá apresentar o traço de tempo progressivo. A linha doze indica que $Y 2$ receberá o traço de tempo progressivo de X2. As linhas dez, onze, doze e treze indicam que $X 0$ receberá os traços de modo, tempo, número e pessoa de $X 1$. X0 corresponde ao sintagma que está sendo formado pela regra. Essa regra $V P$,292 se aplica somente a segunda pessoa do singular. Outras regras similares a essa foram criadas, em que os traços de número e pessoa foram alterados, assim como o respectivo verbo auxiliar, conforme linha quatro.

\subsection{Modo Imperativo}

Nesta seção trataremos do modo imperativo.

O modo imperativo apresenta divergências quanto aos demais modos. Enquanto o indicativo e subjuntivo estão relacionados com a modalidade epistêmica, o imperativo apresenta relações com a modalidade deôntica, caracterizada pela obrigação ou permissão. Embora apresente somente formas para a segunda pessoa do singular e do plural, os demais casos podem ser substituídos pelas formas do subjuntivo, em especial a primeira pessoa do plural e a terceira pessoa do singular e do plural como em fale/falemos/falem [25].

$$
\text { a. Fale alto }
$$


b. Speak louder

O exemplo (39) ilustra o uso do modo imperativo para veicular ordem, e tem seu correspondente verbal em inglês, a forma bare infinitive. Abaixo, a regra de transferência para ambos os tempos verbais.

1. $\{\mathrm{VP}, 55\}$

2. ; ;FALE

3. ; ; SPEAK

4. VP::VP [V] $\rightarrow[\mathrm{V}]$

5. (

6. $(\mathrm{X} 1:: \mathrm{Y} 1)$

7. $\quad((X 1$ tense $)=c$ imp $)$

8. $\quad((\mathrm{Y} 1$ tense $)=(\mathrm{X} 1$ tense $))$

9. $((\mathrm{X} 0$ tense $)=(\mathrm{X} 1$ tense $))$

10. )

Na regra $V P, 55$ o verbo em português deverá estar no modo imperativo. As linhas dois e três apresentam um exemplo da aplicação da regra. As linhas cinco e dez apresentam o início e término da condição para aplicação da regra. A linha seis apresenta a correspondência entre o verbo em português, $X 1$ e o verbo em inglês $Y 1$. A linha sete indica que $X 1$ deverá apresentar o traço de tempo imperativo. A linha oito indica que $Y 1$ receberá o traço de tempo $X 1$. A linha nove indicam que $X 0$ receberá os traços de tempo de $X 1$. X0 corresponde ao sintagma que está sendo formado pela regra. Essa regra não apresenta restrição quanto a pessoa e número. 


\section{Capítulo 5}

\section{Resultados}

Neste capítulo, apresentaremos os resultados obtidos através da avaliação automática dos corpora dos tempos verbais.

\subsection{Corpora dos tempos verbais}

Os corpora dos tempos verbais, composto pelas 495 sentenças criadas manualmente para avaliação do sistema, respeitavam às três classes de conjugação dos verbos em português. Com a construção dos corpora seguindo essa classificação, buscávamos verificar se as regras construídas se aplicavam indistintamente a todas as conjugações verbais. O objetivo maior era verificar se os ajustes e a inserção de novas regras melhorariam o desempenho do sistema de tradução Avenue.

Para mensurarmos o estado inicial do sistema de tradução Avenue, submetemos nossos corpora dos tempos verbais à métrica de avaliação METEOR. Apresentamos abaixo a tabela 5.1 com os resultados obtidos através dessa avaliação. Em seguida, iniciamos as modificações no sistema Avenue.

No estado inicial da pesquisa, o componente Gramática apresentava um total de 110 regras de transferência estrutural. Desse total, apenas 25 regras destinavam-se a transferência entre os tempos verbais do português para o inglês. Ao longo da pesquisa muitas alterações foram feitas, como por exemplo, o ajuste de traços ausentes em algumas regras e a criação de regras para os tempos verbais ausentes nesse componente. Atualmente, o componente Gramática dispõe de um total de 163 regras, em que 78 delas são referentes a transferência dos tempos verbais entre as línguas português e inglês.

Outra modificação significante foi realizada no componente Léxico. No estado inicial da pesquisa, o sistema contava com um total de 56.665 entradas e suas respectivas traduções. Entretanto, muitas dessas entradas lexicais ne- 
cessitavam ser revisadas para a remoção de traduções impróprias, repetições e até mesmo a inserção de itens lexicais ausentes. Para ajudar o desenvolvimento do nosso sistema, o Léxico sofreu algumas alterações para limpeza de itens repetidos, correção de traduções e inclusão de novos itens lexicais. Atualmente o sistem Avenue conta com 58.341 entradas e suas respectivas traduções.

Recentes experimentos com sistemas baseados em métodos string-to-string e sintático têm apresentado melhores resultados quando traços linguísticos são adicionados aos sistemas de tradução automática [26]. Dessa forma, esperávamos que os corpora contendo as três classes de conjugação verbal apresentassem significativas melhorias em seus resultados após as modificações no sistema Avenue, quando comparado com o estado inicial. Para verificarmos se as modificações realizadas no sistema apresentaram melhora nos resultados, submetemos novamente os corpora dos tempos verbais à métrica METEOR.

Contudo, o uso da métrica de avaliação automática METEOR revelou que, para todas as três classes de conjugação, os resultados apresentaram uma regreção em seu desempenho, ou seja, os ajustes e a adição das regras não geraram melhorias significativas para o sistema.

\begin{tabular}{ccc}
\hline Conjugações & Resultado inicial & Resultado atual \\
\hline Primeira conjugação & 0.5387 & 0.5270 \\
Segunda conjugação & 0.4488 & 0.4484 \\
Terceira conjugação & 0.4179 & 0.3957 \\
\hline
\end{tabular}

Tabela 5.1: Resultados das avaliações dos corpora dos tempos verbais

A tabela 5.1 apresenta os resultados das avaliações dos corpora dos tempos verbais, ou seja, a tabela apresenta os resultados classificados entre as três classes de conjugação verbal em português. Cada conjugação verbal apresentava um total de 165 sentenças distribuídas pelos tempos verbais dos modos indicativos, subjuntivo e imperativo, juntamente com as formas nominais.

Para a avaliação dos resultados do sistema Avenue, presente na tabela 5.1, levamos em consideração apenas a sentença n-best oferecida pelo sistema, ou seja, aquela que o sistema apresentou com a maior probabilidade de ser a tradução da sentença em língua de origem, considerando o modelo de linguagem e o modelo de tradução.

Ainda, a tabela 5.1 chama a atenção para a pequena variação entre os resultados para a avaliação das 495 sentenças distribuídas entre as 3 classes de conjugação. Vê-se que não houve grandes alterações nos resultados, embora 
as modificações tenham apresentado resultados negativos.

Uma outra hipótese para justificar o resultado negativo diria que o sistema falhou em ordenar apropriadamente as sentenças candidatas. Assim, a sentença a ser escolhida não foi exatamente a primeira que foi oferecida, mas pelo menos estaria entre as mais altas sugeridas pelo sistema. Para eliminar esta hipótese, efetuamos a avaliação para todas as $n$ primeiras sentenças oferecidas pelo sistema, onde $\mathrm{n}$ varia de 1 (reproduzindo o caso $n$-melhor anterior) até 50 (onde consideramos todas as sentenças geradas pelo sistema, independentemente da ordem, e selecionamos aquela com maior pontuação apresentada pela métrica METEOR).

O resultado deste experimento está disposto na Figura 5.1. Para cada cenário avaliado, isto é, para cada conjunto de $\mathrm{n}$ sentenças oferecidas pelo sistema em sua versão inicial e atual (com as regras novas), selecionamos a sentença com maior pontuação apresentada pela métrica METEOR. Finalmente, representamos no eixo $\mathrm{Y}$ a diferença entre a avaliação apresentada pelo METEOR do estado atual e a avaliação do estado inicial. Como todos os pontos deste gráfico são negativos, pode-se concluir que em todos estes cenários a avaliação atual foi considerada de menor qualidade do que aquela do estado inicial. Isto demonstra que 1) a métrica METEOR não foi sensível à aplicação das regras descritas anteriormente, e 2) este fenômeno não se deu por acaso devido a um problema de ordenamento das sentenças prováveis pelo sistema Avenue.

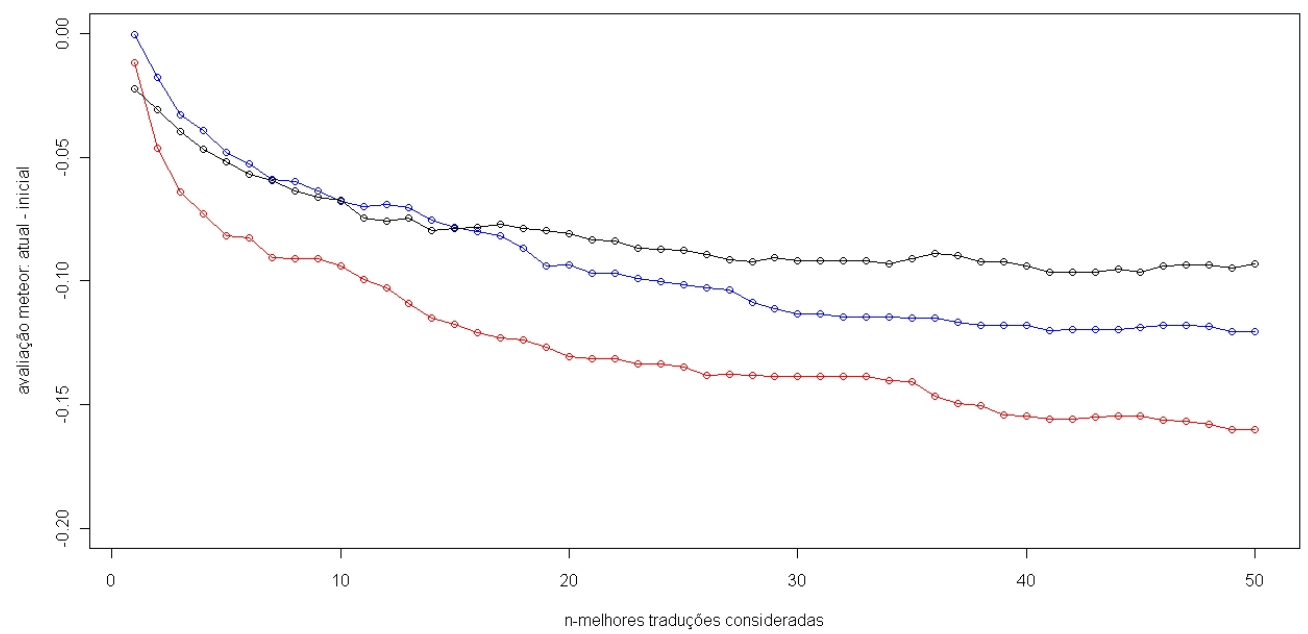

Figura 5.1: Avaliação dos corpora dos tempos verbais

Na Figura 5.1, a cor vermelha indica os resultados do corpus da pri- 
meira conjugação, a cor azul indica os resultados da segunda conjugação e a cor preta representa os resultados da terceira conjugação. A avaliação dos resultados fornecidos pela métrica METEOR apresentou resultados muito próximos para os corpora das três classes de conjugação, por isso realizou-se uma segunda avaliação utilizando um corpus composto por senteças extraídas da Revista Fapesp.

Apresentaremos na seção a seguir, a avaliação e os resultados do corpus Fapesp.

\subsection{Corpus Fapesp}

Para estudar melhor o efeito da inclusão de novas regras de transferência estrutural relativas aos tempos verbais entre o par de língua português e inglês, realizamos uma segunda avaliação do sistema Avenue usando um corpus composto por sentenças não analisadas para a construção das regras. Na literatura, esse tipo de avaliação é conhecido como blind test.

O novo corpus foi construído a partir de textos extraídos da Revista Fapesp $^{1}$, disponibilizados livremente na Web pelo projeto Lácio-Web ${ }^{2}$. A Revista Fapesp é uma publicação online designada à comunidade científica brasileira. Para a composição desse novo corpus foram extraídas 567 sentenças das seções Humanidades, Destaque e Capa.

A avaliação dos resultados seguiu a mesma metodologia aplicada aos corpora dos tempos verbais, em que selecionamos apenas a $n$-melhor sentença apresentada pelo sistema para cada input. Todas as sentenças foram traduzidas pelo sistema Avenue em seu estado inicial e atual, ou seja, foram traduzidas pelo sistema com o uso do componente Gramática contendo as regras iniciais e as regras atuais. Os resultados comparativos estão dispostos na tabela 5.2 .

\begin{tabular}{lc}
\hline Estado do sistema & Pontuação \\
\hline Estado inicial & 0.5445 \\
Estado atual & 0.5391 \\
\hline
\end{tabular}

Tabela 5.2: Resultados das avaliações para o corpus da Revista Fapesp

A avaliação dos resultados fornecidos pela métrica METEOR apresentou resultados similares aos resultados dos corpora das três classes de conjugação.

\footnotetext{
${ }^{1}$ http://revistapesquisa.fapesp.br /

${ }^{2}$ http://www.nilc.icmc.usp.br/lacioweb/index.htm
} 
Apresentaremos no próxímo capítulo uma discussão sobre os resultados apresentados para os corpora dos tempos verbais. 


\section{Capítulo 6}

\section{Discussão}

Apresentaremos, neste capítulo, a discussão para os resultados das avaliações dos corpora dos tempos verbais obtidos através da métrica de avaliação automática METEOR.

Verificamos, no capítulo anterior, que os resultados obtidos através das avaliações dos corpora apresentaram uma regressão, quando comparados ao estado inicial do sistema. Dois tipos de avaliações foram realizadas: a primeira em que se selecionou apenas a sentença $n$-best do arquivo de saída do sistema, ou seja, aquela contendo a maior probabilidade de ser a tradução hipótese; e a segunda, em que foi selecionada a sentença contendo a maior pontuação advinda da métrica METEOR. Ambas as avaliações apresentaram uma queda nos resultados, quando esperávamos um crescimento.

Após analisarmos os arquivos de saída dos sistema, verificamos que as novas regras construídas para o aperfeiçoamento do sistema estavam sendo aplicadas à construção das sentenças em língua de destino em todas as três classes de conjugação. Abaixo, os exemplos de saída do sistema. A ordem de apresentação dos exemplos segue a seguinte estrutura: a. sentenças de entrada em português; b. sentenças de referência; c. traduções apresentadas pelo sistema Avenue no estado inicial da pesquisa, e d. traduções apresentadas pelo sistema Avenue no estado atual da pesquisa.

\section{Primeira conjugação}

A sentença de entrada Eu passaria na tua casa se fosse cedo apresenta o verbo da oração principal no tempo futuro do pretérito do modo indicativo, conforme exemplo (1) abaixo. Porém, percebemos que a saída fornecida pelo sistema em seu estado inicial contém esse tempo verbal traduzido pelo tempo infinitivo. O tempo em inglês que corresponde ao futuro do pretérito é o tempo conditional. 
(1) a. Eu passaria na tua casa se fosse cedo

b. I would drop by your house if it was early

c. THEM TO PASS IN YOUR HOME IF IT IS EARLY

d. IT WOULD BE AT YOUR HOME IF IT WAS EARLY

A Figura 6.1 apresenta a saída do sistema no estado inicial contendo a maior probabilidade para ser a tradução para a sentença de entrada.

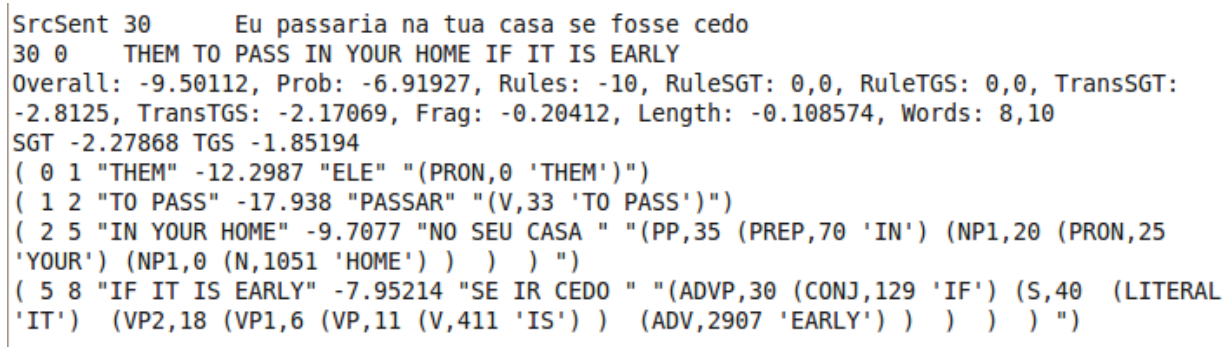

Figura 6.1: Sentença n-best no estado inicial do sistema

É importante notar que, após a criação da regra para a transferência entre os tempos verbais mencionados, essa regra é aplicada pelo sistema para geração da sentença em língua de destino. A Figura 6.2, abaixo, ilustra a aplicação da regra $V P, 24$, na geração da saída do sistema no estado atual.

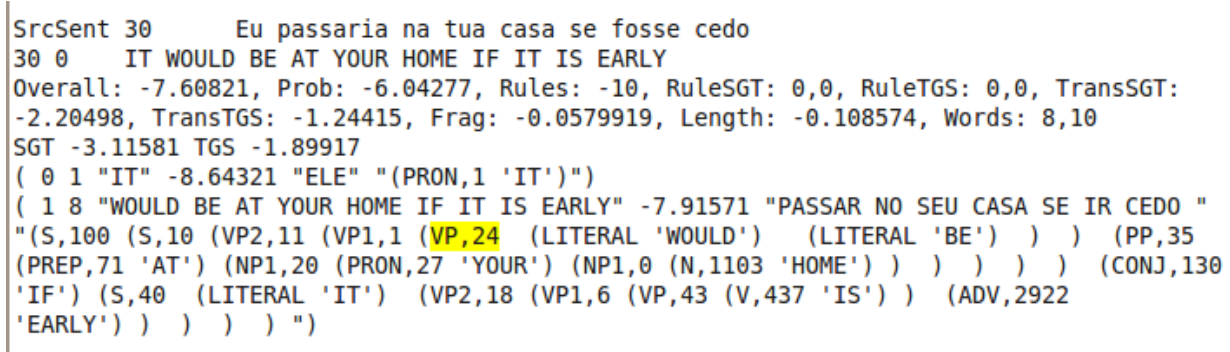

Figura 6.2: Sentença n-best no estado atual do sistema

A tabela 6.1 apresenta a avaliação fornecida pela métrica METEOR para ambas as $n$-best sentenças de saída, no estado inicial e atual do sistema Avenue, apresentadas no exemplo (1).

Em ambas as traduções fornecidas pelo sistema, o verbo principal da sentença apresenta um problema de ordem lexical. O verbo passar apresenta traduções com os verbos pass e be. Entretanto, a métrica METEOR atribui uma baixa pontuação à sentença cuja regra de transferência verbal foi aplicada na geração da sentença de saída. Este fenômeno ocorreu apesar de 


\begin{tabular}{lc}
\hline Estado do sistema & Pontuação \\
\hline Estado inicial & 0.4158 \\
Estado atual & 0.2598 \\
\hline
\end{tabular}

Tabela 6.1: Resultados das avaliações da sentença número 30 do corpus da primeira conjugação

a sentença (1) d. apresentar uma maior correlação com a sentença de referência, visto que em ambas o tempo verbal da oração principal encontra-se no tempo conditional.

\section{Segunda conjugação}

$\mathrm{Na}$ sntença de entrada $O$ banco antederá todos os clientes, o verbo atender está no tempo futuro do presente do modo indicativo, conforme exemplo (2) abaixo. A tradução apresentada pelo sistema em seu estado atual, apresenta o verbo no tempo infinitivo. Em inglês, o tempo futuro formado pelos auxiliares will e to be + going corresponde ao futuro do presente em português.

(2) a. O banco atenderá todos os clientes

b. The bank will see all the clients

c. THE BANK SERVICE ALL THE CUSTOMERS

d. THE BANK IS GOING TO SERVICE ALL THE CUSTOMERS

A Figura 6.3 apresenta a saída do sistema no estado inicial contendo a maior probabilidade para ser a tradução para a sentença de entrada.

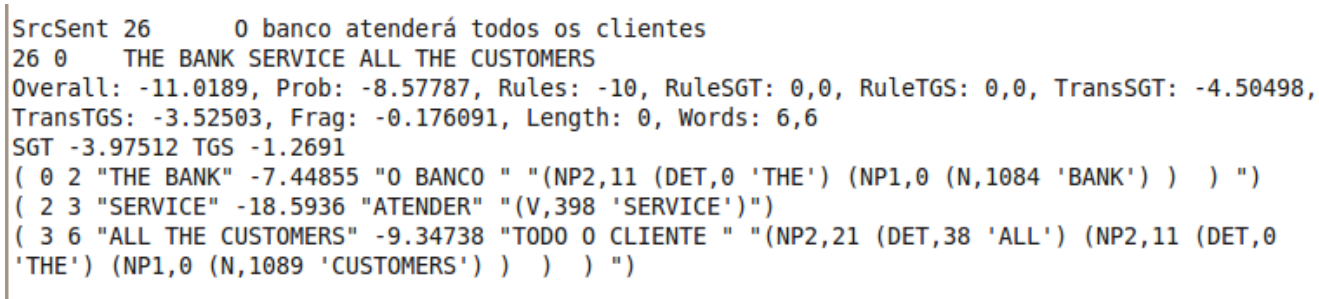

Figura 6.3: Sentença $n$-best no estado inicial do sistema

Após a criação das regras $V P, 20$ e $V P, 211$ para a transferência do tempo futuro do português para o inglês, verificamos que a regra $V P, 211$ é aplicada pelo sistema na geração da sentença em língua de destino. A figura 6.4, abaixo, ilustra a aplicação da regra $V P, 211$. 
Destacamos que verbo principal apresenta um problema de cunho lexical, em que atender foi traduzido pelo verbo service enquanto a tradução de referência apresenta o verbo see.

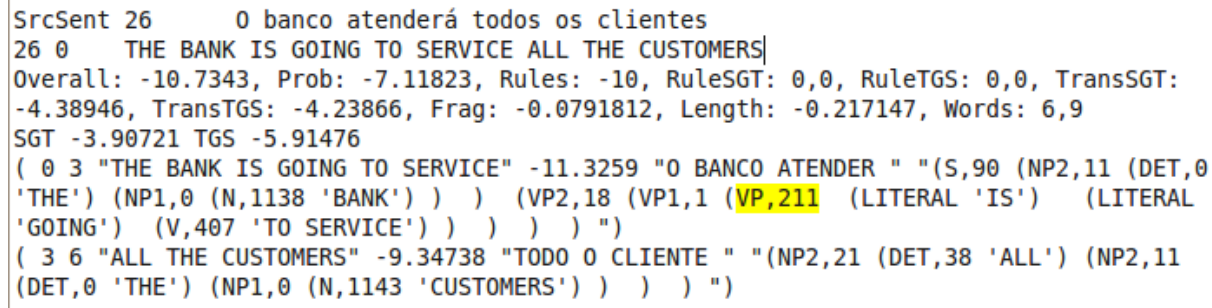

Figura 6.4: Sentença n-best no estado atual do sistema

A tabela 6.2 apresenta a avaliação fornecida pela métrica METEOR para ambas as $n$-best sentenças de saída, no estado inicial e atual do sistema Avenue, apresentadas no exemplo (2).

\begin{tabular}{lc}
\hline Estado do sistema & Pontuação \\
\hline Estado inicial & 0.6868 \\
Estado atual & 0.5931 \\
\hline
\end{tabular}

Tabela 6.2: Resultados das avaliações da sentença de entrada $O$ banco atenderá todos os clientes pertencente ao corpus da segunda conjugação

Conforme os resultados fornecidos pela métrica METEOR, verificamos que a aplicação da regra de transferência para os tempos futuros em ambas as línguas não trouxe melhorias para o desempenho do sistema. É importante destacar que a tradução da forma verbal apresentada pelo sistema no estado atual não é a mesma apresentada na tradução de referência, porém a tradução candidata e a referência possuem o mesmo valor aspectual de tempo futuro. Entretanto, a tradução do tempo verbal fornecida pelo sistema no estado inicial é de tempo presente e apresenta maior pontuação em comparação com a sentença com o valor de futuro.

\section{Terceira conjugação}

A sentença de entrada Eles seguiram o caminho apresenta o tempo verbal no pretérito mais-que-perfeito ${ }^{1}$ do modo indicativo, conforme exemplo (3)

\footnotetext{
${ }^{1}$ Ressaltamos que seguiram possui a mesma forma para a terceira pessoa do plural para o tempo pretérito perfeito do modo indicativo, porém a título de exemplo expomos apenas o tempo pretérito mais-que-perfeito
} 
abaixo. Porém, percebemos que a saída fornecida pelo sistema em seu estado inicial contém esse tempo verbal traduzido pelo tempo infinitivo, quando deveria apresentar os tempos past perfect ou simple past.
a. Eles seguiram o caminho
b. They followed the path
c. IT TO FOLLOW THE PATH
d. HE HAD FOLLOWED THE PATH

A Figura 6.5, apresenta a saída do sistema no estado inicial contendo a maior probabilidade para ser a tradução para a sentença de entrada.

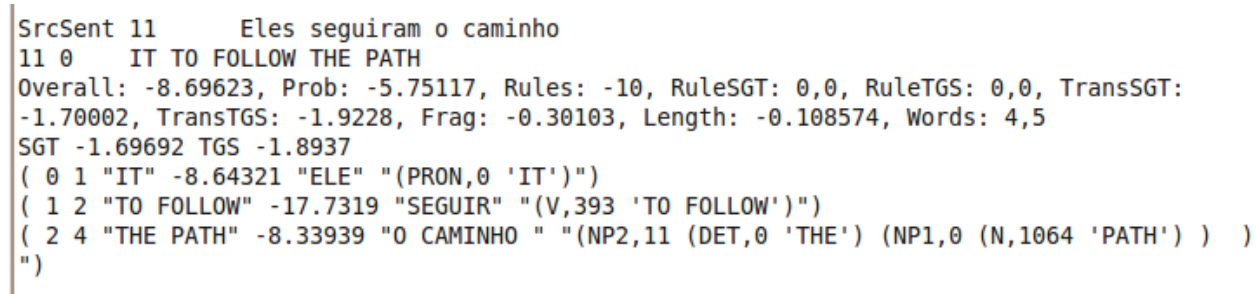

Figura 6.5: Sentença $n$-best no estado inicial do sistema

Nota-se que, após a criação das regras referentes aos tempos verbais mencionados, obtivemos a aplicação da regra $V P, 44$ na geração da sentença de saída. Embora essa regra não seja exatamente a correspondente com à tradução de referência, ela constitui uma das duas possibilidades de tradução para o tempo pretérito mais-que-perfeito do modo indicativo. Figura 6.6, abaixo, ilustra a aplicação da regra $V P, 44$, específica para a transferência entre esses tempos verbais.

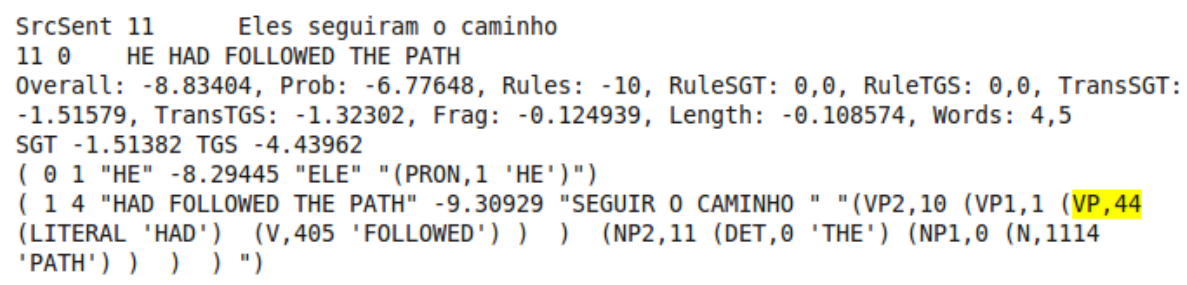

Figura 6.6: Sentença n-best no estado atual do sistema

A tabela 6.3 apresenta a avaliação fornecida pela métrica METEOR para ambas as $n$-best sentenças de saída, no estado inicial e atual do sistema Avenue, apresentadas no exemplo (3). 


\begin{tabular}{lc}
\hline Estado do sistema & Pontuação \\
\hline Estado inicial & 0.6466 \\
Estado atual & 0.6466 \\
\hline
\end{tabular}

Tabela 6.3: Resultados das avaliações da sentença número 11 do corpus da terceira conjugação

Conforme os resultados fornecidos pela métrica METEOR, verificamos que a aplicação da regra de transferência para os tempos futuros em ambas as línguas não trouxe melhorias para o desempenho do sistema. O resultado manteve o mesmo para os dois estados utilizados na avaliação. É importante destacar que a tradução da forma verbal apresentada pelo sistema no estado atual não é a mesma apresentada na tradução de referência, porém a tradução candidata e a referência possuem o mesmo valor aspectual de tempo passado. Entretanto, a tradução do tempo verbal fornecida pelo sistema no estado inicial é de tempo infinitivo e apresenta maior pontuação em comparação com a sentença com o valor de passado.

Nos exemplos (1), (2) e (3), vimos que a métrica METEOR falha ao correlacionar valores de tempos similares, como por exemplo, tempos verbais passado. No entanto, verificamos também que essa métrica falha ao correlacionar tempos correspondentes entre a tradução de referência e a tradução candidata. O exemplo (4), a seguir ilustra essa falha na correlação.
a. Quando tu estiveres falando com ele a carta chegará
b. When you are speaking to him the letter will arrive
c. WHEN HE WAS SPEAKING WITH IT THE CHARTER TO GET
d. WHEN YOU ARE TALKING WITH HIM TO CHARTER IS GOING TO GET

A sentença de entrada Quando tu estiveres falando com ele a carta chegará apresenta o verbo da oração principal no tempo futuro progressivo do modo subjuntivo, conforme exemplo (4) acima. Porém, percebemos que a saída fornecida pelo sistema em seu estado inicial contém esse tempo verbal traduzido pelo tempo past continuous, quando deveria apresentar uma tradução com o tempo presente continuous. Adicionalmente o tempo do verbo chegar na oração encaixada foi traduzido pelo tempo infinitivo, embora o tempo devesse apresentar a tradução com o tempo futuro.

A Figura 6.7 apresenta a saída do sistema no estado inicial contendo a maior probabilidade para ser a tradução de hipótese para a sentença de 
entrada Quando tu estiveres falando com ele a carta chegará.

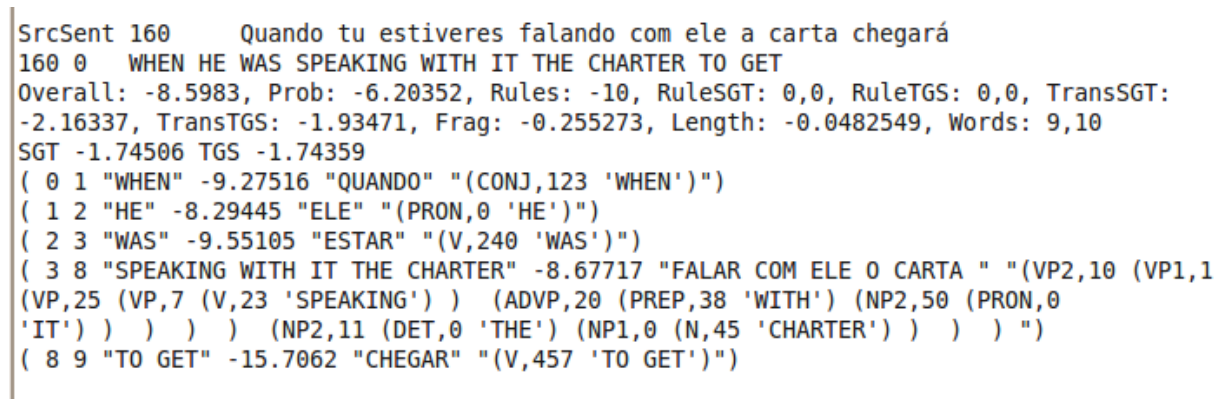

Figura 6.7: Sentença n-best no estado inicial do sistema

Após a criação da regra $V P, 294$ referente à transferência do tempo futuro progressivo do modo subjuntivo para o present continuous, obtivemos a sua aplicação para a geração da sentença de saída. A regra aplicada fornece o tempo verbal para a sentença candidata correspondente ao tempo presente na tradução de referência. A figura 6.8, abaixo, ilustra a aplicação da regra $V P, 44$, específica para a transferência entre os tempos verbais mencionados.

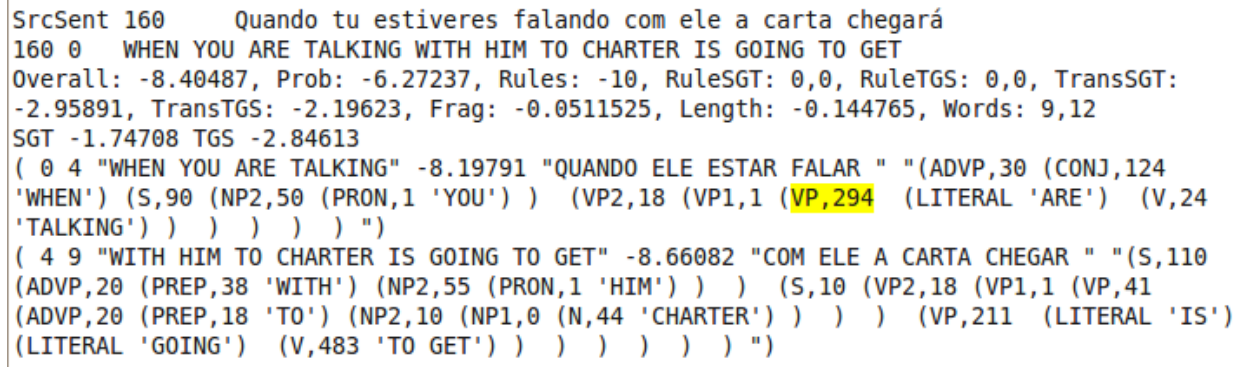

Figura 6.8: Sentença $n$-best no estado atual do sistema

A tabela 6.4 apresenta a avaliação fornecida pela métrica METEOR para ambas as $n$-best sentenças de saída, no estado inicial e atual do sistema Avenue, apresentadas no exemplo (4).

Os resultados fornecidos pela métrica METEOR sugerem que a aplicação da regra de transferência entre os tempo futuro progressivo do modo subjuntivo e present continuous não trouxe melhorias para o desempenho do sistema. Verificamos que a tradução do tempo verbal da oração principal fornecida pelo sistema em seu estado inicial é feita com o uso do tempo past perfect, que não corresponde ao tempo apresentado pela tradução de referência. No entanto, a sentença com verbo principal no tempo past perfect apresenta maior pontuação quando comparada com a sentença cujo verbo se 


\begin{tabular}{lc}
\hline Estado do sistema & Pontuação \\
\hline Estado inicial & 0.3033 \\
Estado atual & 0.1649 \\
\hline
\end{tabular}

Tabela 6.4: Resultados das avaliações da sentença número 11 do corpus da terceira conjugação

encontra no tempo present continuous, o mesmo apresentado pela tradução de referência. Ainda é interessante notar que no estado atual, o sistema forneceu a tradução para tempo do verbo chegar na oração encaixada com o tempo futuro com o uso dos auxiliares to be e going, e portanto, deveria apresentar uma uma maior correlação com a referência, que apresenta o mesmo tempo futuro, embora seja realizado com o auxiliar will.

Baseados nessas evidências, concluímos que a métrica de avaliação automática METEOR apresenta falhas ao correlacionar os tempos verbais apresentados nas traduções candidatas com as traduções de referência. Os exemplos acima demonstram que, apesar das regras construídas para os tempos verbais serem eficientes, no sentido em que fornecem os tempos verbais similares à tradução de referência, a pontuação gerada pelo METEOR não apresenta a sua correlação. 


\section{Capítulo 7}

\section{Conclusão}

Mostramos, com esse trabalho, que as regras de transferência adicionadas contendo traços linguísticos pertencentes a classe dos verbos em português apresentam traduções correspondentes aos tempos verbais do inglês. Para isso, analisamos manualmente as saídas do sistema Avenue e constatamos que as regras foram utilizadas para geração do output do sistema. Fizemos também o uso de avaliações dos corpora criados por meio da métrica de avaliação automática METEOR.

Observamos que as três classes de conjugação a que os verbos em português se classificam apresentaram a utilização sistemática das regras criadas.

A contribuição deste trabalho está em discutir os valores apresentados pela métrica METEOR. Também sugerimos que novos ajustes sejam feitos aos parâmetros utilizados pela métrica, assim como a inclusão de um módulo capaz de correlacionar os tempos verbais com valores apectuais semelhantes. Por fim, entendemos que as regras criadas são abragentes, no sentido em que podem ser aplicadas a diversos tipos de textos, por isso esperamos que elas possam ser facilmente aplicadas a quaisquer outros sistemas de traduções baseados em regras entre as línguas português e inglês.

A métrica METEOR possui uma correlação com os julgamentos humanos, porém essa correlação se apresenta quando aplicadas a traduções fornecidas por tradutores automáticos em estágio final de desenvolvimento. Como o tradutor automático Avenue ainda precisa de maiores aperfeiçoamentos para a inclusão de outros fenômenos linguísticos que necessitam ser tratados, a métrica não foi sensível às questões tratadas no capítulo 6 .

Para os trabalhos futuros pretendemos trabalhar com um corpus mais robusto e com mais de uma tradução de referência, feita por outros especialistas, cada um traduzindo independentemente as mesmas frases. Acreditamos que a variedade na tradução de referência pode ajudar na verificação de melhoria feitas no sistema. Também esperamos poder desenvolver uma métrica 
de tradução específica para tempos verbais (ou pelo menos mais sensível a esta parte das frases do que às outras), visto que em traduções o verbo principal é o elemento mais importante para a compreenssão de uma frase. Outro importante trabalho a ser desenvolvido é verificar se o uso do corpus EUROPARL para a extração das probabilidades do modelo de tradução e modelo de linguagem influenciou negativamente na geração das sentenças de saída. O corpus EUROPARL é composto por textos paralelos em português europeu e inglês, por isso seria interessante averiguar se a utilização de um corpus equivalente em português brasileiro forneceria probabilidades similares e se obteríamos sentenças traduzidas com alta correlação. 


\section{Referências Bibliográficas}

[1] HUTCHINS, W. J. Machine translation: Past, present, future. Ellis Horwood, 1986.

[2] SPECIA, L.; RINO, L. H. M. Introdução aos métodos e paradigmas de tradução automática. Technical report, Núcleo Interinstotucional de Linguística Computacional, 2002.

[3] HUTCHINS, W. J. Twenty years of translating and the computer. Translating and the Computer 20:Proceedings of the 20th International Conference on Translating and the Computer, November 1998.

[4] SCHWARZL, A. The (im)possibilities of machine translation. Peter Lang, 2001.

[5] HUTCHINS, W. J.; SOMERS, H. L. An introduction to machine translation. Academic Press, 1992.

[6] HOUAISS, A. Dicionário houaiss eletrônico da língua portuguesa. Editora Objetiva Ltda, 2009.

[7] DORR, B. J.; JORDA, P. W.; BENOIT, J. W. A survey of current paradigms in machine translation. Advances in Computers, v. 49, p. 1-68, 1999.

[8] UNU/IAS/UNL. The universal networking language (unl) specifications, 2001.

[9] DORR, B. The use of lexical semantics in interlingual translation. Journal of Machine Translation, p. 135-193, 1992.

[10] MODESTO, M. Tradução automática entre línguas com poucos recursos computacionais. Technical report, Fundação da Amparo à Pesquisa do Estado de São Paulo, 2008. 
[11] LAVIE, A.; WINTNER, S.; EYTANI, Y.; PETERSON, E.; PROBST, K. Rapid prototyping of a transfer-based hebrew-to-english machine translation system. Proceedings of the 10th International Conference on Theoretical and Methodological Issues in Machine Translation (TMI2004), 2004.

[12] PROBST, K.; LEVIN, L.; PETERSON, E.; LAVIE, A.; CARBONELL, J. Mt for minority languages using elicitation-based learning of syntactic rules. Machine Translation, v. 17, 2002.

[13] LAVIE, A.; VOGEL, S.; LEVIN, L.; PETERSON, E.; PROBST, K.; FONT LLITJOS, A.; REYNOLDS, R.; CARBONELL, J.; COHEN, R. Experiments with hind-to-english transfer-based mt system under a miserly data scenario. ACM Transactions on Asian Language Information Processing, v. V, 2003.

[14] SILVA, L. Fine-tuning in brazilian portuguese-english statistical transfer machine translation: Verbal tenses. Proceedings of the NAACL HLT 2010 Student Research Workshop (SRW), p. 58-63, June 2010.

[15] MA, W.-Y.; MCKEOWN, K. Where's the verb? correcting machine translation during answering. Proceedings of the ACL-IJCNLP., p. 333336, 2009.

[16] RAPOSO, F. Regras de transferência dos tempos verbais de português para inglês em software de tradução automática. Technical report, Conselho Nacional de Desenvolvimento Científico e Tecnológico, 2008.

[17] BECHARA, E. Moderna gramática portuguesa. Lucerna, 2004.

[18] LAVIE, A.; DENKOWSKI, M. The meteor metric for automatic evaluation of machine translation. Machine Translation, 2009.

[19] LAVIE, A.; AGARWAL, A. Meteor: An automatic metric for mt evaluation with high levels of correlation with human judgments. Proceeding of the 2nd Workshop on Statistical Machine Translation at the 45th Meeting of the Association for Computational Linguistics, p. 228-231, 2007.

[20] CUNHA, C.; LINDLEY CINTRA, L. F. Nova gramática do português contemporâneo. Nova Fronteira, 2001.

[21] REICHENBACH, H. Elements of symbolic logic. Macmillan Co. Dover, 1947. 
[22] COMRIE, B. Tense. Cambridge University Press, 1993.

[23] CUNHA, C. Gramática do português contemporâneo. Padrão Livraria Editora, 1980.

[24] FIORIN, J. L. As astúcias da enunciação: as categorias de pessoa, espaço e tempo. Editora Ática, 2002.

[25] MATEUS, M. H. M.; BRITO, A. M.; DUARTE, I.; FARIA, I. H.; FROTA, S.; MATOS, G.; OLIVEIRA, F.; VIGáRIO, M.; VILLALVA, A. Gramática da língua portuguesa. Editorial Caminho, 2003.

[26] CHIANG, D.; KNIGHT, K.; WANG, W. 11,001 new features for statistical machine translation. Proceedings of Human Language Technologies: The 2009 Annual Conference of the North American Chapter of the Association for Computational Linguistics, p. 218-226, 2009. 


\section{Apêndice A}

\section{Corpus preliminar}

Português - Inglês

1. No verão saio daqui para me casar. I'm leaving in the summer to get married.

2. Com o bilhete na mao, ando de plataforma em plataforma a fim de não ficar tão exposto. Ticket in hand I walk from bay to bay trying not to stand out.

3. Com o canto dos olhos observo. Out of the corner of my eye, I observe.

4. Mas, para ser sincero, amo a minha mulher. But, to coin a phrase, I love my wife.

5. As pessoas querem ser amadas, ate pelo seu carrasco. People long to be loved, even by their executioners.

6. Custa-me dizer que sai de lá encantado. It pains me to have to say that I left there bewitched.

7. Ela deu uma risada curta, como um latido, que me deixou apreensivo. She gave a brief, barking laugh, which unsettled me.

8. Satanáss levou o manuscrito consigo para o inferno. Satan took the manuscript with him to hell.

9. Ela riu tanto que perdeu o controle e derramou a vodca no vestido. She laughed immoderately, and spilled some vodka on her frock.

10. À hora aprazada partiram. At the appointed hour, they set out.

11. Eu caminhava ao seu lado, descuidado, aspirando o ar marinho, tostando-me ao sol atlântico. I walked beside her, carefree, breathing in the ocean air, tanning under the Atlantic sun.

12. Não jogava futebol, bilhar, cartas, não dançava aos domingos, nem ia à missa. He didn't play soccer, pool or cards, didn't dance on Sunday or go to mass.

13. Já ele ria, ja brincava, tinha o ar do costume; a ferida sarou de todo. He laughed, he joked, he was his usual self; the wound had healed completely. 
14. Nós escrevíamos os textos às sextas. We used to write the texts on Fridays.

15. Vivíamos dessa antecipação, que era apenas um sonho, e não sentíamos os golpes da fortuna. We lived on this expectation, though it was only a dream, and did not feel the blows dealt us by fortune.

16. Deste modo ganhava na extensão da visita o que perdera na chegada ao cemitério. In this way, he gained in the length of the visit what he had lost in time of arrival at the cemetery.

17. Horas antes, quando tentara deixar a cidade rumo a Jerusalém, foi capaz de encontrar seu caminho sem dificuldades; o mesmo acontecera com os assírios. Hours before, when he was attempting to leave the city for Jerusalem, he had been able to find his way without difficulty; the Assyrians had the same advantage.

18. Ela não lhe dissera nada da pistola, do punhal. She had told him nothing about the pistol or the dagger.

19. Mais de uma vez buscara dissipar a sombra pesarosa. More than once he had sought to dissipate the dark shadow.

20. Ela parara de miar. She had stopped meowing.

21. Quando se apagarem as luzes, irei embora. When the lights go out, I will leave.

22. Lutaremos com bravura, mas estamos numa situação inferior; e morreremos com glória. We shall fight bravely, but our situation is inferior, and we shall die with glory.

23. Eu a encontrarei de novo no Paraíso, e passearemos de mãos dadas. I'll meet her again in paradise, where we shall stroll hand in hand.

24. Temos que pensar no local onde o crime sera cometido. We have to think about the place where the crime will be committed.

25. Você estará cavando a sua própria cova. You'd be cutting your throat.

26. Eu queria falar, fazer perguntas... I wanted to talk, to ask questions...

27. Ele teria de dizer quem era o cabeça do motim. He would have to say who was the leader of the mutiny.

28. Prometi a ela que compraria. I promised her I'd buy one.

29. Se houvesse dança, ele apenas lhe pediria uma quadrilha; duvido que a convidasse a valsar. If it were a question of dancing, he would probably beg for a quadrille; I doubt if he would ask her to waltz.

30. Voce morreria em dois minutos. You'd die in two minutes.

31. Ai espero que fale de nós, de quem fomos e de quem somos. There I hope he will speak of us, of who we were and who we are.

32. Ele não quer que continuemos aqui. He wants us to leave.

33. Não quero que minha mãe seja isto que estou vendo. I don't want my mother to be this that I'm looking at. 
34. Sobre o homem de minha escolha desejo que não paire a mínima desconfiança. I will not have the slightest speck of suspicion fall on the man of my choice.

35. No ano que vem vou ver seu desfile e espero que ganhe o primeiro lugar. I'll go to your pageant next year, and I hope you win first prize.

36. Se pudesse imaginar o que viveria dali em diante, escondido nos matos, afastado dos caminhos, faminto e salteador, pelas picadas e vereias escondidas, teria chorado. If he could have imagined what his life would be like from then on, hiding in the woods, keeping away from the roads, hungry, thieving, sticking to remote pathways and clearings, he would have wept.

37. Ela temia que, mais perto do governo, a discórdia política acabasse com a recente harmonia dos filhos, mas não podia la ficar. She was afraid that, if they were closer to the government, political discord would destroy the recent harmony of her sons, but they could not stay here.

38. O trem das cinco e vinte, vindo do Recife, se chegasse no horário, poderia ser a nossa referência. The five twenty train from Recife, if it were on time, could be our reference point.

39. Tomava o pulso a doente, e pedia-lhe que mostrasse a língua. I took the patient's pulse, and asked her to show her tongue.

40. Pior seria se o testamento ficasse nulo. It would be worse if the will were found null and void.

41. Foi assim que fui criado: sempre se vestir bem quando for ao médico. It's how I was brought up: always dress properly when you're going to the doctor's.

42. Então os dois tem que ser apanhados, quando estiverem... hum... isso é impossível. You mean the two of them would have to be caught when they were...? Mmm... That's impossible.

43. Você só deve abrir os olhos quando eu tiver acabado minha parte, e for lhe ensinar um exercício. You should open your eyes only when I have completed teaching you an exercise.

44. Um dia, quando todos os livros forem queimados por inúteis, há de haver alguem, pode ser que tenor, e talvez italiano, que ensine esta verdade aos homens. One day, when all the books have become useless and been burnt, there will be someone, maybe a tenor - perhaps Italian - to teach this truth to mankind.

45. Leve isso em consideração quando for fazer seu filme. Take that into consideration when you make your film.

46. Some daqui, saia da cidade. Get away from here, get out of the city.

47. Os nomes, diga os nomes. The names, tell us the names.

48. Disseram: pare! They said: Stop! 
49. Componha com eles uma música e dance com todo o corpo. Compose an internal melody based on them, and dance to it with your whole body.

50. Seja homem, ande. Come, come, be a man.

51. Se for, não diga uma palavra. Then don't breathe a word .

52. Por favor, não chore. Please don't cry.

53. O melhor é que não saia... não saia... It's best that he doesn't go out... doesn't go out...

54. Não me fale desse canalha. Don't mention that scum to me.

55. Nao ria. Don't laugh.

56. E pôs-se a rir e a dançar, batendo palmas e cantando. And she began to laugh and dance, clapping her hands and singing.

57. Veio caminhando na minha direção, com tranquilidade. He walked toward me, calmly.

58. Fez um gesto significativo com o dedo atravessando a garganta. He drew a finger expressively across his throat.

59. Diga que esta brincando. Tell me you're joking.

60. Você não vive dizendo que não lê jornal? Aren't you always saying you never read the paper?

61. Os gritos haviam terminado, mas, mesmo assim, fui até a porta do edifício fronteiro. The screaming had stopped, but I approached the door of the building across the street anyway.

62. Estava parado na vitrine de uma livraria. He was standing at the window of a bookstore.

63. Pelo nosso escritório haviam passado criminosos e inocentes de todos os tipos. Innocents and criminals of all types had passed through our office.

64. O pequeno, todavia, depois de preparado com todo o desvelo, foi metido, a chorar, dentro de um navio, e partiu. Even so, after being readied with every care, the little one, in tears, was placed aboard a ship and departed.

65. O hino sacro, cantado em latim. The sacred hymn, sung in Latin.

Inglês - português

66. But, to coin a phrase, I love my wife. Mas, para ser sincero, adoro a minha mulher.

67. I can't make a decision about anything these days. Nestes dias, não consigo decidir nada.

68. I travel up and down a lot on this line. Viajo demais para cima e para baixo nessa linha.

69. With the jewels you can buy your freedom. Com as jóias você compra a sua alforria.

70. After all, we drink the same water eventually. Afinal de contas, a gente bebe a mesma água. 
71. I've tried several treatments for baldness without success. Tentei sem sucesso muitos tratamentos contra a perda de cabelos.

72. He climbed the stairs two at a time, crossed the empty veranda, and went directly to his quarters. Subiu pé ante pé, atravessou a varanda deserta, e foi direito ao seu aposento.

73. He cried on that occasion, too, I seem to remember. Ele chorou também naquela ocasião, lembro-me bem.

74. He smiled as if awarding me a prize. Sorriu como se estivesse me concedendo um prêmio.

75. Will you confirm verbally what you wrote? Confirma verbalmente o que escreveu?

76. What will you buy instead? O que vai comprar, então?

77. I will tell you all about it... Eu lhe direi tudo...

78. We will both go. Iremos ambos.

79. Promise me that you will say nothing. Prometa-me que não dirá nada.

80. You will not be able to speak to me. Você poderá não falar comigo.

81. I have used up sticks, cans of glue, sheets and sheets of the tissue paper. Desperdicei varetas, latas de cola, folhas e folhas de papel de seda.

82. I have known scores of old ages, not to say hundreds. Conheci dezenas de velhices, para não dizer centenas.

83. It's what you have always wanted to accomplish. É aquilo que você sempre desejou fazer.

84. I have passed on to you everything that I have to give. Tudo que eu tinha para lhe transmitir, já-lhe transmiti.

85. The rest of the populace have lost their senses. O resto da população perdeu a razão.

86. She asked me again if I had any allergies. Ela perguntou de novo se eu sofria de algum tipo de alergia.

87. She had recently split up with a partner. Ela tinha acabado de se separar de seu companheiro.

88. I have a car, but I had to work for it. Eu tenho um carro, mas para isso tive de trabalhar.

89. None of these projects had been completed. Nenhum desses projetos foi completado.

90. He had to go to Europe now, to save face. Tinha de ir para a Europa agora, para não ser desmoralizado.

91. And for once he will have the advantage of him. E dessa vez finalmente terá uma vantagem sobre ele.

92. You will have a home and children. Terás um lar e filhos. 
93. If you succeed in finding your sword, you will have to teach the Road to someone else. Se você conseguir encontrar sua espada, terá de ensinar o Caminho a alguém.

94. Now you will have the same fate. Agora você terá o mesmo destino.

95. There you will have a lot to draw. Lá terá muito que desenhar.

96. The pain would make me cry out in the middle of the night. A dor me fazia gritar no meio da noite.

97. He said I would have a general anaesthetic. Ele disse que eu teria uma anestesia geral.

98. You would bring tears to your eyes to watch us, of either laughter or pity. Você derramaria lágrimas só de nos ver jogando, de risada ou de pena.

99. I would go to the dentist. Eu iria ao dentista.

100. I would prefer it to be you. Preferia que fosse você.

101. They would have settled for three. Eles teriam aceitado só três.

102. If the hairs on the back of my neck were shorter, they would have lifted. Se os cabelos na minha nuca fossem mais curtos, eles teriam ficado de pé.

103. I would have been glad to slope off home myself. Eu também teria ficado contente de vir direto para casa.

104. I would have liked to have brought her. Gostaria de tê-la trazido comigo.

105. He would have committed suicide. Ele teria se suicidado.

106. You think I look old? Acha que pareço velha?

107. I play basketball everyday. Eu jogo basquete todos os dias.

108. My study is full of reference books, I buy them compulsively. Meu estúdio está cheio de livros de referência, compro-os por compulsão.

109. We're no children, I know. Nós não somos crianças, eu sei.

110. I want to talk to you alone. Eu quero falar a sós com você.

111. She says I shouldn't do any sport until the symptoms have disappeared. Ela diz que eu não devo praticar nenhum esporte até que os sintomas tenham desaparecido.

112. They surely must have talked it over earlier, as old people always do before making the smallest decision. Com certeza, já deviam ter conversado, como fazem os velhos antes de tomarem a menor resolução.

113. With them I have learned much that I did not know. Aprendi com eles muitas coisas que não sabia.

114. I have thought of joining the circus, working in the dramas, as an actress. Pensei em oferecer-me para ir com o circo, trabalhar nos dramas, como atriz.

115. All the gold, influence and friendship his father must have used. Quanto ouro, quanto valimento, quanta amizade o pai não tinha gasto. 
116. I listened to the plaintive tale. Ouvi a lamurienta história.

117. I read the story again, frightened. Reli a notícia, apavorado.

118. She loved him, without knowing why. Amou-o, sem saber por que.

119. I also said that the night was dark. Eu também disse que a noite era escura.

120. I lost a tooth yesterday. Eu perdi um dente ontem.

121. I had imagined it was just going to be a social lunch, a bit of gossip. Imaginei que fosse apenas um almoço social, um pouco de fofoca.

122. I had just killed a man and I was devastated. Eu tinha acabado de matar um homem e estava arrasado.

123. They said nothing, not daring to compare notes on what they had seen, heard and felt. Não falavam, não ousavam conferir o que tinham visto, ouvido, sentido.

124. Once they had filled their plastic sacks, they left. Depois de encherem seus sacos plásticos foram embora.

125. When I looked again at half-past seven this morning, he had gone. Quando olhei de novo às sete e meia, hoje de manhã, ele tinha desaparecido.

126. Let's talk! Vamos conversar!

127. Eat! Coma! 


\section{Apêndice B}

\section{Mapeamento dos tempos verbais português - inglês}

\section{B.1 Modo Indicativo}

\section{B.1.1 Tempos simples}

\section{Presente}

Eu falo - I speak, I am speaking, I am going to speak, I will speak

Tu falas - You speak, You are speaking, You are going to speak, You will speak

Ele fala - He speaks, He is speaking, He is going to speak, He will speak

Nós falamos - We speak - We are speaking, We are going to speak, We will speak

Vós falais - You speak, You are speaking, You are going to speak, You will speak

Eles falam - They speak, They are speaking, They are going to speak, They will speak

Eu falo inglês

I speak English

Eu viajo pra França amanhã

I am travelling to France tomorrow

Eu falo com você amanhã

I am going to speak with you tomorrow 
Eu falo com você amanhã

I will speak with you tomorrow

\section{Pretérito perfeito}

Eu falei - I spoke, I have spoken

Tu falaste - You spoke, You have spoken

Ele falou - He spoke, He has spoken

Nós falamos - We spoke, We have spoken

Vós falastes - You spoke, You have spoken

Eles falaram - They spoke, They have spoken

Eu já falei com você ontem

I already spoke with you yesterday

Eu falei com João sobre essa questão

I have spoken to John about this issue

\section{Pretérito imperfeito}

Eu falava - I used to speak, I was speaking

Tu falavas - You used to speak, You were speaking

Ele falava - He used to speak, He was speaking

Nós falávamos - We used to speak, We were speaking

Vós faláveis - You used to speak, You were speaking

Eles falavam - They used to speak, They were speaking

Eu falava sobre tudo quando era jovem

I used to talk about everything when I was young

$\mathrm{Eu}$ falava quando ele chegou

I was speaking when he arrived

\section{Pretérito mais-que-perfeito}

Eu falara - I had spoken

Tu falaras - You had spoken 
Ele falara - He had spoken

Nos faláramos - We had spoken

Vós faláreis - You had spoken

Eles falaram They had spoken

Ele dormira antes da minha partida

He had slept before my departure

\section{Futuro do presente}

Eu falarei, vou falar - I will speak, I am going to speak

Tu falarás, vais falar - You will speak, You are going to speak

Ele falará, vai falar - He will speak, He is going to speak

Nós falaremos, iremos falar - We will speak, We are going to speak

Vós falareis, ireis falar - You will speak, You are going to speak

Eles falarão, irão falar - They will speak, They are going to speak

Eu estudarei com você semestre que vem

I will study with you next semester

Eu falarei com você nesse mês

I am going to talk to you this month

\section{Futuro do pretérito}

Eu falaria - I would speak

Tu falarias - You would speak

Ele falaria - He would speak

Nós falaríamos - We would speak

Vós falaríeis - You would speak

Eles falariam - They would speak

Eu falaria com ele se tivesse tempo

I would speak with him If I had time

\section{B.1.2 Tempos compostos}

\section{Pretérito perfeito}


Eu tenho falado - I have been speaking

Tu tens falado - You have been speaking

Ele tem falado - He has been speaking

Nós temos falado - We have been speaking

Vós tens falado - You have been speaking

Eles têm falado - They have been speaking

Eu tenho estudado todas as manhãs

I have been studying every morning

\section{Pretérito mais-que-perfeito}

Eu tinha falado - I had spoken

Tu tinhas falado - You had spoken

Ele tinha falado - He had spoken

Nós tínhamos falado - We had spoken

Vós tínheis falado - You had spoken

Eles tinham falado - They had spoken

Eu tinha falado com ele quando você chegou

I had spoken to him when you arrived.

\section{Futuro do presente}

Eu terei falado - I will have spoken

Tu terás falado - You will have spoken

Ele terá falado - He will have spoken

Nós teremos falado - We will have spoken

Vós tereis falado - You will have spoken

Eles terão falado - They will have spoken

Eu já terei falado quando ele chegar

I will have already spoken when he arrives

\section{Futuro do pretérito}

Eu teria falado - I would have spoken

Tu terias falado - You would have spoken 
Ele teria falado - He would have spoken

Nós teríamos falado - We would have spoken

Vós teríeis falado - You would have spoken

Eles teriam falado - They would have spoken

Eu teria falado se ele chegasse na hora

I would have spoken if he arrived on time

\section{Presente progressivo}

Eu estou falando - I am speaking

Tu estás falando - You are speaking

Ele está falando - He is speaking

Nós estamos falando - We are speaking

Vós estais falando - You are speaking

Eles estão falando - They are speaking

Ele está lendo um bom livro

He is reading a good book

\section{Pretérito perfeito progressivo}

Eu estive falando - I had been speaking

$\mathrm{Tu}$ estiveste falando - You had been speaking

Ele esteve falando - He had been speaking

Nós estivemos falando - We had been speaking

Vós estivestes falando - You had been speaking

Eles estiveram falando - They had been speaking

Eles estiveram falando de nós dois durante a apresentação

They had been talking about us during the presentation

\section{Pretérito imperfeito progressivo}

Eu estava falando - I was speaking

Tu estavas falando - You were speaking

Ele estava falando - He was speaking

Nós estávamos falando - We were speaking 
Vós estáveis falando - You were speaking

Eles estavam falando - They were speaking

Eu estava falando quando ela entrou

I was speaking when she came in

\section{Futuro do presente progressivo}

Eu estarei falando - I will be speaking

Tu estarás falando - You will be speaking

Ele estará falando - He will be speaking

Nós estaremos falando - We will be speaking

Vós estareis falando - You will be speaking

Eles estarão falando - They will be speaking

Amanhã a essa hora eu estarei falando de você

By this time tomorrow I will be speaking of you

\section{Futuro do pretérito progressivo}

Eu estaria falando - I would be speaking

Tu estarias falando - You would be speaking

Ele estaria falando - He would be speaking

Nós estaríamos falando - We would be speaking

Vós estaríeis falando - You would be speaking

Eles estariam falando - They would be speaking

Eu estaria falando de você se eu tivesse tempo

I would be speaking about you if I had the time

\section{B.2 Subjuntivo}

\section{B.2.1 Tempos simples}

\section{Presente}

Que eu fale - May I speak, to speak, I will speak Que tu fales - May you speak, to speak, You will speak 
Que ele fale - May he speak, to speak, He will speak

Que nós falemos - May we speak, to speak, We will speak

Que vós faleis - May you speak, to speak, You will speak

Que eles falem - May they speak, to speak, They will speak

Que a força esteja com você

May the force be with you

Desejo que ele fale por horas

I want him to speak for hours

Desejo que ele assista tv todos os dias

I wish he would watch tv every day

Eu espero que ele fale de nós

I hope he will speak of us

\section{Pretérito imperfeito}

Que eu falasse - to speak, I speak, I spoke, I would speak

Que tu falasses - to speak, You speak, You spoke, You would speak

Que ele falasse - to speak, He speaks, He spoke, He would speak

Que nós falássemos - to speak, We speak, We spoke, We would speak

Que vós falásseis - to speak, You speak, You spoke, You would speak

Que eles falassem - to speak, They speak, They spoke, They would speak

Desejava que ele falasse sobre o acontecido

I wanted him to speak about what happened

Eu queria que ele assitisse

I wish he would watch tv every day

Lamentaria se eles chegassem atrasados

I would be sorry if they arrived late

\section{Futuro}

Quando eu falar - to speak, I speak

Quando tu falares - to speak, You speak 
Quando ele falar - to speak, He speaks

Quando nós falarmos - to speak, We speak

Quiando vós falardes - to speak, You speak

Quando eles falarem - to speak, They speak

Quando ele voltar pra casa, eu terei partido

When he comes back home I will have left

Quando ele vier eu estarei aqui

When he comes I will be here

\section{B.2.2 Tempos Compostos}

\section{Pretérito perfeito}

Eu tenha falado - I had spoken, spoke

Tu tenhas falado - You had spoken, spoke

Ele tenha falado - He had spoken, spoke

Nós tenhamos falado - We had spoken, spoke

Vós tenhais falado - You had spoken, spoke

Eles tenham falado - They had spoken, spoke

Ela não acredita que eu tenha falado isso

She doesn't believe that I said that

Ela não acredita que eu tenha falado isso

She doesn't believe that I had said that

\section{Pretérito mais-que-perfeito}

Eu tivesse falado - I had spoken

Tu tivesses falado - You had spoken

Ele tivesse falado - He had spoken

Nós tivéssemos falado - We had spoken

Vós tivésseis falado - You had spoken

Eles tivessem falado - They had spoken

Se eu tivesse esperado mais, tínhamos nos encontrado

If I had waited a little, we would have met 


\section{Futuro}

Eu tiver falado - I have spoken

Tu tiveres falado - You have spoken

Ele tiver falado - He have spoken

Nós tivermos falado - We have spoken

Vós tiverdes falado - You have spoken

Eles tiverem falado - They have spoken

Você só acreditará depois que eu tiver falado com ele

You will only believe after I have spoken to him

\section{Presente progressivo}

Eu espero que eu esteja falando - I am speaking

Eu espero que tu estejas falando - You are speaking

Eu espero que ele esteja falando - He is speaking

Eu espero que nós estejamos falando - We are speaking

Eu espero que vós estejais falando - You are speaking

Eu espero que eles estejam falando - They are speaking

Eu espero que eles estejam falando da prova

I hope they are discussing the exam

\section{Pretérito mais-que-perfeito progressivo}

Ele esperava que eu estivesse falando - I would be speaking

Ele esperava que tu estivesses falando - You would be speaking

Eu esperava que ele estivesse falando - He would be speaking

Ele esperava que nós estivéssemos falando - We would be speaking

Ele esperava que vós estivésseis falando - You would be speaking

Eu esperava que eles estivessem falando - They would be speaking

Eu esperava que ele estivesse cantando em Paris

I expected that they would be singing in Paris 


\section{Futuro progressivo}

Quando eu estiver falando

Quando tu estiveres falando

Quando ele estiver falando

Quando nós estivermos falando

Quando vós estiverdes falando

Quando eles estiverem falando

Quando eu estiver cantando ele chegará

When I am singing he will arrive

\section{B.3 Modo Imperativo}

Fala tu - Speak

Fale você - Speak

Falemos nós - Let's speak

Falai vós - Speak

Falem vocês - Speak

Fale alto

Speak louder

Façamos isso

Let's do it

\section{B.4 Formas nominais}

\section{B.4.1 Tempos simples}

\section{Infinitivo flexionado}

Falar - to speak

Falares - to speak

Falar - to speak

Falarmos - to speak

Falardes - to speak

Falarem - to speak 
Falar sobre amor é complicado

It is complicated to talk about love

\section{Gerúndio}

Falando - Speaking

Chorou soluçando sobre a mesa

Cried sobbing over the table

\section{Particípio}

Falado - Spoke

Achada a solução do problema, dormiu em paz

Once he found the solution to the problem, he slept

\section{B.4.2 Tempos compostos}

\section{Infinitivo não flexionado}

Ter amar - to be loved, had loved, have loved

Ter amado alguém me acalmou

To have loved calmed me down

Eu quero ser amado

I want to be loved

Eu queria ter amado mais durante minha vida

I wish I had loved during my life

\section{Gerúndio}

Tendo falado - Spoke, had spoken

Tendo feito esse erro, fui preso 
Since I had done his mistake, I was arrested

Tendo consertado o carro, partiu

Since he fixed the car, he left 


\section{Apêndice $\mathrm{C}$ \\ Corpora dos tempos verbais}

\section{C.1 Primeira Conjugação}

\section{C.1.1 Modo Indicativo}

\section{Presente}

Eu compro pão diariamente

I buy bread daily

Tu procuras ajuda

You seeks help

Ela indica bons livros

She recommends good books

Nós pagamos o curso

We pay the course

Vós mostrais fotos antigas

You show old photos

Os fofoqueiros falam de tudo

Gossipers speak of everything

Pretérito perfeito 
Eu dei as cartas

I gave the cards

Tu comentaste a vida alheia

You commented others' lives

A chuva passou

The rain passed

Nós usamos tudo

We used everything

Vós ampliastes a foto

You amplified the photo

Eles criaram um novo conceito

They created a new concept

\section{Pretérito imperfeito}

Eu assinava essa revista

I used to subscribe this magazine

Tu olhavas as crianças

You used to watch the children

Ele melhorava com a medicação

I used to get better with medication

Nós assinávamos a lista de presença

We used to sign the presence list

Vós avaliáveis as obras

You used to evaluate the works

Eles salvavam vidas

They used to save lives 


\section{Pretérito mais-que-perfeito}

Eu acompanhara minha mãe na viagem

I had accompanied my mother in the trip

Tu trabalharas no período da noite

You had worked in the night shift

Ele deixara a casa vazia

He had left the house empty

Nós pagáramos o almoço para os colegas

We had paid lunch for the colleagues

Vós ajudáreis nas tarefas

You had helped in the tasks

Eles efetuaram a compra

They had made the buy

\section{Futuro do presente}

Eu cadastrarei meu currículo

I will register my curriculum

Tu lembrarás do gosto da fruta

You will remember the taste of the fruit

O banco atualizará os juros

The bank will update the interest rates

Nós editaremos o filme

We will edit the film

Vós ganhareis um presente

You will get a present

Eles participarão das manifestações 
They will participate in the demonstrations

\section{Futuro do pretérito}

Eu passaria na tua casa se fosse cedo

I would drop by your house if it was early

$\mathrm{Tu}$ andarias mais se tivesse tempo

You would walk if you had more time

Ele refinaria o sal se precisasse

He would refine the salt if it was necessary

Nós filtraríamos a água caso fosse necessário

We would filter the water if it was necessary

Vós publicaríeis as novas leis

You would publish the new laws

Eles falariam se você perguntasse

They would speak if you asked

\section{Pretérito perfeito composto}

Eu tenho evitado esse encontro

I have been avoiding this meeting

Tu tens gerado muitas dívidas

You have been generating a lot of debts

O Jornal tem divulgado boas notícias

The newspaper has been publishing good news

Nós temos instalado muitos aquecedores

We have been installing many heaters

Vós tens tomado muito café

You have been taking a lot of coffee 
Eles têm utilizado muito papel

They have been using a lot of paper

\section{Pretérito mais-que-perfeito composto}

Eu tinha verificado o óleo quando o frentista chegou

I had verified the oil when the employee arrived

$\mathrm{Tu}$ tinhas recomendado o restaurante para a comemoração

You had recommended the restaurant for the celebration

Ele tinha comprado novas roupas mas elas foram roubadas

He had bought new clothes but they were stolen

Nós tínhamos fechado as salas quando o zelador chegou

We had closed the rooms when the janitor arrived

Vós tínheis voltado da aula quando o jogo começou

You had come back to class when the game began

Eles já tinham adicionado açúcar ao bolo quando eu notei They had already added sugar to the cake when I noticed it

\section{Futuro do presente composto}

Eu já terei enviado a trabalho quando o prazo acabar

I will have already finished the job when the deadline arrives

Tu já terás buscado todas as flores quando a festa começar

You will have already collected all the flowers when the party begins

Ele terá avaliado os prejuízos quando o gerente chegar

He will have evaluated the losses when the manager arives

Nós teremos procurado desculpas para justificar o ocorrido

We will have looked for excuses to justify what happened

Vós já tereis acompanhado o processo quando marcarem a audiência 
You will have already followed the process when they schedule the audience

Eles terão pesquisado nos livros quando a biblioteca fechar

They will have browsed the books when the library closes

\section{Futuro do pretérito composto}

Eu teria entrado na sala se eu soubesse do problema

I would have entered the room had I known about the problem

Tu terias mostrado os livros se tu soubesses onde eles estavam

You would have shown me the books had you known they were there

Ele teria criado novos modelos se soubesse que ela viria hoje

They would have created new models had they known she was coming today

Nós teríamos estado lá se soubéssemos da operação

We would have been there had we known about the operation

Vós teríeis ficado na festa se soubésseis que ela acabaria tarde

You would have stayed at the party had you known it would end up late

Eles teriam deixado o cartão se eles quisessem

They would have left the card had they wanted it

\section{Presente progressivo}

Eu estou contando os dias para a viagem

I'm counting the days to the trip

Tu estás pensando nas palavras

You will be thinking about the words

Ele está complementando o curso

He is complementing the course 
Nós estamos utilizando uma fórmula nova

We are using the new formula

Vós estais compartilhando muitos dados

You are sharing lots of data

Eles estão verificando os fatos

They are verifying the facts

\section{Pretérito perfeito progressivo}

Eu estive listando todas as minhas despesas

I had been listing all my expenses

Tu estiveste estudando só o que gosta

You had been studying only what you like

Ele esteve filtrando a conversa

He had been filtering the conversation

Nós estivemos evitando ela

We had been avoiding her

Vós estivestes pegando vossas coisas

You had been taking your stuff

Eles estiveram trocando informações

They had been exchanging information

\section{Pretérito imperfeito progressivo}

Eu estava gerando um incômodo na sala semana passada

I was disturbing the room last week

Tu estavas achando uma solução para o problema essa manhã

You were findin a solution to the problem this morning

Ele estava divulgando o teor do documento no começo da tarde

He was publishing the content of the document in early afternoon 
Nós estávamos publicando as notícias quando ele apareceu

We were publishing the news when he showed up

Vós estáveis parando de fumar no mês passado

You were quitting smoking last month

Eles estavam instalando a rede quando faltou luz

They were installing the network when the lights went out

\section{Futuro do presente progressivo}

Eu estarei tomando café a essa hora amanhã

I will be having coffee this time tomorrow

Tu estarás afetando os pulmões com esse cigarro

You will be affecting your lungs with this cigar

Ele estará esperando por você hoje mais tarde

He will be waiting for you later today

Nós estaremos chamando seu nome quando você chegar

We will be calling your name when you arrive

Vós estareis comprando seu carro mês que vem

You will be buying this car next month

Eles estarão fechando as portas no fim-de-semana

They will be shutting the dors this weekend

\section{Futuro do pretérito}

Eu estaria voltando de viagem hoje se eu pudesse

I would be coming back from the trip today if I could

Tu estarias enviando a correspondência para ele se tivesse tempo

You would be sending the mail to him if you had the time

Ele estaria adicionando os valores às contas se ele soubesse calcular 
He would be adding these values to the bills if he could calculate

Nós estaríamos buscando a palavra no dicionário se tivéssemos dúvidas We would be looking up the Word in the dictionary if we had doubts

Vós estaríeis avaliando as notas se vós estivésseis com as provas

You would be evaluating the notes if you had the evidences

Eles estariam procurando o documento se tivessem perdido

They would be looking for the document had they lost if

\section{C.1.2 Modo Subjuntivo}

\section{Presente}

Tomara que eu fale tudo o que eu sei

I hope I will speak everything I know

Espero que tu chegues cedo

I hope you will arrive early

Acredito que ele mude de cidade

I believe he will move cities

Desejo que nós encontremos o site

I hope we will find the site

Duvido que vós baixeis o tom de voz

I doubt you will lower your voice

É possível que eles cadastrem todos os dados hoje

It's possible that they will enter all data today

\section{Pretérito imperfeito}

Esperava que eu desse mais exemplos

I hoped I would provide more examples

Duvidava que tu ajudasses os necessitados 
I doubted you would help those in need

Acreditava que ele visitasse os tios freqüentemente

I believed that he visited the uncles frequently

Receava que nós comentássemos sobre o acidente

He was afraid that we would comment about the accident

Esperava que vós visualizásseis a imagem do quadro

I expected that you would visualize the image of the frame

Esperava que eles acessassem o site

I expected that they would access the site

\section{Futuro}

Eu te aviso quando eu usar o livro

I will warn you when I use the book

Quando tu colocares os móveis nos lugares me avise

When you place the furniture in place, tell me

Quando ele selecionar o assunto nós começaremos o trabalho

When he selects the topic, we will start the work

Eles pediram para nós efetuarmos o pagamento

They asked us to make the payment

Eles pediram para vós passardes na casa dela

They ask you to drop by her house

Eu vi eles assinarem o acordo

I saw them sign the treaty

\section{Pretérito perfeito composto}

Eu espero que eu tenha lembrado do aniversário dela

I hope that he remembered her birthday 
Nós acreditamos que tu tenhas trabalhado nas férias

We believe that you had worked during vacation

Eu duvido que ele tenha realizado seu sonho

I doubt that he realized his dream

Eles duvidaram que nós tenhamos pago a refeição

They doubted that we had paid for the meal

Eu espero que vós tenhais atualizado a página na Web

I hope that you had updated the Web page

Eu espero que os engenheiros tenham ampliado o quarto

I hope that the engineers have expanded the bedroom

\section{Pretérito mais-que-perfeito composto}

Ele esperava que eu tivesse andado mais

I believed that you had walked more

Ele acreditava que tu tivesses militado contra o invasor

He believed that you had fought the invador

Ele esperava que ele tivesse editado o programa

He expected that he had edited the program

Ele esperava que nós tivéssemos apresentado a coleção

He expected that we had presented the collection

Eu desejava que vós tivésseis jogado xadrez

I wished that you had played chess

Eu desejava que eles tivessem ganhado o jogo

He wished that they had won the game

\section{Futuro composto}

Quando eu tiver participado das manifestações eu ficarei em paz

Once you have participated in the demonstrations, I will be satisfied 
Quando tu tiveres olhado as cartas tu saberás o futuro

Once you have looked at the cards, you will know the future

Quando ele tiver tentado o vestibular poderá tirar férias

Once he has tried the vestibular, he will be able to go on vacation

Quando nós tivermos postado a carta nós avisaremos

Once we have posted the letter, we will tell

Quando vós tiverdes aumentado a velocidade o perigo também aumentará Once you have increased the speed, the danger will increase as well

Quando eles tiverem indicado o objeto saberemos o que é

Once they have indicated the object, we will know what it is

\section{Presente progressivo}

Eu espero que eu esteja pesquisando tudo corretamente I hope that I'm researching everything correctly

Eu espero que tu estejas entrando na sala certa I hope that you are entering the right room

Eu espero que ele esteja mostrando os produtos à venda I hope that he is showing the products on sale

Eu espero que nós estejamos criando belas obras

I hope that we are creating nice works

Eu espero que vós estejais deixando as brigas de lado

I hope that you are leaving the fights aside

$\mathrm{Eu}$ espero que eles estejam falando corretamente

I hope that they are spaking correctly

\section{Pretérito imperfeito progressivo}

Ele esperava que eu estivesse chegando a essa hora 
He expected that I would be arriving at this time

Ele esperava que tu estivesses mudando de cidade

He expected that you would be changing cities

Eu esperava que ele estivesse encontrando novos caminhos para seguir I expected that you would be finding new paths to follow

Ele esperava que nós estivéssemos cadastrando nossas informações

He expected that we were registering our information

Ele esperava que vós estivésseis ajudando nossos pais

He expected that you would be helping our parents

Eu esperava que eles estivessem visitando os doentes

I expected that they would be visiting the sick

\section{Futuro progressivo}

Quando eu estiver chegando em casa o telefone tocará When I'm arriving at home the phone will ring

Quando tu estiveres falando com ele a carta chegará When you are speaking to him the letter will arrive

Quando ele estiver cantando o telefone tocará when he's singing the phone will ring

Quando nós estivermos estudando a visita chegará When we are studying the visitor will arrive

Quando vós estiverdes avaliando as obras o museu fechará When you are evaluating the works the museum will close

Quando eles estiverem entrando na sala a porta fechará When they are entering the room the door will close

\section{C.1.3 Modo Imperativo}


Leva tu a mala para o carro

Take the baggage to the car

Comece você a festejar

Start to celebrate

Salvemos nós os feridos

Let's save the injured

Tirai vós os óculos da gaveta

Take the glasses from the drawer

Denunciem vocês a fraude

Denounce the fraud

\section{C.1.4 Formas nominais}

\section{Infinitivo não flexionado}

Eu ter avaliado esse tópico me alegrou

Having evaluated this topic made me happy

Ele ter comprado a casa me acalmou

Him having bought the house relieved me

\section{Infinitivo flexionado}

É melhor eu auxiliar minha mãe em casa

It is better that I help my mother at home

Ele avisou pra tu utilizares o elevador

He told you to use the elevator

É interessante ele tocar na banda

It is interesting for him to play in the band

Eu farei o possível para anunciarmos a venda do carro

I will do whatever posssible to announce the car sale 
Eu ficarei agradecida se vós colardes os selos nas cartas

I will be thankful if you stick this stamp to the letter

É bom eles pensarem nas suas palavras

It is good for them to think in your words

\section{Infinitivo flexionado composto}

Eu ter comprado esse livro me agradou

It pleased me to have bought this book

Tu teres fechado as malas te cansou

Having closed the bags made you tired

Ele ter procurado a resposta te tranqüilizou

Him having looked for the answer tranquilized you

Nós termos encontrado a saída nos alegrou

We having found the exit made us happy

Eles terem acessado o site me agradou

Them having accessed the site pleased me

\section{Gerúndio}

Trabalhou colando papéis

Worked pasting papers

\section{Gerúndio composto}

Tendo falado, partiu

Having spoken, he left

\section{Particípio}

Achada a solução do problema dormiu em paz

Once found the problem solution, he slept peacefully 


\section{C.2 Segunda Conjugação}

\section{C.2.1 Modo Indicativo}

\section{Presente}

Eu faço pão diariamente

I make bread daily

Tu dizes belas palavras

You say nice words

Ela vende bons livros

She sells good books

Nós escolhemos o curso

We choose the course

Vós recebeis muitas mensagens

You receive lots of messages

Os fofoqueiros vêem tudo

The gossipers see it all

\section{Pretérito perfeito}

$\mathrm{Eu}$ forneci o material para a festa

I provided the material for the party

$\mathrm{Tu}$ recebeste uma herança

You received an inheritance

Ele disse com os olhos que estava triste

He said with his eyes that he was sad

Nós pudemos dirigir

We could drive

Vós resolvestes o problema

You solved the problem 
Eles compreenderam o novo conceito

They understood the new concept

\section{Pretérito imperfeito}

Eu respondia às ofensas

I used to respond to the ofenses

Tu esquecias as obrigações

You used to forget the obligations

Ele vendia remédios

He used to sell medications

Nós assinávamos a lista de presença

We used to sign the presence list

Vós mantínheis obras raras em casa

You used to store rare works in your house

Eles liam revistas de fofoca

They used to read gossip magazines

\section{Pretérito mais-que-perfeito}

Eu conhecera a pobreza

I had known poverty

Tu escreveras um bom romance

You had written a good novel

Ele obtera a proteção dos seguranças

He had obtained the security personnel protection

Nós vivêramos felizes

We had lived happily

Vós procedêreis a acusação 
You had carried out the accusation

Eles reviram a compra

They had reviewed the acquisition

\section{Futuro do presente}

Eu oferecerei minha ajuda meu currículo

I will offer my help with the curriculum

Tu aprenderás uma nova tarefa

You will learn a new task

O banco atenderá todos os clientes

The bank will see all the clients

Nós desenvolveremos um projeto

We will design a project

Vós perdereis a aposta

You will lose the bet

Eles debaterão as manifestações

They will debate the demonstrations

\section{Futuro do pretérito}

Eu pareceria louca se eu usasse essa roupa

I would look crazy if I wore this clothe

Tu entenderias mais se ele estudasse

You would understand more if he had studied

Ele satisfaria meus desejos se eu precisasse

He would satisfy my wishes if I needed

Nós promoveríamos a festa caso fosse necessário

We would promote the party were it necessary 
Vós cresceríeis rápido se tomásseis esse remédio

You would grow up fast if you took this medicine

Eles quereriam seu bem se eles gostassem de você

They would want you own good if they liked you

\section{Pretérito perfeito composto}

Eu tenho sofrido ataques dos adversários

I have been suffering attacks from the adversaries

Tu tens preenchido muitos formulários

You have been filled too many forms

O chefe tem removido os funcionários para outro estado

The boss has been removing the employees to some other state

Nós estamos convencidos da morte dele

We are convinced of his death

Vós tens percebido os significado da mensagem

You have been understanding the meaning of the message

Eles têm vencido várias lutas

They have been winning several fights

\section{Pretérito mais-que-perfeito composto}

Eu tinha comido os salgadinhos quando a festa acabou

I had eaten the snacks when the party ended

Tu já tinhas aparecido na festa quando ele chegou

You had already shown up at the party when he arrived

Ele tinha contido o riso quando ele me contou a estória

He had kept from laughing when he told the story

Nós já tínhamos corrido quando começou a chover

We had already run when it started raining 
Vós tínheis reconhecido lugar quando a prova começou

You had recognized the place when the challenge began

Eles já tinham combatido o resfriado quando eles foram ao médico

They had already fought the cold when they went to the doctor

\section{Futuro do presente composto}

Eu já terei esclarecido as duvidas quando a prova começar

I will have clarified the doubts when the exam starts

Tu já terás reconhecido o lugar quando a festa começar

You will have already recognized the place when the party starts

Ele terá protegido o patrimônio quando a tempestade chegar

He will have protected the patrimony when the storm arrives

Nós teremos interrompido o tratamento ao final do ano

We will have interrupted the treatment by the end of the year

Vós já tereis bebido quando a festa começar

You will already have drank when the party starts

Eles terão escondido os livros quando a biblioteca fechar

They will have hidden the books when the library closes

\section{Futuro do pretérito composto}

Eu teria defendido o réu se eu soubesse do problema

I would have defended the defendent had I known the problem

Tu terias colhido as frutas se tu soubesses onde elas estavam

You would have collected the fruits had you known where they were

Ele teria exercido a profissão se soubesse da necessidade

They would have made the job were they aware of the necessity

Nós teríamos fortalecido a economia se nós soubéssemos da crise 
We would have strengthened the economy had we known about the crisis

Vós teríeis estendido as roupas se ela pedisse

You would have extended the clothes if she asked

Eles teriam agradecido o cartão se eles quisessem

They would have thanked for the card if they wanted

\section{Presente progressivo}

Eu estou devendo dinheiro ao banco

I owe Money to the bank

Tu estás temendo o inimigo

You fear you enemy

Ele está defendendo os fracos

He's defending the poor

Nós estamos exercendo nossos direitos

We are exercising our rights

Vós estais descrevendo muitos dados

You are describing too many data

As crianças estão nascendo

The kids are being born

\section{Pretérito perfeito progressivo}

Eu estive concorrendo aos prêmios

I had been running for awards

$\mathrm{Tu}$ estiveste recorrendo ao juizado

You have been recurring to the court

Ele esteve abrangendo o tema

He had been addressing the issue 
Nós estivemos desfazendo as malas

We had been unpacking our bags

Vós estivestes acendendo as luzes

You had been lighting the lights

Eles estiveram recolhendo informações

They had been collecting information

\section{Pretérito imperfeito progressivo}

Eu estava dependendo da sua ligação para resolver a proposta

I was counting on your call to resolve the proposal

Tu estavas revertendo a situação para o avanço do pais essa manhã

You were reverting the situation to the advancement of the parents this morning

Ele estava merecendo um aumento no mês passado

They were deserving a raise last month

Nós estávamos enchendo a banheira quando o telefone tocou

We were filling the tub when the phone rang

Vós estáveis submetendo os alunos a humilhações durante a prova

You were subjecting the students to humiliations during the exam

Eles estavam convivendo em paz até o começo de janeiro

They were living in peace until the beginning of January

\section{Futuro do presente progressivo}

Eu estarei fazendo café a essa hora amanhã

I will be making coffee by this time tomorrow

Tu estarás escolhendo um lugar para morar amanhã de tarde

You will be picking a place to live tomorrow afternoon

Ele estará sabendo seu nome hoje mais tarde 
He will know your name later today

Nós estaremos respondendo sua carta domingo pela manhã We will be answering you letter Sunday morning

Vós estareis resolvendo um problema no mês que vem

You will be solving a problem next month

Eles estarão vendendo vinhos no fim-de-semana

They will be selling wines during the weekend

\section{Futuro do pretérito progressivo}

Eu estaria lendo o jornal se eu pudesse

I would be reading the newspaper if I could

$\mathrm{Tu}$ estarias conhecendo o mundo se tu tivesses tempo

You would be seeing the world if you had time

Ele estaria escrevendo o texto se ele soubesse

He would be writing the text if he knew

Nós estaríamos obtendo notas altas se nós estudássemos

We would be getting high grades if we studied

Vós estaríeis vivendo calmamente se vós tivésseis dinheiro

You would be living calmly if you had money

Eles estariam revendo o conteúdo se eles tivessem tempo

They would be revising the content if they had time

\section{C.2.2 Modo Subjuntivo}

\section{Presente}

Tomara que eu descreva tudo o que eu sei

I hope that I describe everything that I know

Espero que tu compareças cedo ao cartório 
I hope that you arrive early at the registry

Acredito que ele nasça hoje

I believe he will be born today

Desejo que nós convertamos os índios

I widh that we convert the indians

Duvido que vós acolhais os necessitados

I doubt the you will harbor the needy

É possível que eles desfaçam o penteado

It is possible that they will mess up the hairdo

\section{Pretérito imperfeito}

Esperava que eu recolhesse mais exemplos

I expected that I would gather more examples

Duvidava que tu acendesses as velas

I doubted that you would light up the candles

Acreditava que ele dependesse dos pais para viver

I believed that he would depend on his parents to live

Receava que nós sobrevivêssemos ao acidente

I was afraid that we would survive the accident

Esperava que vós revertêssemos a situação

I expected that you would reverse the situation

Esperava que eles concedessem o prêmio

I expected that they would concede the award

\section{Futuro}

Eu te aviso quando eu encher o balde

I will tell you when I fill the bucket 
Quando tu ofenderes os vizinhos será expulso do prédio

When you offend the neighbors you will be expelled from the building

Quando ele conviver com pessoas diferentes aprenderá a se comportar When he lives with different people he will learn to behave

Eles pediram para nós vermos o filme

They asked us to watch the movie

Eles pediram para vós fazerdes os exercícios na casa dela

They asked you to do the exercises at her home

$\mathrm{Eu}$ vi eles escolherem as alternativas

I saw they choose the alternatives

\section{Pretérito perfeito composto}

Eu espero que eu tenha tido uma boa semana

I hope you have had a good week

Nós acreditamos que tu tenhas inscrito seu trabalho no congresso

We believe you have submitted your work in the conference

Eu duvido que ele tenha sabido do seu sonho

I doubt he has known about your dream

Eles duvidaram que nós tenhamos fornecido a refeição

They doubted that we have provided the meal

Eu espero que vós tenhais recebido a página da Web

I hope that you have received the Web page

Eu espero que os engenheiros tenham dito as mudanças o quarto

I hope that the engineers have mentioned the changes in the room

\section{Pretérito mais-que-perfeito composto}

Ele esperava que eu tivesse resolvido o problema

He expected that I had solved the problem 
Ele acreditava que tu tivesses compreendido a questão

He believed that you had understood the question

Ele esperava que ele tivesse respondido a pergunta

He expected that he would have answered the question

Ele esperava que nós tivéssemos esquecido a sombrinha no carro

He expected that we would have forgotten the umblella in the car

Eu desejava que vós tivésseis vendido o jogo de xadrez

He wished that you had sold the chess game

Eu desejava que eles tivessem mantido as apostas

He wished that you had kept the bets

\section{Futuro composto}

Quando eu tiver lido os textos eu ficarei em paz

When I have read the texts I will be in peace

Quando tu tiveres conhecido o prédio tu poderás voltar lá

When you have known the building you will be able to go back there

Quando ele tiver escrito o cartaz ele poderá tirar férias

When he has written the banner he will be allowed to go on vacation

Quando nós tivermos obtido os resultado nós avisaremos

When we have obtained the results we will tell you

Quando vós tiverdes oferecido uma bebida ele beberá

When you have offered a drink he will drink it

Quando eles tiverem atendido o pedido dela nós descansaremos

When they have anwered her request we will rest

\section{Presente progressivo}

Eu espero que eu esteja aprendendo tudo corretamente 
I hope that you are learning everything correctly

Eu espero que tu estejas atendendo os pedidos perfeitamente I hope that you are answering the requests perfectly

Eu espero que ele esteja desenvolvendo bons produtos I hope that he is developing good products

Eu espero que nós estejamos perdendo pouco dinheiro I hope that we are losing little money

Eu espero que vós estejais trazendo muitos presentes I hope that you are bringing many gifts

Eu espero que eles estejam debatendo por causas nobres I hope that they are debating for noble causes

\section{Pretérito imperfeito progressivo}

Ele esperava que eu estivesse entendendo o assunto I hoped that I would be understanding the subject

Ele esperava que tu estivesses satisfazendo as minhas vontades He hoped that you would be satisfying my will

Eu esperava que ele estivesse promovendo novos encontros I hoped that he would be promoting new meetings

Ele esperava que nós estivéssemos estabelecendo novos contatos He hoped that we would be establishing new contacts

Ele esperava que vós estivésseis sofrendo de tristeza He hoped that you would be suffering from sadness

Eu esperava que eles estivessem comendo carne todos os dias He hoped that they would be eating meat everyday

\section{Futuro progressivo}


Quando eu estiver aprendendo a matéria a aula acabará when I'm exposing the material the class will end

Quando tu estiveres escrevendo a carta ele chegará When you are writing the letter he'll arrive

Quando ele estiver lendo o jornal o telefone tocará When he's reading the newspaper the phone will ring

Quando nós estivermos debatendo o tempo acabará When we are debating the time will end up

Quando vós estiverdes comendo o telefone tocará When you are eating the phone will ring

Quando eles estiverem lendo a revista o telefone tocará When they are writing the song the phone will ring

\section{C.2.3 Modo Imperativo}

Obtenha tu uma mala nova

Get a new bag

Viva você a sua vida

Live your life

Percamos nós o medo de altura

Let's lose our fear of heights

Trazei vós os óculos da gaveta

Bring the glasses from the drawer

Debatam vocês a pauta

Debate the content 


\section{C.2.4 Formas nominais}

\section{Infinitivo não flexionado}

Ter removido a cadeira da sala me alegrou

Having removed the chair from the room made me happy

Ele ter vencido a luta me animou

Him having won the fight made me happy

\section{Infinitivo flexionado}

É melhor eu comer em casa

I had better eat at home

Ele avisou pra tu apareceres na janela

He warned you to show up at the window

É interessante ele reconhecer seu trabalho

It is interesting that he recognizes your work

Eu farei o possível para combatermos as más influências

I will do whatever possible to fight the bad influences

Eu ficarei agradecida se vós permanecerdes em casa

I will be pleased if you stay at home

É bom eles protegerem os olhos

They had better protect their eyes

\section{Infinitivo flexionado composto}

Eu ter aprendido a matéria me acalmou

Me having learn the subject calmed me down

$\mathrm{Tu}$ teres perdido as chaves me desanimou

You having lost the Keys dismayed me 
Ele ter percebido a realidade nos tranqüilizou

Him having perceived the reality calmed us down

Nós termos sobrevivido ao acidente nos alegrou

Us having survived the accident made me happy

Eles terem vendido a casa me alegrou

Them having sold the house made me happy

\section{Gerúndio}

Voltou agradecendo a ajuda

He came back thanking for the help

\section{Gerúndio composto}

Tendo bebido, partiu

Having drank, he left

\section{Particípio}

Defendida a sua escolha ele dormiu em paz

Once having defended his choice, he slept in peace

\section{C.3 Terceira Conjugação}

\section{C.3.1 Modo Indicativo}

\section{Presente}

Eu imprimo meus trabalhos em casa

I print my work at home

Tu exibes nova coleção

You exhibit the new collection

Ela parte para o trabalho pela manhã

She leaves for work in the morning 
Nós saímos do curso

We dropped the course

Vós ides ao mercado comprar comida

You went to the supermarket to buy food

Eles reduziram o orçamento

They reduced the budget

\section{Pretérito perfeito}

Eu ouvi a música

I heard the song

Tu abriste o presente

You opened the gift

Ele inseriu a chave na fechadura

He inserted the key in the lock

Nós diminuímos as despesas

We diminished the expenses

Vós assististes o concerto

You watched the concert

Eles seguiram o caminho

They followed the path

\section{Pretérito imperfeito}

Eu garantia o pagamento

I guaranteed the payment

Tu conseguias atenção das pessoas

You had people's attention

Ele produzia trigo 
He produced wheat

Nós definíamos nossa posição

We defined our position

Vós conferíeis os relatórios

You checked the reports

Eles discutiam sobre a situação

They discussed the situation

\section{Pretérito mais-que-perfeito}

Eu atingira minhas metas

I had reached my goals

Tu pediras segurança

You asked for security

Ele viera de longe

He came from far away

Nós corrigíramos o defeito do aparelho

We would correct the equipment's problem

Vós incluíreis meu nome na lista

You will include my name on the list

Eles descobriram a cesta de pão

They discovered the bread basket

\section{Futuro do presente}

Eu construirei minha casa

I will build my house

Tu assumirás o novo cargo

You will assume the new post 
Ele cumprirá as ordens

He will fulfill the orders

Nós permitiremos algumas mudanças

We will allow some changes

Vós sentireis o aroma das flores

You will feel the flowers' aroma

Os cabelos cairão ao envelhecer

The hair will fall when they get old

\section{Futuro do pretérito}

Eu contribuiria na distribuição dos alimentos se eu pudesse

I would contribute to the food distribution if I could

$\mathrm{Tu}$ adquiririas uma geladeira se tu trabalhasses mais

You would acquire a fridge if you worked more

Ele possuiria terras se ele trabalhasse

He would possess lands if he worked

Nós subiríamos a montanha caso fosse necessário

We would have climbed the mountain were it necessary

Vós excluiríeis o rapaz da empresa se ele pedisse

You would exclude the boy from the firm if he asked

Eles substituiriam as peças do carro se eles gostassem de você

They would replace the car pieces if they liked you

\section{Pretérito perfeito composto}

Eu tenho investido meu dinheiro em ações

I have been investing my money in stocks

Tu tens decidido várias questões

You have been deciding several questions 
Ele tem reemitido os telegramas

He has been re-sending the telegrams

Nós estamos reunidos para tratar de negócios

We are meeting to discuss business

Vós tens traduzido os significados da mensagem

You have been translating the meanings of the message

Eles têm concluído várias provas

They have been finishing various exams

\section{Pretérito mais-que-perfeito composto}

Eu tinha servido os salgadinhos quando a festa acabou

I had already served the snacks when the party was over

Tu já tinhas refletido sobre a proposta quando ele chegou

You had already reflected on the proposal when he arrived

Ele tinha rido quando ele me contou a história

He had laughed when he told me the story

Nós já tínhamos exigido silêncio quando a prova começou

We had already demanded silence when the exam started

Vós já tínheis expandido o lugar quando a obra começou

You had already expanded the place when the repair began

Eles já tinham reunido os documentos para o casamento quando eles foram ao cartório

They had already collected the marriage documents when they went to the registrar

\section{Futuro do presente composto}

Eu já terei impedido a assinatura do contrato quando ele chegar

I will have impeded the contract signature when he arrives 
Tu terás dividido as despesas quando almoço acabar

You will have shared the expenses when lunch is over

Ele terá fugido da prisão quando o alarme tocar

He will have escaped from prison when the alarm rings

Nós já teremos difundido o comunicado quando a notícia se espalhar

We will have already spread the notice when the news spreads

Vós já tereis curtido a festa quando ela começar

You will have already enjoyed the party when it starts

Eles terão interagido com outros profissionais quando o congresso começar

They will have interacted with other professionals when the conference begins

\section{Futuro do pretérito composto}

Eu teria agido com calma se eu soubesse do problema

I would have acted with calm if I knew of the problem

Tu terias repetido piada se tu soubesses que eles gostaram

You would have repeated the joke if you knew they liked it

Ele teria atraído a atenção dos repórteres se ele soubesse da necessidade

He would have attracted the reporters' attention if he knew of the necessity

Nós teríamos sugerido sua ajuda se eles pedissem

We would have suggested your help if they asked for it

Vós teríeis dormido se vós estivésseis cansados

You would have slept if you were tired

Eles teriam unido as turmas se eles quisessem

They would have united the classes had they wanted it 


\section{Presente progressivo}

Eu estou servindo de testemunha do acidente

I'm serving as a witness to the accident

Tu estás expandindo o conhecimento

You are expanding the knowledge

Ele está difundindo a notícia

He is broadcasting the news

Nós estamos dividindo nossas dúvidas

We have been sharing our doubts

Vós estais agindo impulsivamente

You have been acting impulsively

Eles estão sugerindo mudanças no plano

They are suggesting changes to the plan

\section{Pretérito perfeito progressivo}

Eu estive dirigindo carros velozes

I have been driving fast cars

Tu estiveste agindo corretamente

You have been acting right

Ele esteve repetindo o mesmo tema

He has been repeating the same theme

Nós estivemos atraindo os olhares

We have been attracting looks

Vós estivestes sugerindo mudanças

You have been suggesting changes

Eles estiveram dormindo cedo

They have been sleeping early 


\section{Pretérito imperfeito progressivo}

Eu estava transferindo a ligação quando você apareceu

I was transferring the call when you showed up

Tu estavas distribuindo as tarefas quando eu cheguei

You were distributing the tasks when I arrived

Ele estava reproduzindo o discurso quando o chefe chegou

He was replaying the speech when the boss arrived

Nós estávamos desistindo de esperar quando o telefone tocou

We were giving up waiting when the phone rang

Vós estáveis medindo a altura da porta quando o marceneiro chegou

You were measuring the door's height when the carpenter arrived

Eles estavam vestindo roupas claras quando a chuva começou

They were wearing light clothes when the rain began

\section{Futuro do presente progressivo}

Eu estarei competindo a essa hora amanhã

I will be competing this time tomorrow

Tu estarás sorrindo amanhã de tarde

You will be smiling tomorrow afternoon

Ele estará colorindo os desenhos a essa hora amanhã

He will be coloring the sketches by this time tomorrow

Nós estaremos consumindo essa comida domingo pela manhã

We will be consuming this food Sunday morning

Vós estareis proibindo a entrada dos manifestantes quando a polícia chegar

You will be prohibiting the entrance of the demonstrators when the police arrives 
Eles estarão transmitindo vários filmes no fim-de-semana They will be transmitting several movies in the weekend

\section{Futuro do pretérito progressivo}

Eu estaria ouvindo a reportagem se eu pudesse

I would be listening to the news report if I could

$\mathrm{Tu}$ estarias corrigindo as provas se tu tivesses tempo

You would be grading the exams if you had the time

Ele estaria assistindo à missa se ele pudesse

He would be watching the mass if he was able to

Nós estaríamos discutindo conteúdo se nós tivéssemos estudado

We would be discussing the material had we studied

Vós estaríeis investindo em ações se vós tivésseis dinheiro

You would be investing in stock if you had the Money

Eles estariam dormindo se eles tivessem tempo

They would be sleeping if they had the time

\section{C.3.2 Modo Subjuntivo}

\section{Presente}

Tomara que eu distribua os formulários certos

I hope that I will distribute the right forms

Espero que tu transfiras conta para outro banco

I hope that you will tranfer your account to another bank

Acredito que ele reproduza o mesmo discurso hoje

I believe that he will reproduce the same speech today

Desejo que nós admitamos nosso erros

I wish the we admit our mistakes 
Espero que vós emitais o boleto de pagamento

I expect that you will produce the payment receipt

É possível que eles meçam a temperatura do doente

It is possible that they will measure the sick's temperature

\section{Pretérito imperfeito}

Esperava que eu introduzisse mais exemplos no texto

He expected that I would introduce more examples in the text

Duvidava que tu destruísses as provas do crime

I doubted that you would destroy the crime evidences

Acreditava que ele sorrisse de alegria

I believed that he would smile of happiness

Receava que nós extraíssemos o dente

I feared that we would extract the teeth

Esperava que vós proibísseis a passeata

I expected that you would prohibit the parade

Esperava que eles banissem os maus elementos

I expected that they would ban the bad elements

\section{Futuro}

Eu te aviso quando eu aderir a greve

I will warn when I adhere to the strike

Quando tu prosseguires com a explicação eu prestarei atenção When you proceed with the explanation I will pay attention

Quando ele competir o jogo eu assistirei

When he competes in the game I will watch

Eles coloriram o livro 
They colored the book

Eles pediram para vós interferirdes nesse assunto

They asked you to interfere in this topic

Eu vi eles aderirem ao novo partido

I saw them adhere to the new party

\section{Pretérito perfeito composto}

Eu espero que eu tenha reagido bem à crítica

I expect that you have reacted well to the critic

Nós acreditamos que tu tenhas atribuído o milagre ao santo

We believe that you had attributed the miracle to the Saint

Eu duvido que ele tenha residido na Alemanha

I doubt that he has resided in Germany

Eles duvidaram que nós tenhamos consumido a refeição

They doubted that we have consumed the meal

Eu espero que vós tenhais resistido aos apelos

I hope that you have resisted the calls

Eu espero que os engenheiros tenham proibido as mudanças no quarto

I hope that the engineers have prohibited the changes to the room

\section{Pretérito mais-que-perfeito composto}

Ele esperava que eu tivesse impresso o artigo

He expected that I had printed the article

Ele acreditava que tu tivesses exibido filmes antigos

He believed that you had exhibited old movies

Ele esperava que ele tivesse partido o bolo

He expected that he had cut the cake 
Ele esperava que nós tivéssemos saído cedo

He hoped that we had left early

Eu desejava que vós tivésseis reduzido os gastos

He wished that we had reduced the expenses

Eu desejava que eles tivessem ouvido o som

I wished that they had heard the sound

\section{Futuro composto}

Quando eu tiver aberto a porta a fumaça sairá

When I have opened the door the smoke will leave

Quando tu tiveres inserido a citação no texto o trabalho terá terminado When you have inserted the citation in the text the job will be finished

Quando ele tiver diminuído o cartaz eu poderei pendurá-lo When he has made the banner smaller I will be able to hang it

Quando nós tivermos assistido o concerto nós iremos para casa When we have watched the concert we will go home

Quando vós tiverdes seguido os assaltantes a polícia chegará When you have followed the robbers the Police will arrive

Quando eles tiverem garantido o pedido dela nós descansaremos When they have guaranteed her request we will rest

\section{Presente progressivo}

Eu espero que eu esteja dirigindo corretamente I expect that I am driving correctly

Eu espero que tu estejas reagindo bem aos comentários

I expect that you are reacting well to the comments

Eu espero que ele esteja distribuindo os livros indicados

I expect that he is distributing the indicated books 
Eu espero que nós estejamos vestindo as roupas adequadas

I expect that we are wearing the adequate clothes

Eu espero que vós estejais admitindo seus erros

I expect the you are admitting your mistakes

Eu espero que eles estejam saindo de casa na hora

I expect that they will be leaving home at the time

\section{Pretérito imperfeito progressivo}

Ele esperava que eu estivesse abrindo a loja

He expected that I would be opening the store

Ele esperava que tu estivesses reduzindo os gastos

He expected that you would be reducing the expenses

Eu esperava que ele estivesse indo aos encontros

He expected that he would be attending the meetings

Ele esperava que nós estivéssemos discutindo novos tópicos

He expected that we would be discussing new topics

Ele esperava que vós estivésseis assumindo as vossas falhas

He expected that you would be admitting your flaws

Eu esperava que eles estivessem adquirindo bons produtos

I expected that they would have been acquiring good products

\section{Futuro progressivo}

Quando eu estiver abrindo a loja ele chegará

When I'm opening the store she will arrive

Quando tu estiveres saindo de casa ele chegará

When you are leaving home she will arrive

Quando ele estiver dirigindo bem ele passará na prova 
When she is driving well she will pass the exam

Quando nós estivermos dormindo o telefone tocará

When we are sleeping, the phone will ring

Quando vós estiverdes transferindo a ligação ele desligará

When you are transfering the call she will hung up

Quando eles estiverem dormindo o telefone tocará

When they are sleeping the phone will ring

\section{C.3.3 Modo Imperativo}

Consegue tu uma mala nova

Arrange a new bag

Produza você um bom quadro

Produce a good painting

Definamos nós novas metas

Define new goals

Conferi vós o preço das mercadorias

Check out the products' price

Discutam vocês a pauta

Discuss the agenda

\section{C.3.4 Formas Nominais}

\section{Infinitivo não flexionado}

Era para eu ter discutido esse assunto

I should have discussed this topic

Era para ele ter cumprido a promessa

He should have kept his promise 


\section{Infinitivo flexionado}

É melhor eu pedir perdão pelos meus erros

I had better ask for forgiveness for my mistakes

Ele avisou pra tu contribuíres na janela

He warned you to contribute at the window

É interessante ele reconhecer seu trabalho

It is interesting that he is recognizing your work

Eu farei o possível para combatermos as más influências

I will do whatever possible to fight the bad influenced

Eu ficarei agradecida se vós permanecerdes em casa

I will be pleased if you stay at home

É bom eles protegerem os olhos

They had better protect their eyes

\section{Infinitivo flexionado composto}

Eu ter discutido esse assunto me acalmou

I having discussed this topic calmed me down

$\mathrm{Tu}$ teres subido as escadas te cansou

You having climbed the stairs made you tired

Ele ter cumprido a promessa o tranqüilizou

Him having honoured him promise tranquilized us

Nós termos investido nos estudos nos alegrou

We having invested in the studied made us happy

Eles terem contribuído no trabalho foi justo

They were fair that they contributed in the job 


\section{Gerúndio}

Ele voltou pedindo a ajuda

He came back asking for help

\section{Gerúndio composto}

Tendo caído, levantou

Having fallen, he stood up

\section{Particípio}

Descoberto o caminho ele dormiu em paz

Once the path was discovered he slept in peace 
Apêndice D

Frequência dos verbos 


\section{Apêndice D}

\section{Frequência dos verbos}

\begin{tabular}{|c|c|c|c|c|c|}
\hline Verbo -AR & $\begin{array}{c}\text { Frequência } \\
\text {-AR }\end{array}$ & Verbo -ER & $\begin{array}{c}\text { Frequência } \\
\text {-ER }\end{array}$ & Verbo -IR & $\begin{array}{c}\text { Frequência } \\
\text {-IR }\end{array}$ \\
\hline comprar & 41700000 & ver & 67400000 & imprimir & 22100000 \\
\hline fechar & 38400000 & fazer & 38000000 & exibir & 14900000 \\
\hline voltar & 37200000 & ser & 29600000 & partir & 13500000 \\
\hline adicionar & 35700000 & escolher & 19200000 & sair & 13300000 \\
\hline enviar & 35000000 & ter & 16200000 & ir & 10800000 \\
\hline buscar & 31600000 & inscrever & 15600000 & reduzir & 8500000 \\
\hline avaliar & 20300000 & saber & 15000000 & ouvir & 6940000 \\
\hline procurar & 17800000 & fornecer & 14700000 & abrir & 6370000 \\
\hline acompanhar & 17600000 & receber & 14600000 & inserir & 5690000 \\
\hline musicar & 16600000 & dizer & 13800000 & diminuir & 5230000 \\
\hline pesquisar & 16300000 & poder & 12800000 & assistir & 4960000 \\
\hline entrar & 15500000 & resolver & 11600000 & seguir & 4930000 \\
\hline mostrar & 15000000 & compreender & 10800000 & sobre-sair & 4190000 \\
\hline criar & 14700000 & responder & 10700000 & garantir & 4090000 \\
\hline estar & 14200000 & esquecer & 10400000 & conseguir & 4050000 \\
\hline ficar & 14200000 & vender & 9960000 & produzir & 3960000 \\
\hline deixar & 13600000 & manter & 9400000 & definir & 3870000 \\
\hline falar & 13400000 & ler & 9280000 & conferir & 3810000 \\
\hline chegar & 13300000 & conhecer & 9130000 & discutir & 3750000 \\
\hline mudar & 13300000 & escrever & 8420000 & atingir & 3640000 \\
\hline
\end{tabular}




\begin{tabular}{|c|c|c|c|c|c|}
\hline encontrar & 13300000 & obter & 7830000 & pedir & 3590000 \\
\hline baixar & 13100000 & viver & 6770000 & vir & 3590000 \\
\hline cadastrar & 12600000 & proceder & 6690000 & corrigir & 3570000 \\
\hline dar & 12300000 & rever & 5790000 & incluir & 3440000 \\
\hline ajudar & 10800000 & oferecer & 5450000 & descobrir & 3300000 \\
\hline visitar & 10700000 & aprender & 5270000 & cair & 3130000 \\
\hline comentar & 10600000 & prazer & 5220000 & construir & 3120000 \\
\hline visualizar & 10300000 & atender & 4930000 & assumir & 3100000 \\
\hline acessar & 9880000 & desenvolver & 4920000 & cumprir & 3060000 \\
\hline usar & 9780000 & bem-fazer & 4870000 & permitir & 2950000 \\
\hline colocar & 9770000 & bem-fazer & 4790000 & sentir & 2780000 \\
\hline selecionar & 9730000 & perder & 4710000 & contribuir & 2770000 \\
\hline efetuar & 8920000 & ocorrer & 4670000 & adquirir & 2710000 \\
\hline passar & 8890000 & haver & 4420000 & possuir & 2620000 \\
\hline assinar & 8530000 & trazer & 4330000 & subir & 2580000 \\
\hline lembrar & 8410000 & debater & 4250000 & excluir & 2550000 \\
\hline trabalhar & 8220000 & acontecer & 4240000 & substituir & 2370000 \\
\hline realizar & 7890000 & parecer & 4100000 & investir & 2360000 \\
\hline escolar & 7590000 & entender & 4040000 & existir & 2170000 \\
\hline pagar & 7270000 & bem-dizer & 4010000 & decidir & 2090000 \\
\hline atualizar & 7260000 & bem-dizer & 3990000 & reemitir & 2020000 \\
\hline ampliar & 7240000 & afazer & 3960000 & traduzir & 2000000 \\
\hline andar & 7150000 & satisfazer & 3860000 & concluir & 1890000 \\
\hline militar & 6980000 & estabelecer & 3570000 & servir & 1860000 \\
\hline editar & 6920000 & promover & 3500000 & refletir & 1840000 \\
\hline apresentar & 6910000 & crescer & 3490000 & rir & 1840000 \\
\hline jogar & 6700000 & querer & 3470000 & exigir & 1800000 \\
\hline ganhar & 6680000 & sofrer & 3210000 & reunir & 1780000 \\
\hline literaturar & 6640000 & comprometer & 3200000 & expandir & 1780000 \\
\hline participar & 6550000 & preencher & 3030000 & impedir & 1750000 \\
\hline olhar & 6350000 & remover & 2970000 & dividir & 1740000 \\
\hline tentar & 6300000 & convencer & 2880000 & fugir & 1680000 \\
\hline postar & 6260000 & perceber & 2840000 & difundir & 1620000 \\
\hline aumentar & 6250000 & morrer & 2770000 & curtir & 1560000 \\
\hline indicar & 6250000 & vencer & 2740000 & dirigir & 1550000 \\
\hline levar & 6240000 & bater & 2640000 & interagir & 1550000 \\
\hline começar & 6060000 & comer & 2590000 & preferir & 1540000 \\
\hline
\end{tabular}




\begin{tabular}{|c|c|c|c|c|c|}
\hline tornar & 5830000 & aparecer & 2540000 & agir & 1490000 \\
\hline salvar & 5780000 & conter & 2480000 & repetir & 1490000 \\
\hline tirar & 5670000 & correr & 2320000 & atrair & 1490000 \\
\hline denunciar & 5670000 & reconhecer & 2250000 & usufruir & 1470000 \\
\hline ordenar & 5660000 & combater & 2240000 & sugerir & 1460000 \\
\hline melhorar & 5650000 & esclarecer & 2170000 & dormir & 1260000 \\
\hline alterar & 5530000 & permanecer & 2170000 & unir & 1240000 \\
\hline registrar & 5530000 & proteger & 2150000 & prevenir & 1230000 \\
\hline recomendar & 5460000 & interromper & 1990000 & divertir & 1210000 \\
\hline refinar & 5410000 & beber & 1890000 & transferir & 1190000 \\
\hline auxiliar & 5400000 & dever & 1870000 & distribuir & 1180000 \\
\hline atuar & 5320000 & temer & 1830000 & suprir & 1110000 \\
\hline comparar & 5300000 & esconder & 1820000 & reproduzir & 1090000 \\
\hline tocar & 5140000 & decorrer & 1760000 & desistir & 1080000 \\
\hline anunciar & 5080000 & defender & 1730000 & vestir & 1070000 \\
\hline colar & 5070000 & exercer & 1710000 & conduzir & 1020000 \\
\hline executar & 4910000 & fortalecer & 1660000 & transmitir & 998000 \\
\hline contar & 4910000 & colher & 1630000 & constituir & 981000 \\
\hline pensar & 4810000 & valer & 1590000 & cobrir & 979000 \\
\hline complementar & 4770000 & estender & 1560000 & medir & 973000 \\
\hline utilizar & 4750000 & descrever & 1500000 & emitir & 966000 \\
\hline compartilhar & 4700000 & agradecer & 1480000 & surgir & 933000 \\
\hline verificar & 4620000 & concorrer & 1440000 & admitir & 893000 \\
\hline continuar & 4570000 & prevalecer & 1410000 & introduzir & 867000 \\
\hline listar & 4490000 & nascer & 1350000 & restringir & 843000 \\
\hline estudar & 4400000 & mexer & 1270000 & destruir & 840000 \\
\hline filtrar & 4350000 & empreender & 1180000 & sorrir & 838000 \\
\hline troçar & 4340000 & comparecer & 1180000 & prosseguir & 820000 \\
\hline evitar & 4330000 & recorrer & 1170000 & banir & 782000 \\
\hline pegar & 4300000 & abranger & 1160000 & embutir & 738000 \\
\hline trocar & 4190000 & converter & 1160000 & competir & 725000 \\
\hline gerar & 4180000 & acolher & 1150000 & colorir & 694000 \\
\hline achar & 4070000 & envolver & 1110000 & interferir & 660000 \\
\hline divulgar & 4060000 & crer & 1060000 & extrair & 656000 \\
\hline publicar & 3950000 & desfazer & 1050000 & aderir & 646000 \\
\hline parar & 3950000 & recolher & 1050000 & reagir & 642000 \\
\hline instalar & 3930000 & acender & 1040000 & atribuir & 626000 \\
\hline
\end{tabular}




\begin{tabular}{|c|c|c|c|c|c|}
\hline tomar & 3900000 & sobreviver & 1040000 & residir & 612000 \\
\hline afetar & 3900000 & meter & 994000 & consumir & 609000 \\
\hline esperar & 3810000 & depender & 983000 & referir & 571000 \\
\hline mandar & 3800000 & reverter & 968000 & coibir & 549000 \\
\hline hospitalar & 3780000 & bem-querer & 960000 & resistir & 537000 \\
\hline chamar & 3760000 & merecer & 949000 & proibir & 535000 \\
\hline
\end{tabular}

